\title{
Toward a political economy of on-reserve Indigenous education in Canada: Problematizing Bill C-33
}

by

Katalin Koller

A thesis submitted to the Faculty of Graduate and Postdoctoral Affairs in partial fulfillment of the requirements for the degree of

\author{
Master of Arts \\ in \\ Political Economy
}

Carleton University

Ottawa, Ontario

(C) 2015

Katalin Koller 


\begin{abstract}
In 2008, the federal government began a reform process for on-reserve Indigenous education that culminated in approximately ten months of consultation with Indigenous and public stakeholders and the drafting of federal legislation. Bill C-33 was placed on hold in 2014 after opposition from Indigenous groups across Canada. This thesis examines the consultation process and the corresponding government discourse for evidence of the reproduction of colonial power relations and the subjectification of Indigenous rationalities to free-market ideology. Analysis is informed by a conceptual framework linking David Harvey's accumulation by dispossession, Wendy Larner's neoliberalism as policy, ideology, and governmentality, and an original interpretation of the logics of settlercolonialism operating in Canada based upon Andrea Smith's logics of White supremacy. Through a Foucauldian discourse analysis of consultation documents and government public relations messaging, the ways in which Indigenous sovereignty is suppressed by state paternalism and Indigenous Peoples commodified by economic rhetoric are revealed.
\end{abstract}




\section{Acknowledgements}

For Simon, Warren, Ivan, Ken, and most of all, Levi. I am forever grateful to you for your kindness, your mentorship, and your support, against all odds. You are my kin your teachings will always be a part of who I am and who I will be.

Wela'lioq! Woliwon! 


\section{Table of Contents}

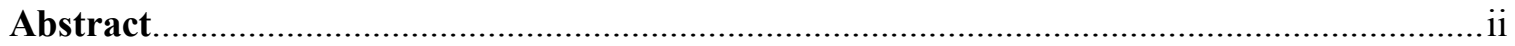

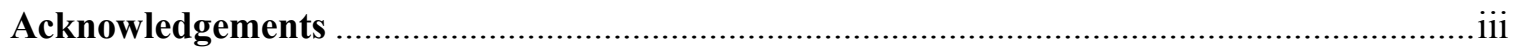

Chapter 1: Introducing Indigenous Education in Canada................................................. 1

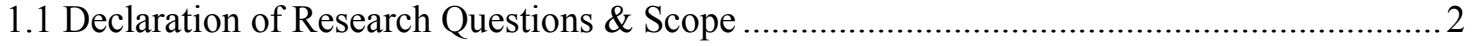

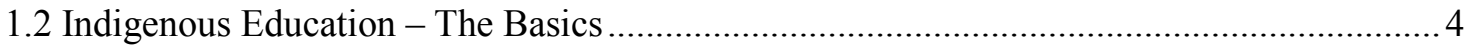

1.3 Theorizing Indigenous-State Relations through Educational Reform .............................. 10

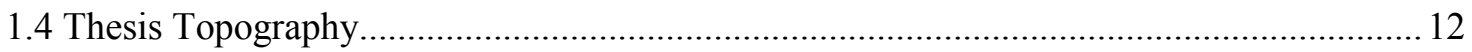

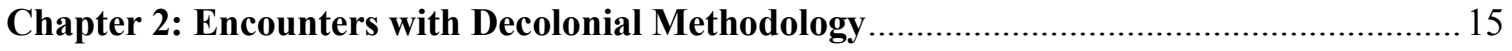

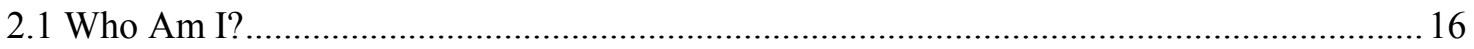

2.1.1 Methodological Scope, Assumptions, and Motivations.............................................. 23

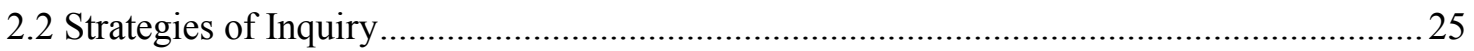

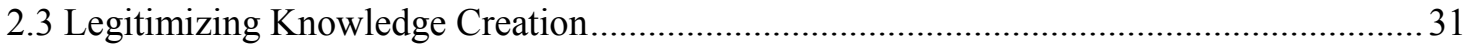

Chapter 3: Theorizing Indigenous-State Relations in Contemporary Canada..................... 37

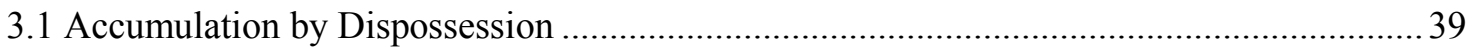

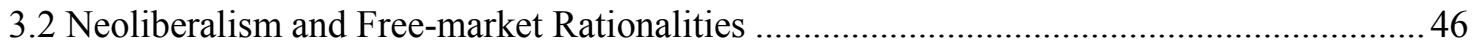

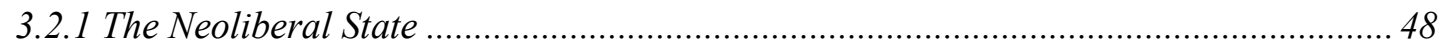

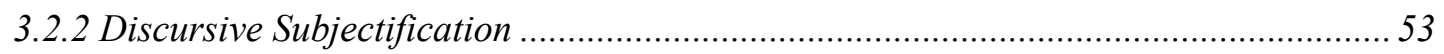

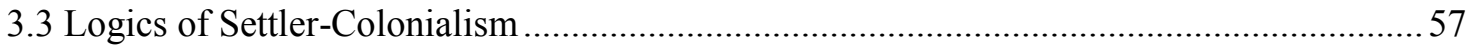

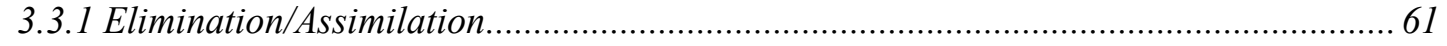

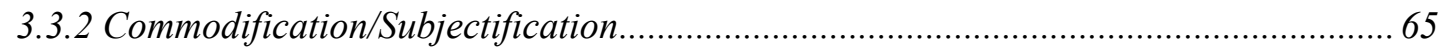

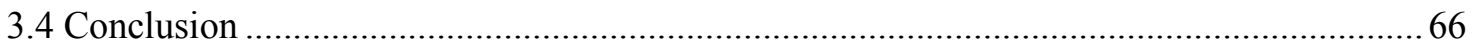

Chapter 4: Historical Development of Indigenous Education Policy in Canada ...................68

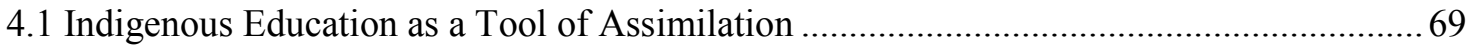

4.2 Treaties, Indigenous Education, and the Canadian Constitution ......................................... 75

4.3 Indigenous Education in Supranational Rights Frameworks …......................................... 77

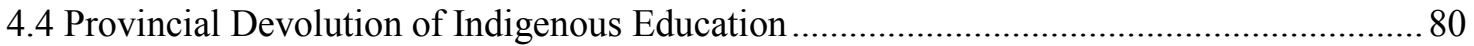

4.5 The Struggle for Indigenous Control of Indigenous Education ......................................... 83

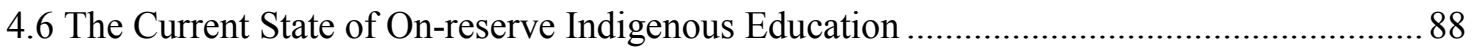

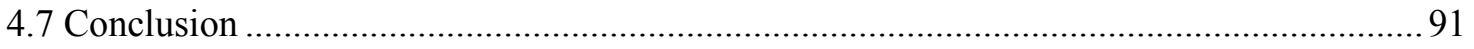




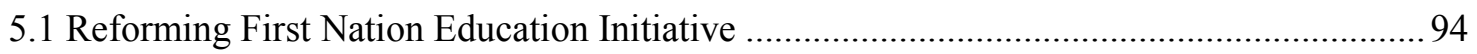

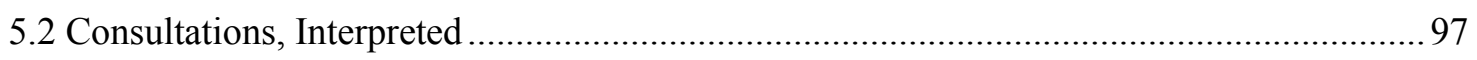

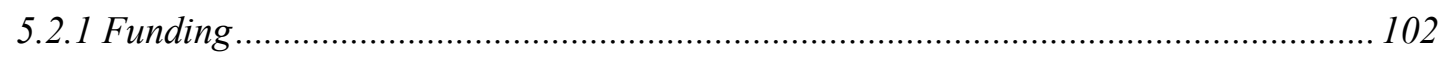

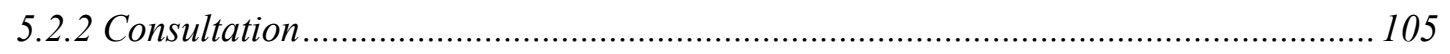

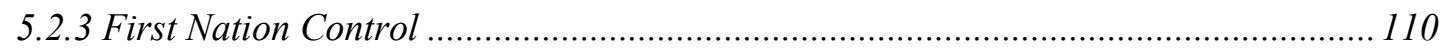

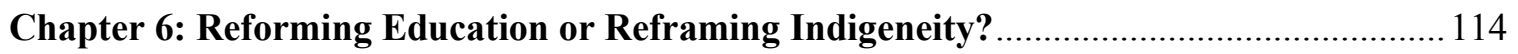

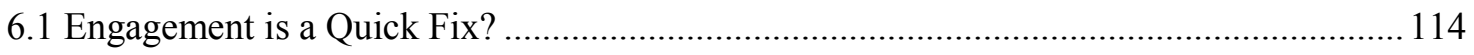

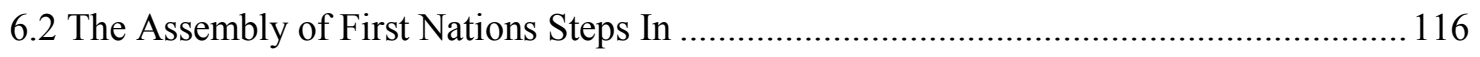

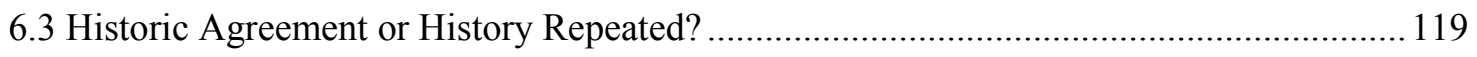

6.4 Framing Indigenous Education Reform as Economic Benefit....................................... 124

Chapter 7: Theoretical Explorations and Further Reflections.......................................... 130

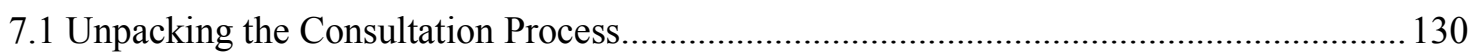

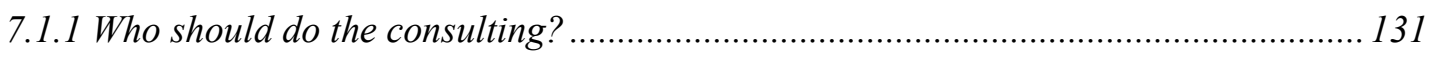

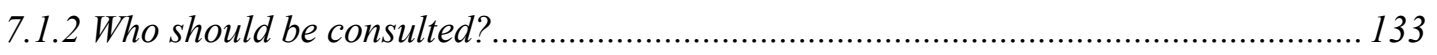

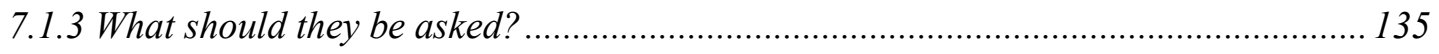

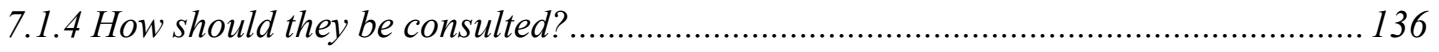

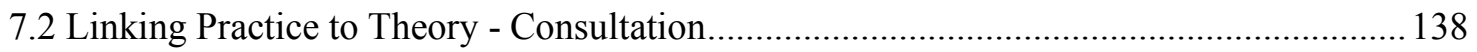

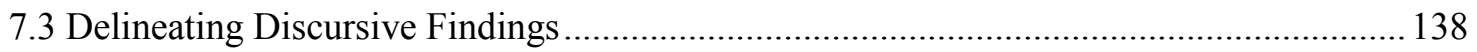

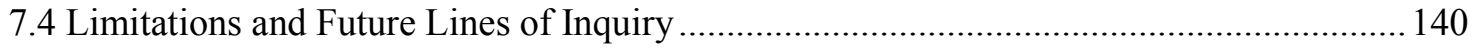

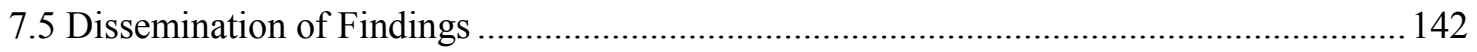

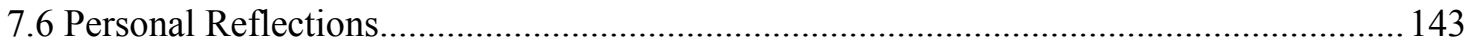

Appendix A: Assembly of First Nations open letter to the Minister of Aboriginal Affairs and

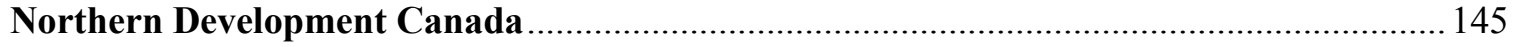

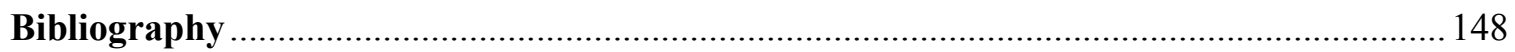




\section{Chapter 1: Introducing Indigenous Education in Canada}

The provision of Indigenous education in the settler-colonial nation-state of Canada is complex. In the past, government-sponsored education was part of an aggressive policy of assimilation to integrate Indigenous ${ }^{1}$ Peoples into mainstream society. In the 1970 s, the government ${ }^{2}$ agreed to close down the assimilative Indian Residential and Day Schools System ${ }^{3}$ to adopt a policy of First Nations ${ }^{4}$ control over education. (Mendelson, 2008) Additional schools were constructed on reserve and mechanisms to disperse educational funding to First Nation governments put in place. First Nations thereby assumed partial control (85\%) over the education of Indigenous youth living on reserve, while the federal government entrenched its role as a funding agency, overseeing the implementation of funds through an administrative reporting regime (retaining 15\% control). (Stewart, 2006) Since the transition to First Nations management of education, Indigenous Peoples have worked to develop the administrative and operational capacity to administer federal education funding toward the provision of a quality education for Indigenous students living on reserve. As this thesis will explain, this transformative process has been impacted by systemic structural impediments and government paternalism toward Indigenous Peoples, as well as the intergenerational impacts of

\footnotetext{
${ }^{1}$ The term 'Indigenous' is used to refer to all Indigenous Peoples living in Canada, as opposed to using the government-imposed 'Aboriginal', which has colonial origins.

${ }^{2}$ All references to the 'government' refer to the federal government of Canada, unless otherwise specified.

${ }^{3}$ The Indian Residential School System will be referred to throughout this thesis as the Indian Residential and Day Schools System as a show of respect to the survivors of Indian Day Schools. Although students of day schools had similar experiences to students of residential schools, day school survivors were not recognized in the class action lawsuit that led to the Indian Residential Schools Settlement Agreement of 2006.

${ }^{4}$ The scope of this thesis is on-reserve Indigenous education for First Nations people. The term 'First Nations' is used when referring directly to Indigenous peoples or governments (Bands) on reserve. Otherwise, the term 'Indigenous' is used more broadly to include all Indigenous peoples.
} 
colonialism on the well-being of Indigenous nations. (Mendelson, 2008; Battiste \& McLean, 2005; Stewart, 2006)

The federal government launched a process to reform the on-reserve school system in 2008 to address these issues, among others. The reform process culminated in federal commitments to introduce legislation to govern education on reserve by September of 2014. In preparation for the introduction of legislation, the government sponsored a consultation process to engage with Indigenous Peoples and public stakeholders regarding the contents of the bill. (Government of Canada, 2013) This research focuses directly on the power dynamics revealed by an analysis of this process, including the ways in which settler-colonial power relations are reproduced through government-led consultation and the discursive framing of Indigenous education in terms of national economic interest.

In the following chapter, Section 1.1, titled Declaration of Research Questions \& Scope, will define the scope of this research, its guiding research questions and the methodological approach employed. Section 1.2, titled Indigenous Education - The Basics, will give an overview of the structure of Indigenous education in Canada. Section 1.3, Theorizing Indigenous-State Relations through Educational Reform, will briefly discuss the conceptual framework that informs this research. Finally, Section 1.4, Thesis Topography, will summarize the contents of each of the following chapters.

\subsection{Declaration of Research Questions \& Scope}

This thesis broadly documents the historical development of on-reserve Indigenous education in Canada and critically examines the recent efforts at reform toward a political 
economy of Indigenous-state relations in the area of education. The work herein should not be taken as comprehensive in nature, as the topic is multi-faceted and extremely complex, stratified as it is by the actions of many agents with a myriad of diverse and sometimes contesting views. Rather, this research aims to start a conversation about the political-economic nature of Indigenous education policy in Canada, with the hopes of motivating others to take up the issues raised herein.

Although a wealth of contextual information is included throughout this research, this thesis will focus on the policy domain related to Indigenous education on reserve. To ground this work, a case study of the recent federal consultation process undertaken as a part of Indigenous educational reform will be examined, as will the government's discursive construction of Indigenous education in terms of national economic interest. However, this research will not explore Indigenous education in provincial education systems, provincial policies related to education, Indigenous self-government in education, the internal workings of the Assembly of First Nations, or the applicability of the proposed Bill C-33: First Nations Control of First Nations Education Act. The scope of this thesis is contained to Indigenous-state relations as evident through the recent consultation process regarding educational reform for on-reserve students.

Two distinct, yet interrelated, groups of research questions will guide this research:

\section{$\underline{\text { Research Questions: Consultation }}$}

1. How is Indigenous sovereignty suppressed through government methods of public and Indigenous consultation that reproduce settler-colonial power relations and invisiblize Indigenous difference? 
2. How did the government respond to feedback from public and Indigenous consultations regarding on-reserve educational reform and the federal legislation tabled as Bill C-33, First Nations Control of First Nations Education Act?

Research Questions: Discourse

1. How does discursive rhetoric shaped by the government construct the education of Indigenous Peoples as good economic policy? How does this discursive framing contribute to the commodification of Indigenous Peoples and the invisiblization of historical, settler-colonial power relations?

2. How were discursive constructions of Indigenous Peoples circulated by the government during the period of consultations regarding on-reserve educational reform in Canada? Which discursive frames dominated, and which were silenced, and to what effect?

To explore the questions related to consultation, primary source data from the reform consultation sessions was obtained from the federal government and analyzed for thematic elements and relations of power as observed through textual analysis. To explore the questions related to discourse, primary source data in the form of federal government public relations messaging was analyzed for discursive messages that construct Indigenous education as economically beneficial for Canada. The following section will give a brief overview of Indigenous education policy to introduce the reader to the substantive topic of this research.

\subsection{Indigenous Education - The Basics}

According to the federal government, there are approximately 113,000 Indigenous elementary and secondary students living on reserve in Canada. (AANDC, 2015) These students, their families and their community leadership, have two choices for their education. If the population of their community is large enough to support an on-reserve school, the student may choose to attend their community's First Nation-operated 
school ${ }^{5}$. Should the community be too small to support a school, the student may only have the option to attend a nearby provincial school. If a community school and a provincial school are both an option, the student and their family may choose either ${ }^{6}$.

The federal government is constitutionally responsible for the elementary and secondary education of on-reserve students, whereas the provinces are responsible for the education of the general public within provincial borders. (Department of Justice, Canada, 2013) In the 1970s, the government implemented a policy of (partial) Indigenous control over education, retaining the primary role of funding agent while First Nation governments became responsible for the local delivery of education to students. Federal funding administered by the Department of Aboriginal Affairs and Northern Development (AANDC) ${ }^{7}$ through the Elementary and Secondary Education Program for students ordinarily resident on reserve is distributed to First Nation governments through one-year or multi-year Set, Fixed, or Block contribution agreements.

Contribution agreements are used to transfer federal funds to First Nation governments for the delivery of social services that would otherwise be delivered to citizens by provincial, territorial, or municipal governments. (AANDC, 2013j) Set contribution agreements are based upon pre-determined program objectives whereby funds will be recovered by AANDC if they are unspent or used for unidentified

\footnotetext{
${ }^{5}$ Several terms may be used throughout this thesis to refer to the school system on-reserve, such as: community schools; First Nation-operated schools; on-reserve schools; etc.

${ }^{6}$ Unless the First Nation government has policies in place to constrain student choices, such as requiring that students attend the community-operated school until a certain grade level.

${ }^{7}$ AANDC is the current name of the federal department that administers the Indian Act and this term will be used to refer to the federal government throughout this thesis. However, AANDC has been known in the past by many other names, including the Department of Indian Affairs (DIA) and Indian and Northern Affairs Canada (INAC).
} 
objectives. Fixed contribution agreements are similar to set contribution agreements except that unused funds can be retained by the First Nation government for use the following year in the same program, or in a different program, if a plan is created and approved by AANDC. Finally, Block contribution agreements are for more than one program area (i.e. social, education, health, etc.) and the funding therein can be applied among the programs as long as program objectives are being met and a plan is approved by AANDC. (AANDC, 2011)

Funding dispersed to communities for education provision via contribution agreements is based upon a per-capita formula, the breakdown of which is unknown as it is undisclosed by the government. Per-capita funding allocations are based upon a community's 'nominal roll', which is a registry of the students ages 4-21 that have a permanent address on reserve, that live with a parent who has joint-custody and lives on reserve, or that have no other permanent address, but is staying on reserve. ${ }^{8}$ (AANDC, 2014a)

The nominal roll determines the quantity of students for which the community will receive per-capita education funding from the federal government. Per-capita rates of funding for education are different depending on where an on-reserve student attends school (on or off reserve) and where the community is located, geographically (i.e. the per-capita funding allocation varies by geographic location). For on-reserve students that

\footnotetext{
${ }^{8}$ Determining which children to include on a community's nominal roll can be problematic. For instance, non-Indigenous children are included if they have an on-reserve address. However, due to a lack of formal policy governing the nominal roll process and the transitory nature of many students and families between communities, urban centres, and even group homes, First Nation governments often experience significant uncertainty and spend an abundance of time finalizing their nominal roll, which is due to the government two-four times per school year.
} 
attend community schools, the First Nation government receives funding per student enrolled for the administration and operation of the school. For on-reserve students that attend provincial schools, the First Nation government receives funding per student to pay a tuition fee to the province for the provision of public education to that student. In the instance of on-reserve students attending provincial schools, the federal government requires the First Nation government to establish a local tuition agreement with the provincial Ministry of Education and/or school district for the transfer payment of federal tuition.

In other words, when a student with an on-reserve address attends a provincial school, the federal government provides the First Nation government with an annual tuition that is then remitted to the province for the provision of education to that student. Therefore, provincial governments receive indirect federal transfer payments for the education of on-reserve students in provincial schools. ${ }^{9}$ The province determines the tuition rate charged for on-reserve student tuition by calculating the per-capita funding for students in the public system. Although local tuition agreements outline the provincially-determined rate of tuition for on-reserve students, agreements may or may not stipulate how the tuition may be expended by the provincial government. This means that the tuition may go toward the provincial education system, toward the enhancement of provincial education services for Indigenous students in particular, or toward the provincial coffers in general.

\footnotetext{
${ }^{9}$ In some cases, First Nation governments can stipulate in the local tuition agreement that federal tuition flows directly from the federal government to the provincial government, cutting out the role of the First Nation.
} 
The per-capita funding dispersed to First Nations for the delivery of education on reserve must adhere to certain expenditure guidelines in accordance with the First Nation government's contribution agreement. Additionally, federal policy dictates that First Nations maintain a school system comparable to the local provincial system as a condition of funding. (Mendelson, 2008) Eligible expenditures under the Elementary and Secondary Education Program include instructional services, such as: principal, viceprincipal, and teacher salaries; instructional resources; para-professional services, such as audiologists, speech and language pathologists, etc.; curriculum development; school administration such as a secretary and office supplies; nutrition programs; internet connectivity and more. Certain student support services are also eligible, as are expenditures related to the operation of a school board. ${ }^{10}$ (AANDC, 2014a)

Due to the fact that federal policy states that First Nation school systems must maintain comparability to the services provided in provincial education systems, there is considerable interest in whether or not the per-capita funding provided for on-reserve students in each system is comparable. Controversy arises because critics question how comparability can be maintained if funding is not on par. It is difficult to ascertain the exact rates of funding to First Nation schools, not only because the funding formula remains undisclosed by AANDC, but also because every nation receives an amount based upon their particular situation. However, the issue of funding equity has been investigated by numerous reports and evaluations and has found to be inequitable in comparison to provincial funding rates. For instance, the Auditor General of Canada

\footnotetext{
${ }^{10}$ The government does make other supplementary funding programs available to First Nations, such as for high-cost special education. However, for the purposes of this research, the focus will be operational and administrative funding for Band schools.
} 
identified inadequate funding of on-reserve schools as a structural impediment to the delivery of quality education on reserve. (Auditor General of Canada, 2011) A report for the Mi'kmaq Confederacy of Prince Edward Island found that First Nation government operated schools are historically funded at $75 \%$ of provincial tuition rates for on-reserve students attending provincial schools. (Walton, et al., 2009) Similarly, a report comparing the rates of tuition funding to First Nation schools and provincial schools in Saskatchewan found that on-reserve schools receive $40-50 \%$ less funding per student than what the provincial budget allocates per student. (R. J. Kowalchuk Consulting, 2013)

However, the comparison exercise is complex at best. AANDC uses a policybased funding formula, while most provinces use a needs-based funding formula to determine per-capita funding rates. (R. J. Kowalchuk Consulting, 2013) These two approaches to budgeting for education are vastly different, which makes it difficult to make an accurate comparison. Additionally, AANDC only publicizes a per-capita rate of funding for Indigenous students that includes all expenditures for students attending school on and off reserve. For instance, AANDC states that it funded education for onreserve students in the year 2012-13 at about $\$ 14,342$ on average, per student, a number comparable to provincial school board rates in many provinces. (AANDC, 2015a) However, this figure does not solely represent the operational and administrative funding provided to communities to operate schools on reserve. The figure was calculated by taking the entire cost of the Elementary and Secondary Education Program for students on reserve in 2012-13, \$1.62 B, and dividing it by the total number of on-reserve students. This includes funding provided for students whether they attend school on 
reserve or off, which means that it includes funding provided for provincial tuitions. AANDC does not provide a specific breakdown of per-capita funding for Indigenous students in First Nation-operated schools.

Unfortunately, regardless of whether Indigenous students attend an on-reserve community school or a provincial school, the system is failing them. About $61 \%$ of Indigenous students living on reserve attend a First Nation-operated school, with 39\% attending provincial schools across Canada. (AANDC, 2014c) On-reserve students attending provincial schools graduate at a rate of approximately $37 \%$, while those attending First Nation-operated schools graduate at a rate of approximately $26 \%$. By comparison, non-Indigenous students in the general Canadian population graduate at a rate of $87 \%$. (AANDC, 2012a) These graduation rates are just one measure of the inability of current education systems to meet the needs of Indigenous students, prompting Indigenous and government desire for educational reform.

\subsection{Theorizing Indigenous-State Relations through Educational Reform}

The argument of this thesis can be situated within a complex conceptual framework based upon David Harvey's theory of Accumulation by Dispossession (2003), Wendy Larner's theory of Neoliberalism as Policy, Ideology and Governmentality (2000), and an original interpretation of Andrea Smith's Logics of White Supremacy (2010) in the settler-colonial context.

I argue that capitalism's inherent drive to accumulate by dispossession through processes of creative destruction is driving the neoliberalization of Indigenous education 
in contemporary Canada. ${ }^{11}$ Through a reform process that distances the state from its constitutional obligations and links Indigenous education to labour market demands, a neoliberal discourse of restructuring shapes Indigenous subjectivities to free-market rationalities. Founded upon the settler-colonial logics of elimination/assimilation and commodification/subjectification, the reform of Indigenous education to facilitate the quickened entry of Indigenous Peoples to Canadian economic society invisiblizes Indigenous difference through the suppression of Indigenous alternatives to the economic, political, social and cultural production of space.

I argue that the settler-colonial government of Canada utilized a unilateral process of educational reform, masked in a discourse of rhetorical messaging related to consultation and Indigenous control, to suppress the exercise of Indigenous sovereignty related to education. Further, the colonial government's use of a discourse of restructuring links Indigenous education to labour market outcomes with the objective of commodifying Indigeneity and assimilating Indigenous Peoples to the capitalist marketplace.

This thesis harnesses methods of historiography and Foucauldian discourse analysis to contextualize Indigenous-state relations related to education. Primary source documents are explored for key messages related to the consultation process and evidence of a neoliberal discourse of restructuring.

\footnotetext{
${ }^{11}$ Joseph Schumpeter wrote about the creative destruction inherent to capitalism, stating that capitalism is an evolutionary process whereby the innovation of existing capitalist structures is required to allow for the facilitation of opportunities for continued capitalist accumulation. (Schumpeter, 1943) In regard to on-reserve Indigenous education, this concept applies to the breakdown and reconstruction of the current structures governing the education system through a process of policy reform.
} 
This research is a step toward a political economy of Indigenous-state relations related to education. The application of the theoretical framework herein is an original contribution meant to engage the reader and provoke questions regarding this important issue. In decolonial style, further defined in Chapter 2, this thesis is not intended to exhaustively situate the subject within academic research and professional reports. Instead, this thesis is based upon the lived experience of the author and exercises a critical perspective informed by personal encounters with federal education policy at the grass-roots level.

\subsection{Thesis Topography}

Chapter 2 of this thesis, titled Encounters with Decolonial Methodology, adopts a decolonizing conversational-style format to engage with central tenets of Shawn Wilson's Research is Ceremony. (Wilson, 2008) Throughout the chapter, concepts of relationality, intersubjectivity, and positionality are explored through a personal exercise of critical reflection. My connections to the research topics and reasons for choosing it are declared, as are my philosophical biases. The components of an Indigenous research paradigm, as proposed by Wilson, are examined for links to my own research methodologies and ontologies. Finally, the chapter ends with a detailed description of how this research was undertaken, for the purposes of establishing legitimacy and trust with the reader.

Chapter 3 of this thesis, titled Theorizing Indigenous-State Relations in Contemporary Canada, lays out a broad conceptual framework against which the findings of this research are later interpreted. As aforementioned, the framework links David Harvey's definition of accumulation by dispossession in contemporary times 
(2003) to Wendy Larner's conceptualization of neoliberalism as policy, ideology and governmentality. (2000) These two interrelated theories are further informed by my original application of the logics of settler-colonialism operating in contemporary Canada in relation to education, based upon Andrea Smith's work with the logics of White supremacy operating in the United States. (2010) Each of these theories will be explored in turn, with examples provided to link them to the issue of Indigenous education.

Chapter 4, titled Historical Development of Indigenous Education Policy in Canada, harnesses historiography to detail the development continuum of Indigenous education policy in Canada. Indigenous-state relations in the area of education are explained through an examination of state-sponsored assimilation of Indigenous Peoples through education, the devolution of education to the provinces, and the development of policies leading up to the Indian Act. (Government of Canada, 1985) Situating Indigenous education within the supranational rights infrastructure further contextualizes this research. Finally, the state of Indigenous education in Canada today is illustrated in preparation for the analysis of reform in Chapter 5.

Chapter 5, titled Analyzing Government-Sponsored Reform of Indigenous Education, introduces the federal reform of Indigenous education initiated by the government in 2008. A detailed timeline of the government-sponsored consultation process is described, followed by the presentation of primary evidence relating what was said during consultation sessions. Feedback from Indigenous and public stakeholders is examined along three main themes: Funding, Consultation and First Nations Control. The government's duty to consult and accommodate is introduced to frame this portion of the analysis. (Government of Canada, 2011) 
In Chapter 6, titled Reforming Education or Reframing Indigeneity?, the reform process is described from the close of in-person consultations in April, 2013, to the tabling of Bill C-33 in the House of Commons in April, 2014. Indigenous frustration with the federal consultation process is revealed through one group's experience with the government's community engagement strategy, while the Assembly of First Nations' concerns for First Nations control over First Nations education is expressed through a new framework for educational autonomy and an open letter from the National Chief. The myriad of political interests between and among First Nations and the government are glimpsed through the lens of the multiplicity of perspectives related to reform and Indigenous control of education on reserve. Finally, the government's discursive framing of Indigenous education in terms of national economic benefit is explored through a discourse analysis of federal public relations documents.

Finally, Chapter 7, titled Theoretical Explorations and Further Reflections, links key findings to the broad conceptual framework presented in Chapter 3. The limitations of this research are defined, options for future inquiry contemplated, and dissemination of research findings discussed. 


\section{Chapter 2: Encounters with Decolonial Methodology}

After reading Research Is Ceremony: Indigenous Research Methods (2008) by Shawn

Wilson, I wanted to include a personal engagement with a decolonial method of writing in this thesis. Wilson pursues the identification of the elements of an Indigenous research paradigm throughout his book. Knowledge related to questions about what Indigenous ontologies, epistemologies, methodologies, and axiologies look like in practice are delivered through unique textual exchanges.

Each chapter lays out research findings as conversations between research participants, the author's personal communications with his sons (in the form of letters), and even a text version of a talking circle, the Indigenous method of creating a space free of judgement for sharing. Wilson encourages readers to explore Indigenous ways of relating to their own research paradigms. As a researcher interested in [post] colonial $^{12}$ studies and Indigenous movements, I thought it important to explore this compelling research paradigm. What follows is my version of a talk story that engages the ideas put forth by the author Shawn Wilson.

In conversational style, I will introduce myself in the following section and share my journey of critical reflexivity in relation to this research. I will explore the concept of relationality and inter/subjectivity in decolonial research, as well as my encounter with the insider/outsider binary as a White woman of privilege conducting research on Indigenous issues. Section 2.2, titled Strategies of Inquiry, will detail the methodological

\footnotetext{
12 Bracketing the 'post' in [post]colonial recognizes that neocolonialism and colonial legacies are still operating in contemporary times. For the purposes of this thesis, [post]colonialism is defined as "a range of critical perspectives on the diverse histories and geographies of colonial practices, discourses, impacts and, importantly, their legacies in the present - critical engagements that often preceded and must continue long after formal political independence." (Nash, 2002, p. 221)
} 
framework for this thesis and assert the appropriateness of Foucauldian discourse analysis for advancing an Indigenous research paradigm. Then, in the final section, titled Legitimizing Knowledge Creation, I will explore mainstream and alternative interpretations of research axiologies, addressing expectations of validity and rigour in this research.

\subsection{Who Am I?}

Shawn Wilson, author of Research Is Ceremony: [I] freality is based upon relationships, then judgement of another's viewpoint is inconceivable. One person cannot possibly know all of the relationships that brought about another's ideas. Making judgements of others' worth or values then is also impossible. Hierarchy in belief systems, social structure and thought are totally foreign to this way of viewing the world. Thus, egalitarianism and inclusiveness become not merely a norm but the epistemologically inevitable. (Ibid., p. 92)

Me: What I interpret the author as referring to above is the assertion that because every person has experienced different realities throughout their lives, they will have unique perspectives and responses to the ideas of others. One part of an Indigenous epistemology then is the egalitarianism and inclusiveness of all voices, the encouragement of authentic expression, and a space free from judgement. Since reality is shaped by relationships (relationships to one another, to culture, to land, to other species, to the environment) there can never be one universal truth, but rather many varied perspectives that must be respected for their contributions to the grander conversation.

The adherence to a relational epistemology, then, infers the importance of relationality to Indigenous Peoples and Indigenous research paradigms. Relationality was defined differently by different people throughout Research Is Ceremony, but the definition of Indigenous relationality that stayed with me the most was " $[r] a t h e r$ than viewing ourselves as being in relationship with other people or things, we are the 
relationships that we hold and are part of". (Ibid. 80) This is a concept that I hold as central to my worldview: it is the interconnectedness of all life.

Following from this, the author describes the way the talking circle, a method of sharing in Indigenous cultures, allows those participating to communicate their experiences without judgement. The interpretation of each person to what came before them inspires authentic responses, to which the next person can then process and build upon through the sharing of their story. In this way, each person learns from the ideas of those before them, adding to them and building upon them the imprint of their own unique perspective. (Ibid., p. 41, 92-93) With this relational process in mind, I will engage with the ideas of Shawn Wilson in conversational style for the remainder of the chapter, integrating the voices of other scholars as necessary and appropriate. Through this dialogue, I hope to practice decolonial methods of communicating research concepts in the hopes that the experience will inform my current and future undertakings.

Shawn Wilson, author of Research Is Ceremony: Indigenous people in Canada recognize that it is important for storytellers to impart their own life and experience into the telling. They also recognize that listeners will filter the story being told through their own experience and thus adapt the information to make it relevant and specific to their life. When listeners know where the storyteller is coming from and how the story fits into the storyteller's life, it makes the absorption of the knowledge that much easier. (Ibid., p. 32)

Me: To me, this passage is about subjectivity and intersubjectivity in research. As

Dowling explains: "Subjectivity involves the insertion of personal opinions and characteristics into research practice." (Dowling, 2010, p. 35) Subjectivity is especially pertinent to discourse analysis because the interpretation of discursive messages is processed through the researcher's unique understanding of the world. Intersubjectivity "refers to the meanings and interpretations of the world created, confirmed, or 
disconfirmed as a result of interactions (language and action) with other people within specific contexts". (Ibid.)

This makes me think of research ontologies, which are about how we view the world to be. Indigenous ontologies recognize that there may be multiple, varied realities, all shaped by an individual's relationships. Importantly, because an Indigenous ontology uses relationships to define what is true about the world, it also directly informs an Indigenous epistemology - the theory of knowledge. (Wilson, 2008, p. 73) Ontologies, epistemologies, axiologies (ethics and morals), and methodologies (how we gather information about reality) are the underlying belief structures that guide our actions as individuals and as researchers. (Ibid., p. 13) Considering the many encounters that enabled me to develop a deep understanding of the chronic inequity of Indigenous education, leading me then to become a researcher in order to critically reveal the injustice of it, an Indigenous research paradigm informed by one's own truth seems a complementary way of communicating with my subject.

Critical reflexivity is a useful tool for critical researchers to lay bare their positionality and address inter/subjectivity in their work. (Dowling, 2010, p. 35) In revealing their bias, researchers alert the audience to the nature of their interpretation of reality in relation to the research topic. ${ }^{13}$ Although many (more positivist) research paradigms suggest that researchers should strive to limit the amount of inter/subjectivity throughout their work, the relationality central to Indigenous research paradigms suggests something very different.

\footnotetext{
${ }^{13}$ This entire section is my engagement with critical reflexivity
} 
Instead of resisting the insertion of personal experiences and perspectives into research, Indigenous research paradigms encourage researchers to express their ideas through their authentic experiences. Wilson argues that "it is not possible to be accountable to your relationships if you are pretending to be objective." (Wilson, 2008, p. 101) This concept proved particularly relevant, since my theoretical framework has been directly shaped by my myriad experiences with Indigenous education for the past seven years.

Working in the areas of Indigenous education policy, negotiation, and program management for a provincial government and a First Nations educational alliance, my research questions, theoretical lens, and methodology have all been (necessarily) informed by my past experiences. My encounters with this policy area and the complex socio-political relations that inform its administrative structure, from federal government funding formulations to community hiring practices for Indigenous schools, motivated me to investigate the recent federal reform of Indigenous education. In this regard, I hope to utilize what I have learned to bring awareness to this critical area of Indigenous social policy, for social justice ends, while highlighting the often slanted and silencing nature of the public discourses surrounding it.

Like Paulo Freire (Pedagogy of the Oppressed, 1970), I believe fundamentally that education is emancipatory. Not only are Indigenous rights to autonomy over education in Indigenous communities linked to the well-being of Indigenous societies. But I truly believe that critical public education regarding the inequitable power dynamics and legacies of colonialism surrounding Indigenous-state relations in Canada will result in progressively stronger public opinion promoting the resolution of these 
issues. By shedding light on the political economy of on-reserve Indigenous education in Canada, I hope to inspire other scholars to join in the conversation and motivate readers outside the academy to question their assumptions.

Shawn Wilson, author of Research Is Ceremony: One thing that most of these Indigenous inquiries hold in common is that they look at social, historical and economic factors to explain the differences between Indigenous and non-Indigenous peoples and then make recommendations that are intended to adapt the dominant system to the needs of Indigenous people. These programs proceeded with the assumption that if economic and environmental conditions were the same for Indigenous and non-Indigenous people, Indigenous people could "pull themselves up" to the standards of dominant society. This same attitude promoted the forced assimilation of Indigenous people through such social tragedies as the 'stolen generation' and forced residential schooling. (Wilson, 2008, p. 20)

Me: In this passage, Wilson is referring to the pre-nineties trend in academia to study Indigenous Peoples anthropologically and from a colonial perspective. During the 1990s, the trend in academia shifted to research conducted with and for Indigenous Peoples. (Ibid., p. 51) One such example of this was Canada's Royal Commission on Aboriginal Peoples (RCAP) (1996), which was a landmark undertaking partly because it engaged with Indigenous Peoples to share, for the first time, the true history of Indigenous-state relations in Canada. RCAP laid bare the colonial assault on Indigenous Peoples in Canada and made solid recommendations for action to reconcile the relationship between Indigenous Peoples, the government, and Canadian society. Nowadays, just the presence of a book that delineates an Indigenous research paradigm is an indication of how far scholarship has come in relation to research with, for and by Indigenous Peoples.

Similarly, most Indigenous educators I have worked with advocate for Indigenous-created solutions for on-reserve and provincial education. In my experience, resistance to educational solutions imposed on Indigenous nations by the federal government is common. Indeed, this thesis aims to make visible the Indigenous response 
to recent federal education reform processes as part of the movement for Indigenous autonomy over education on-reserve.

Considering that in the past, researchers often entered a community, collected their data, and left, never to be heard from again, Wilson remains critical of any research conducted by an 'outsider' regarding Indigenous Peoples when the research does not provide constructive information that might contribute to the well-being of Indigenous communities. He argues: "In addition, this approach focuses on problems, and often imposes outside solutions, rather than appreciating and expanding upon the resources available within Indigenous communities." (Wilson, 2008, pp. 15-16) In truth, my own position within the 'insider/outsider' binary is one that has plagued me.

I maintain an ongoing dialogue in my head about the appropriateness of a White woman of privilege (me) engaging in cross-cultural research without utilizing participatory methods. When I was developing the methodological framework for this thesis, I was contemplating whether in-person interviews were necessary to effectively address my research questions. Being under certain time constraints, I felt that the research questions could be directed through a policy lens, thereby limiting the need for narrative and allowing me to utilize my learned knowledge in that sphere. Nonetheless, I worried about the implications of researching Indigenous education from a cross-cultural place of privilege without the inclusion of individual Indigenous voices. Would my research be received as legitimate? Do I have a unique perspective that this research could benefit from, or is this a topic for someone else? Indeed, Wilson strongly suggests that decolonial, Indigenous paradigms includes the involvement of Indigenous Peoples in all aspects of the research. (Ibid., p. 110) 
I brought my concerns to an Indigenous mentor and he reminded me that we are all Treaty people - there should be no feelings of an 'us', and a 'them'. We are all interconnected, and it will take 'faces of all colors' to achieve the reconciliation required to move ahead from our colonial past. He said that the struggle for equitable and autonomous Indigenous education requires solidarity amongst Indigenous and nonIndigenous Peoples to bridge cultural differences to achieve united and transformational change. He suggested that I have insider knowledge on this critical issue and therefore, a duty to share it - to communicate my experience and critical perspective especially to non-Indigenous Peoples. Revealing the power dynamics and strategies of resistance related to Indigenous education is of use to policy makers and Indigenous leadership, but it could also be harnessed for decolonizing Indigenous education and challenging public misconceptions.

Stan Stevens, 'Cross-cultural Research: Ethics, Methods, and Relationships': In my view, post-colonial research aims at being emancipatory not simply through being more culturally sensitive or seeking local research approval but through respect for the legitimacy of others' knowledge and their ways of knowing and being and through activism in support of their pursuit and exercise of self-determination. This requires acknowledging and repudiating the dynamics of power that shape colonial research interactions with subordinated and marginalized peoples and groups, attempting to overcome whatever ethnocentrism and paternalism we bring to the research and whatever suspicion we are greeted with, persuading people that we are worthy of being taught and capable of learning, and being willing to put aside preconceptions (and academic and activist preoccupations), to listen, and to be of service to local concerns and projects. (Howitt \& Stevens, 2010, p. 46)

Me: I agree wholeheartedly with Stan Stevens that research conducted through a decolonial lens, in recognition of the many truths and valued knowledge systems that exist, is the appropriate means by which the researcher escapes the insider/outsider binary. And given the flexible nature afforded by the concepts that underpin Indigenous research paradigms, such as relationality, there can be no one right way, no prescription, 
for conducting decolonial research. Therefore, it is up to the researcher to govern themselves throughout the research process to ensure their work does not reproduce colonial relations. Personally, I would not have been able to continue in this research process without the inner dialogue that has allowed me to address some of the concerns I had about my own positionality.

\subsubsection{Methodological Scope, Assumptions, and Motivations}

I found the conversation with my mentor empowering, and, as a result, I decided to focus my research on the area of my professional expertise: policy engagement. First, I will investigate the use of power in the nationwide federal consultation process on Indigenous education reform, and second, I will demarcate the discursive messages surrounding it to delineate the myriad, conflicting truths. Consulting regularly with my mentor and other Indigenous colleagues, I shaped my thesis proposal and prepared my federal and provincial requests to information under the public access to information acts. Initially, I planned to include a case study analysis of the experience of an Indigenous educational organization I am allied to. But, after receiving the information from my right to information requests, I realized that my thesis could include the voices of all those that participated in the nationwide consultation process. Instead of a case study of one group's experience, power-laden though it was, I now have the evidence required to demarcate the stories of geographically dispersed and culturally diverse Indigenous and public interests.

Indigenous and government perspectives were analyzed and decoded through the analysis of public and Indigenous feedback captured during the consultation process. Although direct person-to-person data collection methods were not used, I feel that the 
political-economic lens I adopted to explore the power dimensions of this encounter in Indigenous education reform will adequately highlight the Indigenous perspective through textual discourse and structural analysis.

To summarize my positionality and personal assumptions that may impact my findings: my interest in this issue arose out of my genuine concern for all students, for Indigenous nations, and for the future of Canada. I believe in the potential for strong and sovereign Indigenous nations and that there exists an alternative reality for Canada whereby Indigenous Peoples can live self-determining lives within the context of their Indigenous inherent and Treaty rights, as nations within a nation - Canada would be enriched by this authentic cultural, social, economic and political diversity. Finally, fundamentally, I believe that education is key to social change and the realization of Indigenous sovereignty.

In the specific case of Indigenous educational reform, I felt there was a truth not being told and I wanted to help reveal it. Not only am I familiar with the reform process, I lived it. I participated in consultations as both a government representative and then later as the organizer of Indigenous engagement sessions. I have worked with a threecommunity educational alliance for two years, as an advisor in the area of nation to nation relations, while assisting them in preparing for the pending systemic reform.

While I am neither Indigenous, nor do I live on-reserve, I do not consider myself to be an 'outsider' in the binary sense of 'us' versus 'them'. As my Indigenous mentor stressed, we are all Treaty people, and if we continue to extend discourses that 'other' each other, we will only encourage relational dissonance. Similarly, an acquaintance recently shared with me his disdain for the term 'settler-ally'. As an Indigenous person, 
he felt that this terminology interrupted the reconciliatory process through a guilt-laden othering of non-Indigenous Peoples. Although I recognize Wilson's perspective that non-Indigenous peoples are 'outsiders' that have not experienced settler-colonialism as Indigenous Peoples have, I must respectfully disagree that non-Indigenous peoples do not have a role to play in the movement to advance Indigenous rights through decolonial research. We are all Treaty people, we are all Canadian, and we all have a role to play in the reconciliatory process. I feel that constructing the movement along an insider/outsider or 'us versus them' binary only amplifies anger and leads to continued antagonism, not to mention recreating the same behaviours that led us down this road in the first place.

I do not intend to document this Indigenous-state encounter for the history books. Instead, I hope to spur a discussion that will motivate interest in this important policy area, and give 'outsiders', those external to, but part of the process, a critical look at what the federal consultations actually entailed. Lessons learned from this analysis have the potential to inform the actions of the complex web of stakeholders in Indigenous education in the future.

\subsection{Strategies of Inquiry}

This section will explore the methodological framework of this thesis, describe the particular methods of data collection and analysis used, and detail the various considerations therein. The use of 'strategies of inquiry' to refer to methodology is embraced as a way of decolonizing research terminology, as promoted in Research is Ceremony. 
Shawn Wilson, author of Research Is Ceremony: Some Indigenous scholars may attempt to "decolonise" methodologies and turn them into something that can be useful in Indigenous research. This is an attempt to insert an Indigenous perspective into one of the major paradigms. It is my belief that this will not be very effective, as it is hard to remove the underlying epistemology and ontology upon which the paradigms are built. On the other hand, if one starts from an Indigenous paradigm, then one can choose to use any tool from within that paradigm that may be effective. (Wilson, 2008, p. 39)

Me: In all honesty, I read Research Is Ceremony near the end of my research process.

But what was immediately apparent, was that my worldview is compatible with an Indigenous research paradigm. The reality I live and the way I interpret it, my ethics and spiritual beliefs - these elements of my personal worldview coincide with a decoloniality. Through the years, my relationships with Indigenous Peoples taught me to question the domination of what I now know as the colonial truth. These relationships made me the person I am the today, living in the place I am today.

All this to say, I did not initially understand the ways in which I was enacting an Indigenous research paradigm when I proposed my research. Instead, my lived experience working with Indigenous Peoples informed my research questions. I now know that this is called relationality, and it is the central concept to Indigenous paradigms. (Ibid.) After reading Research Is Ceremony, I have realized that it is also central to this project. First, for the ways in which my own relationality to the topic affects my intersubjectivity with the research, and second, for the ways in which colonial relationality underpins the history and perceptions of Indigenous education in Canada.

Considering the aim of this thesis is to explore how settler-colonial power relations are reproduced through neoliberal Indigenous education reform, an analysis of the relationality of Indigenous Peoples and the government was required. Deconstruction of the discursive messages framing the issue through textual analysis, as a method of data 
collection, proved more than suitable given the power-laden nature of the relationship.

Textual analysis allowed me to access written evidence of discursive structures that socially construct knowledge and shape subjectivities. The textual analysis performed for this thesis was guided by the principles of a Foucauldian discourse analysis, which assert that:

... [A]ll knowledge production is caught up in power relationships. Certain ways of knowing the world are privileged and others are silenced. Discourse analysis involves being alert to different strategies of conviction deployed by authors to help persuade audiences that a particular form of knowledge is intrinsically better than others. (Waitt, 2010, pp. 238-9)

Interestingly, Foucauldian discourse analysis recognizes that all knowledge is socially constituted, even the ontology of the researcher, and that a researcher's positionality will have implications for how they perceive discourse. (Ibid., p. 224) In this regard, critical reflexivity is an important process through which researchers can declare their personal philosophical, theoretical, and political predispositions, making the audience aware of the position of the writer. (Bradshaw \& Stratford, 2010, p. 78) Because this methodological frame acknowledges the socially constituted aspect of all knowledge, including how a researcher's perspective is shaped by their experiences, I interpret it as being compatible with an Indigenous research paradigm. I also found that the subjective nature of Foucauldian discourse analysis and the intuitive nature of its application as a research method meant that it was conducive to the concept of relationality. It seems that Gergen felt the same way.

\section{Kenneth Gurgen, author of 'Relational theory and the discourses of power':} [A] mong the most important sources of disciplinary power are discursive or disciplinary regimes, roughly organized bodies of discourse and associated practices that serve both to engender beliefs and to rationalize their own existence. As the system of discourse, often taken to be truth or knowledge by its advocates, becomes the argot of everyday 
activity, seeping into the capillaries of the normal or taken for granted, so does the aggregate become complicit in its own subjugation. (Gergen, 2015, p. 35)

Me: Now that I have established how Foucauldian discourse analysis is in tune with Indigenous relationality and research paradigms, I would like to tell you a story to help demarcate the application of this method.

The first time I used discourse analysis as a researcher, I was looking at an issue related to my current topic. I was exploring the discursive structures contained within the Federal Framework for Aboriginal Economic Development (Government of Canada, 2009) related to the subjectification of Indigenous Peoples. Discursive structures can be thought of as "the sets of ideas that typically inform dominant or common sense understandings of interconnections between people, places, plants, animals and things." (Waitt, 2010, p. 233) Luckily, I already had my primary document for the application of textual discourse analysis. However, in most cases it will be necessary to perform a preliminary scan of what source documents might be available to you as a researcher, and then to select a sampling of data that is both rich in meaning, and required to enrich your analysis. (Ibid., 222) Although there is no set limit on how many sources should inform a qualitative analysis, it is crucial to recognize when you have reached the threshold for enabling an authentic contribution. In other words, it is important not to get too hung up on trying to be overwhelmingly comprehensive by including everything under the sun. Sometimes, more is less. Now let's return to my story.

After an initial read through my primary evidence, I marked words and concepts that appeared more than once with descriptive codes. After a second read, some of my categories were broken down into further sub-categories. Finally, when I read the 
document a third time, I attempted to suspend my existing preconceptions to enter a more reflexive state. (Ibid., 224) To do this, I engaged in an exercise of critical reflexivity where I identified my own preconceived notions of what I might find in the text. Then, I asked myself how other readers from various positions and backgrounds might interpret the text. I questioned what the purpose of the message was, and who the target audience was. Through this exercise, I was able to open my mind to the myriad ways in which the text might be received, not only from my point of view, but from others as well. As I identified each structure, I coded it with a theme, or what is sometimes referred to as an analytical code.

I find the discovery of underlying messages within text to be one of the most gratifying parts of discourse analysis. By analysing the interactions that occur within and between texts, the way that sentences are structured, and the way that 'others' are referred to, research can reveal the power dynamics at play. As Waitt (2010) explains:

Discourse is especially potent at shaping social relations because through it some voices may be silenced while others become dominant. After time, dominating discourses can overcome 'others', resulting in a hegemonic version of reality. (Waitt, 2010, p. 217)

Power relations can be reproduced and knowledge shaped according to how discourse plays out in text, especially in the public domain. That is why an in-depth analysis that recognizes when the perspective of subaltern 'others' are absent can be particularly relevant in [post]colonial contexts.

In order to properly deconstruct discourse, the researcher must be critically familiar with the social context through which it is constituted. (Ibid., p. 225) It could be an arduous task to interpret the interplay between power and knowledge within a text or 
to identify silenced voices if the context of the discourse is foreign. Because of this, it is especially important to analyse which discursive messages are dominant or privileged within the discourse, as they may promote an alternate truth while simultaneously subjectivizing key audiences. (Ibid., p. 236) As I have found within Canadian policy documents targeted to Indigenous Peoples, the text often invokes the use of the term “Aboriginal Canadian" to describe Indigenous Peoples without any mention of Indigenous Peoples as distinct, autonomous nations. For instance, in the 2009 Federal Framework for Aboriginal Economic Development, an opening paragraph states "Aboriginal Canadians are well-positioned to help build a vibrant Canadian economy". (Government of Canada, 2009) Throughout the document, Indigenous nations are not mentioned; only 'Aboriginal Canadians' are poised to take advantage of market society to prosper and move forward into the future. In my experience, Indigenous voices are absent from policy documents and the messages relating to them subjectify them as individualized, market-driven Aboriginal Canadians.

I should mention that a part of coding my text for categories and then themes automatically required me to employ some content analysis. By this I mean that I noted when specific terms were used several times, and even weighed my theme passages according to the number of times they occurred. Although content analysis is an instinctive part of the structural analysis of text, it is more explicitly used by researchers for quantitative research. (Frey, Botan, \& Kreps, 1999)

After coding for key themes, I was able to better interpret the aspects of power and persuasion the text contained. In order to legitimate discursive messages, disciplinary power is evoked through persuasion and rhetoric. Some scholars refer to the 
study of this aspect of discourse as rhetorical criticism, which is "a systematic method for describing, analyzing, interpreting, and evaluating the persuasive force of messages embedded within texts." (Frey, Botan, \& Kreps, 1999) Others still refer to it as the study of the disciplinary power of dominant institutions. (Gergen, 2015) Each of these concepts was useful in preparing me for the discourse analysis performed for this thesis.

\subsection{Legitimizing Knowledge Creation}

This section focuses on research axiologies, the ethics and morals that guide the research process. Researchers that document the research process, along with the considerations and thought processes that went into it, establish the legitimacy of their research and their reputation as a trustworthy researcher.

Shawn Wilson, Author of Research Is Ceremony: An Indigenous axiology is built upon the concept of relational accountability. [...] The knowledge that the researcher interprets must be respectful of and help to build the relationships that have been established through the process of finding out information. Furthermore, the Indigenous researcher has a vested interest in the integrity of the methodology (respectful) and the usefulness of the results if they are to be of any use in the Indigenous community (reciprocity). Following this axiology, an Indigenous methodology must be a process that adheres to relational accountability. Respect, reciprocity and responsibility are key features of any healthy relationship and must be included in an Indigenous methodology. (Wilson, 2008, p. 77)

Me: Regardless of whether you call it validity or authenticity, as one of Wilson's research participants suggested, when we talk about rigour we are talking about accountability. By this I mean that in order for my research herein to be legitimate, the reader must trust that I have conducted my research in a transparent, authentic way, while upholding principles of respect, reciprocity and responsibility to my research subject.

The trustworthiness of the relationship between reader and researcher comes through the researcher's documentation of the entire research process. Not only must I explain how and why I chose certain texts, but I must also explain how I addressed my bias so that it 
did not interfere with my analysis (that I was thorough), that my findings are supportable (my sources are triangulated, or 'encircled', meaning that they have been compared against other sources for validation), and that I have produced truthful work that is my own (authorship). (Bradshaw and Stratford 2010, 77; Wilson 2008, 101) What follows is my declaration of legitimacy to my reader.

Considering that my research topic was specific to a policy reform process that had recently been completed and that I had been a participant to, I was familiar with the documentation that was available to me in the public domain. As discourse analysis involves the interpretation of relationships and the construction of meaning through discursive interactions, the use of multiple kinds of texts, including media coverage, government press releases, internal briefings, letters between government and Indigenous groups, or between Canadian provinces and the government, would all be useful. But for analyzing relationships of power through textual interactions, such as the interplay of ideas in the consultation process for Indigneous educational reform, the intertextuality of consultation documents proved the most pertinent. To obtain these papers I submitted two access requests for information to the federal government:

1. Ministerial briefing notes and financial forecasts regarding on-reserve education reform and/or the development of federal legislation for First Nations education on-reserve from 1996 to present day. Please also include the recent report comparing provincial funding levels in education for the purpose of informing a new funding model for $F N$ education on-reserve. Please include any financial forecasts that would have been produced by the Atlantic Region.

2. All correspondence, email, hard-copy and any attachments, to or from Three Nations Education Group Inc. (TNEGI representing Tobique, Burnt Church and Elsipogtog First Nations) regarding proposed federal legislation and the national consultation process (this should include the Atlantic Engagement Strategy) to reform on-reserve education from 2009 
to present day. Please include correspondence to or from the Atlantic Regional Office.

Notably, my requests reflect the informed nature of my involvement with this issue. Submitted in January of 2015, I received the information I requested August 3, 2015. I sympathized with the officials handling this involved request, having been in the position in the past whereby I had to respond to an external request to information while working for the government. In the end, 867 pages of text were delivered to me, with hundreds of pages removed due to privacy restrictions. I should note here that whereas my original research proposal included a case study of the Indigneous educational alliance Three Nations Education Group Inc., my request was framed in that regard. ${ }^{14}$ However, when I received my information, included within were the consultation documents submitted from stakeholders across the country, revealing multiple, conflicting realities and conversations regarding the nature of consultation. The discovery of this goldmine led me to restructure my research questions and re-align my scope to that of the many voices that participated in the national consultation process.

Initially, I briefly reviewed the documents to gain an understanding of the subject matter. With my theoretical framework and research questions in mind, I then did a thorough review of every document, putting irrelevant documentation aside and categorizing the remaining information into two categories: (1) consultation submissions from stakeholders (letters and reports) and government summaries of consultation activities (in-person sessions, feedback submissions received, and video and audio conferences); and, (2) internal government briefings on consultation activities and public

\footnotetext{
${ }^{14}$ I also obtained two requests to information from the Government of New Brunswick, as well as one other from the federal Department of Aboriginal Affairs and Northern Development Canada. None of these were utilized in this research project.
} 
relations/communications backgrounders. Some documents overlapped both categories. Interestingly, the latter category contained messaging formulated by the government in anticipation of specific media questions. This was particularly useful for my discourse analysis.

After this categorization and in-depth review, I was steadily familiar with the evidence. I prepared for coding the consultation documents first, and found that the strongest themes that emerged were Funding, Consultation, and First Nations Control. The government summaries of the consultation process contained therein also related these common themes, among others such as concerns regarding how reform would affect self-government agreements (from British Columbia and Nova Scotia) and the provision of targeted funding for language and culture programming (which I coded as 'funding'). The government's summaries of the consultation process also included how officials responded to the concerns raised through all consultation activities, which was very useful in my analysis.

Considering this component of the research was intended to highlight the perspectives of Indigenous Peoples regarding the educational reform process, and to evaluate the government's response to said concerns, my analysis was structured by presenting verbatim Indigenous expressions of feedback followed by a summary of the government's rebuttal. With the evidence laid out so plainly, it was not difficult for me to then construct a critical analysis informed by the groundwork context laid out in Chapters 1, 3, and 4 .

In response to the research questions regarding the discursive messaging of the federal government in relation to Indigenous educational reform as national economic 
benefit, I turned to the second category of documentation that contained internal government briefings. I coded for key words related to economy, national interest, Canadian society, First Nations control, labour, and prosperity. I was careful to watch for what was not contained in the messaging, such as references to First Nations well-being, sovereignty, First Nations societies, First Nations identity, and First Nations rights.

My analysis pointed to how the absence of messaging related to Indigenous rights, identity and sovereignty invisiblizes Indigeneity ${ }^{15}$ and works to subjectify Indigenous Peoples to economic imperatives. This section of my findings merely touched upon the way the government uses discursive rhetoric to shape the meaning of Indigenous education and educational reform in the public sphere. My analysis would have been significantly strengthened by including popular and alternative media coverage of the reform process, but it was not possible to widen the scope of my evidence within the time and space constraints of this thesis. That is a whole other research project in itself, and one I look forward to pursuing!

Shawn Wilson, Author of Research Is Ceremony: I do not appreciate being told which paradigms and tools I can or cannot use in my research, so I cannot decide for other researchers whether the paradigms they have chosen will work or will not work for them in their unique situations. (Wilson, 2008, p. 42)

Me: In this final passage from Research Is Ceremony, the author addresses the autonomy afforded by the research process. Although certain ethical principles must be abided by, research fundamentally depends on the ontologies and epistemologies of the researcher, or in other words, the researcher's personal paradigm/worldview. I have chosen to adopt an Indigenous research paradigm informed by my own experiences working with

\footnotetext{
${ }^{15}$ Indigeneity is a term I often use to denote Indigenous difference, that of collective inherent and Treaty rights as original occupants of the territory now known as Canada.
} 
Indigenous Peoples and government in the area of Indigenous education. Utilizing a Foucauldian lens of power and subjectivity has allowed me the freedom to explore the discursive structures present in the consultation interactions, but also to reveal the means through which meaning is constructed and settler-colonial power dynamics maintained within this particular discourse.

The adoption of a decolonial method of communicating knowledge throughout this chapter has proven incredibly rewarding for me. Not only was I able to critically self-reflect on the many concepts related to the design of a research methodology, but I also benefitted from the more unrestrained way of sharing my ideas. I hope the reader will find this approach as compelling as I do.

In the next chapter, I will return to the traditional method of writing as I introduce my theoretical framework and go into additional detail regarding the historical context of Indigenous education in Canada. 


\section{Chapter 3: Theorizing Indigenous-State Relations in Contemporary Canada}

Undertaken much more aggressively in the past through the Indian Residential and Day Schools System, the assimilation of Indigenous Peoples continues in 2015 through the neoliberalization of on-reserve education. Neoliberal educational reform includes the government's use of discursive messages to promote Indigenous education as national economic interest and to assert the government's support of Indigenous control over education. The government's use of rhetoric referring to consultation and partnership with Indigenous Peoples invisiblizes the reproduction of state paternalism and colonial power relations. Linking the education of Indigenous Peoples to neoliberal imperatives instead of to the attainment of Indigenous self-government veils the public to Indigenous difference and state strategies for the assimilation of Indigenous Peoples to market-driven society.

In these ways, the suppression of Indigenous autonomy continues to underpin Indigenous educational reform in Canada. A key feature of neoliberalism, the state distances itself from the social sphere while continuing to govern from afar, as evidenced by the government's partial devolution of the provision of Indigenous education to the provinces and First Nation governments. Although reform Bill C-33 of 2014 was titled First Nations Control of First Nations Education Act, careful examination of the bill and the reform consultation process reveals the government's unwillingness to relinquish total control over Indigenous education. As such, this thesis argues that the government maintains paternalistic control for fear of the implications of allowing Indigenous Peoples to govern their own education systems. 
Even though Indigenous self-determination has been shown to result in improved educational outcomes and community well-being, (Stavenhagen, 2004) which in Canada could potentially decrease the costs to the social welfare system caused by chronically high rates of incarceration, mortality, unemployment and negative health outcomes among Indigenous Peoples (attributed to legacies of settler-colonialism), (Battiste \& McLean, 2005) the government is also concerned with the suppression of Indigenous sovereignty. Indigenous control of education, a mechanism for emancipation, is perceived by the government as a threat to Canada's neoliberal, settler-colonial project. This perception is linked to the subordination of Indigenous Peoples, whereby the government must sustain a relationship of wardship for fear that Indigenous Peoples, if given the educational tools to revitalize the capacity of their communities, will spur revolutionary change in Indigenous-state relations and Canadian federalism.

Considered a strategy of accumulation by dispossession, the expropriation of Indigenous Peoples from their lands and their identities is facilitated by the government through Indigenous education policy. Canada, a settler-colonial nation constituted upon territorial expansion for capitalist growth, is driven to eliminate Indigenous difference in order to gain access to Indigenous territories and labour. The assimilation and commodification of Indigenous Peoples through education is one means of achieving the dissolution of collective Indigeneity while dismantling the threat Indigenous sovereignty poses as an alternative to capitalism.

The remainder of this chapter will provide in-depth explanations of the theories of accumulation by dispossession, neoliberalism, and the logics of settler-colonialism, qualified by examples of how each concept operates in Canada through the neoliberal 
reform of Indigenous education. In the following section, an abstract examination of capitalism will provide a basis for understanding the ways in which accumulation by dispossession reproduces space in times of neoliberal globalization. Then, in Section 3.2, titled Neoliberalism and Free-market Rationalities, the state's role under neoliberalism and the subjective nature of neoliberal ideology will be reviewed. In Section 3.3, The Logics of Settler-colonialism, the logics of elimination/assimilation and commodification/subjectification, will be unpacked to reveal how the intersecting logics inform Indigenous-state relations in the area of on-reserve education in Canada. Finally, this chapter will conclude with a few words of closing and a description of Chapter 4.

\subsection{Accumulation by Dispossession}

In contemporary times of global capitalism, capitalist strategies of accumulation by dispossession have become more and more commonplace. (Harvey, 2004) Coinciding with the transformation of popular political-economic governance and economic thought to that of neoliberal imperatives, deregulation, privatization, and commodification of all Peoples, places, and things are at once the hallmarks of accumulation by dispossession and indicative of a transition to neoliberalism. Indigenous alternatives to the production of social, economic, cultural, and political space, are particularly at risk of being dispossessed for purposes of capitalist accumulation. This is because the commodification of all life under neoliberalism requires the expansion of capitalist social relations to subsume alternative and Indigenous space.

Importantly, not all dispossessed space under capitalism is negative. In many cases, the inhabitants of the space may embrace capitalist expansion as opportunity for progress. Still others may struggle to maintain the traditional organization of their 
societies. Perhaps considered more radical, other movements may exercise autonomy to challenge dominant trends and harness creativity for the construction of alternative relations within the new capitalist space. (Harvey, 2005, pp. 165-169) The agency of those dispossessed is therefore exercised in unique ways dependent upon the demographic, geographic, and historical context of the space. This is particularly relevant when considering the position of Indigenous Peoples in relation to the government of Canada and Indigenous perspectives regarding systemic educational change. Further informed by the logics of settler-colonialism, explored in Section 3.3, this thesis argues that the dispossession of Indigenous Peoples in contemporary Canada is advanced through neoliberal strategies of on-reserve educational reform.

Free market capitalism, when considered in the abstract, is driven by the neverending need to expand and reproduce. For capitalism to arise, capitalist social relations must be created through the transformation of existing social-property relations to freemarket imperatives. In other words, "[t]he origin of capitalism is not rooted in the concentration of wealth. It has to do with the imposition of market imperatives, often by coercive means and always by painful social transformations." (Wood, 2006) This definition is especially pertinent when considering how capitalism reproduces in contemporary times through the expropriation of pre-existing cultures and places.

Critical geographer David Harvey's works The New Imperialism (2003) and his Brief History of Neoliberalism (2005) provide the essential foundation to this thesis' interpretation of accumulation by dispossession under neoliberalism. Consider the instance where a surplus of labour or unspent capital arises, whereby capitalism will seek out and create new spaces for accumulation to avoid idleness and spur productivity. 
Should opportunities for the disbursement of labour and capital surplus be unavailable in a given territory, capitalism will destroy what has previously been created in its own image to reconstruct new capitalist relations in its place. This process is known to political economists as the creative destruction characteristic of capitalism, defined by David Harvey as follows:

... [C]apital necessarily creates a physical landscape in its own image at one point in time only to have to destroy it at some later point in time as it pursues geographical expansions and temporal displacements as solutions to the crises of overaccumulation to which it is regularly prone. (Harvey, 2004, p. 66)

Unfortunately, the displacement of surplus labour and capital through the creative reconstruction of existing capitalist relations grows more difficult as capital becomes increasingly globalized. Regardless, capitalism is instinctively driven to expropriate spaces occupied by alternative social relations to create opportunities for market growth. In other words, capitalism will continue to grow until it subsumes all space, even and especially that already occupied by historical, alternative, and often Indigenous, social relations. Recognizing that global capitalism has experienced a protracted crisis of accumulation since the 1970s, Harvey asserts that capitalism's “[...] inability to accumulate through expanded reproduction on a sustained basis has been paralleled by a rise in attempts to accumulate by dispossession.” (Ibid., p. 64) In its inherent determination to reproduce, while limited by opportunities to enhance accumulation in unoccupied space, capitalism pursues the transformation of space possessed by preexisting alternative social relations. In describing the fundamental nature of dispossession under capitalism, Wood writes:

It is not simply a matter of repeated exercises in the seizure and concentration of wealth but, more fundamentally, of the continuing imposition, maintenance and intensification of market imperatives. To be sure, theft, fraud and violence continue; but what enables capital to exploit economies throughout the globe in 
its own distinctive ways is the subjection of ever more spheres of human life everywhere to market-dependence and the imperatives that go with it. (Wood, 2006, p. 21)

In this text, Wood importantly notes that the expansion of capitalism does not only subsume physical space, but also 'human life everywhere'. In Canada, capitalist expansion is enacted through the extra-economic dispossession of Indigenous Peoples. Historically, aggressive assimilation and dispossession of Indigeneity in Canada was furthered through the Indian Residential and Day Schools policies governed by the Indian Act. (Government of Canada, 1985)

Harvey describes other such strategies of dispossession, historically informed by Marx's original primitive accumulation, whereby feudal peasants were displaced from their land to make way for the imposition of capitalist property relations. (Marx, 1887) Dispossession in contemporary times is often global in nature and manifested through many and varied processes. Harvey proposes these include, but are not limited to: the international financial system; consumer debt; intellectual property rights; the commodification of nature; the suppression of rights to the commons; the privatization of public assets; the conversion of alternative forms of property rights - common, collective, state, etc. - to exclusive private property regimes; the suppression of alternative and indigenous forms of knowledge and socio-economic relations; colonial, neo-colonial and imperial processes of appropriation of assets and natural resources; and, the monetization of exchange and taxation. (Harvey, 2004, p. 74) These tactics shape significantly the global landscape of neoliberal capitalism and provide a backdrop against which to further evaluate the ways in which accumulation by dispossession operates via neo-colonial Indigenous education policy. 
Paulo Freire (1970) advocates the emancipatory potential of education, should it be harnessed to enable the development of a creative, critical mind. But in the settlercolonial context of Canada, there is a long history of education being used for the purposes of assimilating Indigenous Peoples to mainstream society. While education serves as the tool, economic, social and political subordination of Indigenous Peoples has been the final objective. (Godlewska, Schaefli, \& Chaput, 2013) In other words, historically, the assimilation of Indigenous Peoples through education has been a primary means to advance the political-economic goals of the capitalist, settler-colonial project.

Although education was the vehicle, policies of assimilation have broad, longstanding, detrimental impacts on the lives, heritage, and cultures of Indigenous Peoples. The colonial legacies of Indigenous dispossession through education have manifested as intergenerational social challenges that include high rates of suicide, incarceration and mortality; low educational attainment, poverty, substance abuse, and cognitive, cultural, and social dissonance. (Battiste \& McLean, 2005) The dispossession of Indigenous Peoples through education affects Indigenous capacity to assert self-determination and claims to sovereignty. (Stavenhagen, 2004) In these ways, dispossession is understood as a multi-faceted phenomenon that has not only dire geographical impacts, but existential implications for identity as well.

In 2015, the suppression of Indigenous sovereignty for the advancement of the capitalist, settler-colonial project in Canada is maintained through continued paternalism of on-reserve education. The federal government, in an effort to 'govern from afar', partially devolved the responsibility for on-reserve education to Indigenous First Nation governments in the 1970s. This policy directive responded to the increasing demands of 
Indigenous Peoples for "a greater degree of control in these areas, commensurate with Treaty rights and constitutional status". (Abele, 2004, p. 12) However it also allowed the neoliberal state to distance itself from its constitutional responsibilities. Neoliberal imperatives of individualism and a minimalist state can be used to subjectify Indigenous sovereignty to free-market rationalities. (Larner, 2000) In other words, Indigenous claims to self-government may provide the rationale for the state to renege on its constitutional obligations under the guise of enabling Indigenous autonomy. This thesis argues that Indigenous sovereignty is suppressed by the government's sustainment of paternalistic control over education on-reserve.

When the Canadian government reversed its political stance on Indigenous education in the 1970s, it devolved the administration of education from residential and day schools operated by religious institutions (the history of which is more explicitly explored in Chapter 4) to First Nation governments. This systemic disruption to the education of Indigenous Peoples resulted in enhanced autonomy for Indigenous governments. However, the abrupt reversal of responsibility for the administration of education was undertaken without due regard for how to invoke Indigenous jurisdiction while still providing essential services. (Mendelson, 2008) Abele highlights the implications of this transition, which became more common in the 1990s across a number of social policy areas: "[o]ne convergence of these two forces has been the creation of relatively lean financial provisions for many of the new "devolved" programs, a pronounced lack of stability in funding regimes, and a focus on measures and standards of accountability". (Abele, 2004, p. 12) 
In regard to the changes to on-reserve education in the 1970s, the government immediately began to pull back from its constitutional obligations for the provision of Indigenous education without a legislative base upon which to regulate the allocation and disbursement of funding, jurisdictional roles and responsibilities, and the development of administrative capacity on reserve. As this thesis will show, this abrupt shift in policy set the stage for the state's continued neoliberalization of education, leading up to present day efforts for reform.

Decades later, the negative results are apparent, with the educational attainment rates of Indigenous students in a dire state. The Auditor General of Canada, through several detailed audits of the Department of Aboriginal Affairs and Northern Development Canada (AANDC) since 2001, has found that the difference in educational attainment levels between Indigenous Peoples and the general population is 28 years and growing. This is interpreted as meaning that the educational outcomes of Indigenous Peoples are 28 years behind those of the general population and that to address this chasm, significant reform and intervention to improve the rates of education among Indigenous Peoples is required. (Office of the Auditor General of Canada, 2011) The Auditor General of Canada asserts that structural impediments, including the lack of local service delivery mechanisms; the lack of defined roles and responsibilities among Indigenous, federal and provincial jurisdictions; the lack of an adequate funding model; and, the lack of a legislative base are the root causes of the under-education of on-reserve Indigenous Peoples in Canada. (Ibid.)

The suppression of Indigenous sovereignty through state paternalism in education continues to plague Indigenous Peoples in Canada. However, dispossession is enacted in 
many varied ways through the neoliberal restructuring of on-reserve education. The next section will examine how the dispossession of Indigenous Peoples is manifested under neoliberalism.

\subsection{Neoliberalism and Free-market Rationalities}

Harvey's assertion of the rise in accumulation by dispossession coincides with the proliferation of the most advanced state of capitalism, termed neoliberalism. Emerging from the closets of minority economic thought, neoliberalism arose to replace Keynesian welfarism as the central guiding principle of economic thought in the late 1970s through infamous political actors and institutions that include Margaret Thatcher, Ronald Reagan, and the World Bank. Whereas Keynesianism is associated with the state provision of goods and services to enhance social well-being, neoliberalism is concerned primarily with competition, economic efficiency, and freedom of choice. (Larner, 2000, p. 5) In $A$ Brief History of Neoliberalism, David Harvey declares the revolutionary importance of this turning point in the global political-economic configuration:

Neoliberalism is in the first instance a theory of political economic practices that proposes that human well-being can best be advanced by liberating individual entrepreneurial freedoms and skills within an institutional framework characterized by strong private property rights, free markets, and free trade. The role of the state is to create and preserve an institutional framework appropriate to such practices. (Harvey, 2005)

An attempt to develop a more in-depth definition of neoliberalism highlights its complexities. As Wendy Larner notes, neoliberalism is a form of political-economic governance with various manifestations. Some scholars might recognize it as a certain policy framework, others as an ideology, and still others as a form of governmentality. (Larner, 2000) However, there are obvious tenets of neoliberalism: a preference for a minimalist state that governs from afar; deregulation of the public sphere to facilitate 
unfettered expansion of capital markets; individualized citizen subjectivities; and privatization and enclosure of previously public assets and spaces. Certain similarities to strategies of accumulation by dispossession are immediately apparent, however, given the common use of such strategies to enable a neoliberal restructuring of socio-economic relations, the relatedness of these processes should be understood as part and parcel of the same phenomenon.

The transition to neoliberalism has also featured prominently capitalism's inherent tendency for creative destruction. Previously developed state institutions, social welfare provisions, and collective social movements have been targeted for deconstruction and remade in the image of free-market economics through processes of privatization, deregulation, and commodification. Larner terms this 'welfare state restructuring' (Ibid., p. 5) while Harvey acknowledges this as the creative destruction inherent to capitalism, noting that "divisions of labour, social relations, welfare provisions, technological fixes, ways of life and thought, reproductive activities, attachments to the land and habits of the heart" have all been significantly and adversely impacted with the imposition of neoliberalism. (Harvey, 2005, p. 3)

Indigenous education has always been semi-protected from the extension of capitalist social relations because of the state's interest in paternal control and its obligation to provide educational services under the Constitution. However, in neoliberal times, with the distancing of the state from social welfare provision and the capture of the state to free-market imperatives, opportunities for the expansion of capitalism through Indigenous education are becoming apparent. Understanding creative destruction as the cyclical condition of capital to reinvent itself for purposes of expanded reproduction, and 
accumulation by dispossession as a means of opening up pre-existing spaces regardless of the social and environmental consequences, the advancement of neoliberalism has powerful implications. By the same token, instances of accumulation by dispossession are intensified under neoliberalism. (Harvey, 2005, p. 159)

Importantly, I interpret aspects of the restructuring of on-reserve education as a process of creative destruction that exacerbates the dispossession of Indigenous Peoples for capitalist accumulation. Previously inaccessible due to the protected nature of federal reserves, the neoliberalization of education is creating opportunities for capitalism to seep into the jurisdictional fissures surrounding on-reserve education policy. For instance, the federal government leverages public-private partnerships to construct schools on-reserve and to fund post-secondary scholarships for Indigenous students. (Wilkinson \& Leclair, 2013) As well, the Federal Framework for Aboriginal Economic Development commits to link investments in Indigenous education to labour market demands. (Government of Canada, 2009)

Aside from its utilization of accumulation by dispossession as a means for capitalist expansion, there are two other elements of neoliberalism pertinent to the argument of this thesis. First, this research will explore the role of the state in the accumulation of capital and the proliferation of neoliberalism. Second, this research will discuss the ability of neoliberalism to shape citizen subjectivities to build neoliberal rationalities conducive to participation in the free market.

\subsubsection{The Neoliberal State}

Wood asserts that in the case of pre-capitalist ambitions for empire, the colonization of Peoples and places was dependent upon political logics that asserted 
military, legal, and political power to dominate and exploit for purposes of capitalist expansion. However, in contemporary neoliberal times, the state maintains a complementary but distinct role in relation to capital. "In capitalism, property exists independently of political power, and the principal role of the 'political' is essentially external to the process of appropriation." (Wood, 2006, p. 16) In this, she argues that contemporary capitalism consists of both an autonomous economic sphere responsible for appropriation of surplus labour and capital, and a separate political sphere whose role it is to coercively create and enforce the political-economic conditions conducive to capital accumulation. In her analysis of the various manifestations of neoliberalism in the scholarly literature, Larner relates a similar perspective on the function of the state.

... [W] hile neo-liberalism may mean less government, it does not follow that there is less governance. While on one hand neo-liberalism problematizes the state and is concerned to specify its limits through the invocation of individual choice, on the other hand it involves forms of governance that encourage both institutions and individuals to conform to the norms of the market. (Larner, 2000, p. 12)

Harvey too, describes the state's role as securing the national monetary system, enforcing security structures related to military, defence, police, and jurisprudence, and enforcing, through force if necessary, the integrity of private property rights, free markets, and free trade. The state is also responsible for ensuring the institutional scaffolding to enable free-market infrastructure, including facilitating the opening-up of new markets, by state action if necessary. (Harvey, 2005, p. 2) This goes hand in hand with the neoliberal imperative of the privatization of public assets, deregulation of the public and private economic spheres, and commodification of people, places, and things through the imposition of private property rights. 
Neoliberalism as a form of political-economic governance is adopted and sustained through the capture of key institutions and political actors. (Larner, 2000) Characterized by a minimalist state that governs from afar, its key responsibility being the protection of private property rights for the unfettered operation of economic markets, neoliberal ideology promotes the abandonment of the legitimation function of the state to focus on the facilitation of accumulation. To this end, all Peoples, places, and things must be commodified for their entry and acquiescence to the free-market. The commodification of all life enables the complete withdrawal of the state from the protection of environmental and social well-being, leaving the market to govern social relations of wealth distribution and welfare provision. Once liberated of its legitimation function, the state intervenes only to facilitate a climate conducive to capitalist growth. The neoliberal state relegates decisions concerning the distribution of wealth and services for the well-being of the people to the market in the belief that the state could not possibly know better than the economic rules of supply and demand. (Harvey, 2005)

Significantly, federal devolution of Indigenous education to provincial governments reflects the neoliberal tenet to distance the state from social welfare provisions. At the same time, education of Indigenous Peoples in public schools often results in diminished cultural identity and self-esteem, evidenced by the high dropout rates and low graduation rates of Indigenous students in public schools. (Battiste \& McLean, 2005) Informed by the settler-colonial logic of elimination/assimilation, I theorize that the devolution of Indigenous education to the provinces is part of a strategy to dispossess Indigenous Peoples of their Indigeneity. 
For example, the federal government funds on-reserve students attending provincial schools at a rate of tuition at least twenty-five percent or more higher than the per-capita funding awarded to students attending First Nation-operated schools. (Walton, et al., 2009) Yet, to be eligible for funding to administer a school on-reserve, First Nation governments must provide an educational experience comparable to the provincial system. (Mendelson, 2008) This disparity in funding represents clear evidence of a problematic impossibility. Indigenous schools, under the current model, are being set up for failure. On the other hand, off-reserve provincial schools receive an annual tuition for every enrolled student with an on-reserve address. There is absolutely no federal policy stipulating what provincial tuition must be used for. Some jurisdictions, such as New Brunswick, have negotiated partnership agreements with the Indigenous communities within their borders regarding the partial reinvestment of provincial tuition funding for the enhancement of programs and services for Indigenous students. (New Brunswick Aboriginal Affairs Secretariat, 2014) But without any restrictions on the use of funds, federal tuition for Indigenous students in public schools may go to provincial coffers instead of toward initiatives that enhance the school experience for Indigenous students.

The federal government also invests in provincial partnerships. The administration of the Education Partnerships Program (EPP) encourages the development of collaborative mechanisms for the enhancement of Indigenous education supports in the public system. (Wilkinson \& Leclair, 2013) Although this can be a means of assisting Indigenous groups in the development of capacity for educational administration, a critical analysis reveals the Eurocentric nature of the goals of the program. The EPP undermines Indigenous autonomy by integrating Indigenous groups to dominant modes 
of thought related to the provision of education. With project approval of EPP proposals based on 'merit' as opposed to need, those facing the direst challenges are not necessarily the ones that receive funding. (Wilkinson \& Leclair, 2013) Additionally, I can attest from personal experience that Indigenous groups that cooperate - without raising concerns about the state of Indigenous education - are rewarded, while those that speak to their community's desire for systemic change to the on-reserve education system are punished for their dissent through the non-funding of eligible initiatives. This 'divide and conquer' structuring of program eligibility encourages competition among Indigenous groups instead of cooperation in a strategy that undermines Indigenous solidarity.

As demonstrated, the Canadian state plays a significant role in shaping the outcomes of Indigenous education policy. Indeed, this thesis argues that the government has the long-term goal of devolving responsibility for Indigenous education to the provinces for purposes of Indigenous assimilation via provincially-governed education. The most advanced form of provincial devolution in this area was proposed in Bill C-33. (Government of Canada, 2014) Under the First Nations Control of First Nations Education Act, Indigenous communities could choose to delegate the operation of their school to provincial authority. Clearly, an arrangement of that nature would result in a complete loss of autonomy for community members. Should the community choose to continue to operate the school themselves, under Bill C-33 they would not be eligible to receive funding to assist with administration or enhancements such as the creation of local, culturally-relevant curriculum.

The remaining option would see the creation of Indigenous school boards, usually made up of alliances of multiple communities. However, even that decision is dependent 
upon government approval. From personal experience, the government decides which Indigenous organizations are 'ready' to administer their own education, and which are not. Paradoxically, Indigenous organizations that lack the funding to develop the internal capacity required to administer quality education on-reserve are denied access to the very funding they need because they are deemed 'not ready' by the state. Caught in a cycle of paternal dependency, Indigenous educational alliances seek the autonomy to take control of their own destinies, while encountering a never-ending battle against systemic dysfunction. Given the previous examples, this thesis asserts the role of the state in reinforcing colonial power relations, suppressing Indigenous alternatives to capitalist social relations, and as will be discussed next, commodifying Indigenous Peoples through market-inspired education policies and discourse.

\subsubsection{Discursive Subjectification}

Importantly, the state performs another crucial function under neoliberalism critical to this research. Through what Larner terms a 'discourse of restructuring', the state reshapes citizen rationalities to better reflect neoliberal imperatives. (Larner, 2000, p. 12) In other words, when studied as an ideology, neoliberalism exerts strong discursive elements that prove particularly seductive to the general public, framing the free-market as the means to individual prosperity, wealth, and freedom. Following from civil rights movements, neoliberalism thrives upon the individual's desire to be free from state control, to have freedom of choice and opportunity, and to allow competition to decide the survival of the fittest. This mantra displays the values inherent to neoliberalism: private property, free markets, competition, minimal state, and individualism. 
This is symptomatic of Polanyi's theory of the double movement inherent to capitalism, whereby labour and capital are forever engaged in a struggle for the favor of the state's functions of legitimation and accumulation. (Polanyi, 2001) In this eternal struggle, labour is veiled from the social inequities inherent to capitalism by promises of individual accumulation, consumerism, debt, and celebrity culture. (Lukacs, 1923) Labourers must continually work to lift the veil through critical education that raises social consciousness and builds solidarity. Similarly, confronted by coercive strategies of accumulation by dispossession under neoliberalism, workers entranced by capitalist discourse must struggle to resist the rationalization of their identities by neoliberal rhetoric promising individual prosperity.

However, contrary to this ideological rationale, Harvey's analysis of neoliberalism shows that it has failed to result in an increase in the overall accumulation of wealth. Instead, it has resulted only in the redistribution of wealth from the lower classes, to élite political and economic actors. (Harvey, 2005, p. 159) A heightened inequality in the distribution of wealth globally and the erosion of social services and supports in neoliberal states has proved this mantra of trickle down wealth and prosperity faulty. Unfortunately, neoliberal ideology leaves no room for consideration of the social or environmental consequences of such an unfettered arrangement. To that end, without government intervention to regulate the allocation of water or public services such as healthcare, neoliberalism results in the marginalization of the lower classes in society. Indeed,

... [t] he reversion of common property rights won through years of hard class struggle (the right to a state pension, to welfare, to national health care) into the private domain has been one of the most egregious of all policies of 
dispossession, often procured against the broad political will of the population. (Ibid., p. 161)

Nonetheless, neoliberalism is not concerned with social or environmental well-being. Its values rest on profit, economic efficiency and competition. (Larner, 2000) Instead, neoliberalism requires the subjectification of citizens for the universal reproduction of capitalist relations. In other words, under neoliberalism, capitalism is driven to subsume, and therefore commodify, all Peoples, places and things so that they might be relegated to control by the invisible hand of the market. As Harvey describes,

... [t]o presume that markets and market signals can best determine all allocative decisions is to presume that everything can in principle be treated as a commodity. Commodification presumes the existence of property rights over processes, things, and social relations, that a price can be put on them, and that they can be traded subject to legal contract. (Harvey, 2005, p. 165)

A crucial component of the neoliberal discourse of restructuring is the reification of existing social relations for the wholesale participation of society in the neoliberal project. Any and all alternative forms of social relations are to be subsumed or destroyed, such as the transformation of Indigenous territories from collective ownership to private property, or the commodification of Indigenous Peoples through market-based state policies and education linked to labour market demands. The state, delegated the responsibility of securing conditions for market growth, is often the leading manufacturer of a discourse of restructuring, as this thesis will explore in relation to the subjectification of Indigenous Peoples to market-associated rationalities.

In Canada, public opinion regarding the reform of on-reserve Indigenous education policy is shaped by economic rhetoric linking Indigenous educational outcomes to the national interest. As will be presented in detail in Chapter 6, the government's use of a neoliberal discourse of restructuring related to Indigenous Peoples 
frames Indigenous education as central to the economic benefit of all Canadians. Indeed a recent report posted on AANDC's website titled The True Cost of First Nations Government (Fiscal Realities, 2010), asserts that if Indigenous Peoples were to participate as productive members of Canadian society, Canadian productivity would rise $7 \%$ overnight and Canada would surpass Japan and Germany in terms of real per capita GDP. Statements such as this exemplify neoliberal rhetoric that invisiblizes the historical, colonial assault on Indigenous Peoples as well as the many contributions Indigenous Peoples already make to the economic well-being of their communities and Canadian society. Furthermore, with Indigenous social outcomes tied solely to economic participation, the importance of community and cultural development to educational outcomes and vice-versa is ignored. (Battiste \& McLean, 2005)

Often in public discourse, Indigenous Peoples are framed as unemployed, uneducated, dependents that are 'costing taxpayers' money'. However 'Aboriginal Canadians' are framed as the future of Indigenous Peoples, as productive members of Canadian society, and as individuals that have moved out of the 'cultural past' and into the prosperous future. This discursive construct has been explored by Cliff Atleo through the lens of Indigenous economic development in the context of the Royal Commission on Aboriginal Peoples. (Atleo C. J., 2009) This binary of the Indigenous person of the past and the Aboriginal Canadians of the future is part of the neoliberal subjectification of Indigenous rationalities to free-market imperatives. In addition to this discursive framing, the recent Indigenous educational reform process is characterized through government rhetoric as enabling Indigenous autonomy over education. The maintenance 
of state paternalism and the suppression of Indigenous sovereignty remain veiled from the audience.

These theoretical assertions will be analysed in depth through an exercise of Foucauldian discourse analysis in Chapter 6.

\subsection{Logics of Settler-Colonialism}

Any analysis of Indigenous-state relations in Canada must include an explanation of the unique settler-colonialism context. Foremost a land-based project, settler-colonialism was not only driven by the need of European states to extract commodities from foreign lands to feed European industrial expansion. It was unique in that the settlers arrived, and stayed, erecting new societies in their own image upon the most recently 'discovered' lands. Driven by international market forces and capitalism's drive to reproduce and subsume, "settler colonialism was foundational to modernity". (Wolfe, 2006, p. 394) A strong link exists between the goals of the settler-colonial project and the expansion of global capitalism.

The Industrial Revolution, misleadingly figuring in popular consciousness as an autochthonous metropolitan phenomenon, required colonial land and labour to produce its raw materials just as centrally as it required metropolitan factories and an industrial proletariat to process them, whereupon the colonies were again required as a market. The expropriated Aboriginal, enslaved African American, or indentured Asian is as thoroughly modern as the factory worker, bureaucrat, or flâneaur of the metropolitan centre. (Wolfe, 2006, p. 394)

The expropriated Aboriginal referred to above is central to this discussion. European settlers encountered pre-existing inhabitants in their colonial ambitions, whom they interpreted as obstructing their access to land. As such, certain 'laws' were constructed to structure the new relationships, laws that would eventually be seen as the first step in 
facilitating a development continuum that favored the goals of settler-colonialism. (Wolfe, 2006, p. 392)

Indeed, from first contact, settlers were not concerned with respecting Indigenous occupancy. Rather, the right of discovery law terra nullius, which was enacted to grant dominion to a European discoverer, awarded only occupancy rights to the Indigenous inhabitants of a discovered territory. Under terra nullius, a policy of premption restricted Indigenous Peoples from surrendering their lands to anyone other than the primary European sovereign. This evidence indicates that terra nullius was never intended to enable equitable relations between Indigenous and European would-be settlers, but instead to create relationships that would benefit the European sovereign. Indeed, the Royal Commission on Aboriginal Peoples refers to the Treaties and agreements such as terra nullius as devices of statecraft, not covenants of trust and obligation. (Government of Canada, 1996)

In order to further qualify the colonial project, settlers typically employed the organizing grammar of race. A social construct, White supremacist ideology asserted that white Anglo-Saxons were superior beings in relations to Indigenous and colored peoples. (Smith, 2010) This hierarchy of racial superiority proved fundamental to the implementation of the settler-colonial project, as it asserted the dominance of White peoples in society, politics, and economics with the belief that peoples of color and Indigenous Peoples are inferior and need to be ruled. Constructed by Europeans explorers for their own use and benefit, racist ideology was applied variably depending on the historical and political context to exert power over pre-existing Indigenous inhabitants or peoples of color. Indeed, "different racial regimes encode[d] and 
reproduce[d] the unequal relationships into which Europeans coerced the populations concerned." (Wolfe, 2006, p. 287)

These two constructs mutually informed the initial contact and corresponding encounters between Indigenous Peoples and European settlers. However, as Patrick Wolfe argues, settler-colonialism is not an event - it is a hegemonic structure. As such, it emanates throughout history to inform the goals of the state, the development and maintenance of institutions, and even the social dimensions of the newly constructed society. As Wolfe concludes:

In sum then, settler colonialism is an inclusive, land-centred project that coordinates a comprehensive range of agencies, from the metropolitan centre to the frontier encampment, with a view to eliminating Indigenous societies. (Ibid., p. 393)

With that in mind, consider this: Andrea Smith argues that the racial construct of White Supremacy is operating through three distinct, but interrelated logics in the United States. Importantly, these logics underpin the development of society and the actions of the state. They are slaveability/anti-Black racism, which anchors capitalism; genocide/elimination, which anchors colonialism; and orientalism/anti-Semitism, which anchors violent, territorial conquest. (Smith, 2010, p. 1) The logic of slavery renders Black people as property, commodified for the purposes of American capitalist expansion. The logic of genocide maintains that Indigenous Peoples should disappear or always be in the process of disappearing. This logic is anchored in colonialism: it asserts the settler perspective that non-Indigenous peoples are the rightful owners of the land. The third logic of orientalism, "marks certain peoples or nations as inferior and deems them to be a constant threat to the wellbeing of empire". (Ibid.) This logic is anchored in war, as it justifies the military imperialism of the United States through the 'othering' of foreign nations. 
Smith suggests that the logics of White supremacy operating in a certain context are historically and geographically determined. She encourages the application of her theory to other, complex circumstances. As such, I theorize that there are two mutuallyreinforcing logics of settler-colonialism operating in Canada in relation to Indigenous Peoples. These will be elaborated upon in the following paragraphs.

Recall that "the primary motive for elimination is not race (or religion, ethnicity, grade of civilization, etc.) but access to territory. Territoriality is settler colonialism's specific, irreducible element." (Wolfe, 2006, p. 288) Racial hierarchies were created as a tool to impose power over Indigenous inhabitants of land targeted for colonial settlement. In advancing the capitalist project, settler-colonialism is concerned foremost with the extinguishment of Indigenous title to land and the suppression of Indigenous sovereignty, so that all spaces (and the natural resources contained within) in a given territory might be expropriated and remade in the capitalist image. As has been explored in the preceding sections, this is reducible to capitalism's drive to subsume alternative social relations and to commodify all peoples, places, and things, through strategies of accumulation by dispossession.

To that end, settler-colonialism is informed by two distinct, yet intrinsically linked logics: the first, the logic of elimination/assimilation, is grounded in colonialism. The second, the logic of commodification/subjectification, is grounded in capitalism. The two logics underpin the structural integrity of the systems, institutions, and practices governing Indigenous-state relations in Canada, an important component of which is education. The logic of elimination/assimilation seeks to integrate Indigenous Peoples into Canadian society via the capitalist marketplace, invisiblizing their difference, as well 
as their collective inherent and treaty rights. The logic of commodification/subjectification seeks to commodify Indigenous Peoples and their lands through the transformation of their territories to private property and the subjectification of their Indigeneity to free market principles. Each logic feeds the mutual goals of settler-colonialism and capitalism, to subsume all land and alternative social relations for the advancement of accumulation.

\subsubsection{Elimination/Assimilation}

In the logic of elimination/assimilation, Indigenous Peoples are viewed by the settler state in particular and society in general as primitive and therefore racially inadequate to be sovereign. (Williams in Smith 2010, 6) In this logic, assimilation of Indigenous Peoples to White society is required for the erasure of their difference in order for colonialism to subsume the last of their land. Although the end goal is territory, in Canada the assimilation of Indigenous Peoples is also part of a strategy to free the state from its constitutional and treaty responsibilities, in the hopes of mitigating the risk Indigenous sovereignty poses to the settler-colonial project.

Under the Constitution, the Canadian government has the responsibility for protecting the Aboriginal and Treaty rights of Indigenous Peoples. Similar to the rights of occupancy Indigenous Peoples maintained to their lands under terra nullius, these Aboriginal rights include hunting, fishing, harvesting, logging and other traditional activities connected to the land, as well as the enforcement of the Treaties. (Act, 1982) However, strategies of accumulation by dispossession in contemporary Canada work toward disconnecting Indigenous Peoples from their Indigeneity, which fundamentally drives Indigenous struggles for sovereignty. Assimilation of Indigenous Peoples to 
mainstream society would eventually result in the erasure of Indigenous difference and therefore free the government of its obligations in regard to the protection of their rights. This is particularly relevant considering the nature of neoliberal capitalism and its preference for a minimalist state. In the absence of these protective measures, Indigenous lands and Peoples would be subsumed by the settler-colonial project. In the process, the threat tribal collectivism and Indigenous sovereignty pose to capitalism's imperatives of competition, private property, and individualism, is dissolved.

In regard to Indigenous education in Canada, the logic of elimination/assimilation is enacted through the absence of federal funding opportunities to support the development of language and culture initiatives. However, the federal government maintains that funding for language and culture is accessible through existing channels of on-reserve education funding. (Wilkinson \& Leclair, 2013) But, considering the chronic underfunding of Indigenous education, it is not often possible for Indigenous schools to realign priorities to pay the heavy costs of local curriculum development. As a result, provincial curriculum is used and reflects Eurocentric representations of history, values, and cultural identities, the problematic nature of which is elaborated upon in the following paragraphs.

The logic of assimilation/elimination is also furthered through continued federal paternalism, including the government's apparent promotion of Indigenous students to enrol in provincial schools. The suppression of Indigenous sovereignty is central to this logic as it is perceived to lead eventually to the dissolution of Indigenous societies to the benefit of capitalist expansion. While on-reserve schools struggle to operate within conditions of sustained underfunding and systemic dysfunction, the government 
simultaneously funds Indigenous students attending provincial schools at approximately twenty-five percent more (or higher), historically, (Walton, et al., 2009) thereby promoting the attrition of on-reserve students to better funded, off-reserve schools. The on-reserve school system also lacks a legislative base, but federal funding is distributed based upon conditions of comparability, meaning that on-reserve schools must attempt to replicate provincial systems. (Mendelson, 2008) The easiest way on-reserve schools accomplish this is through the use of provincial curriculum, which is problematic.

The provincial curricula used in provincial and on-reserve schools are often criticized for a lack of cultural relevancy and for the proliferation of Eurocentric stereotypes regarding Indigenous Peoples. (Battiste \& McLean, 2005) An example I have personally encountered is the way in which Canadian history is told in many social studies textbooks, often beginning at first contact, invisiblizing the prior occupancy of Indigenous Peoples and constructing European settlers as the saviours to 'unenlightened' Indigenous societies. Another example includes the use of discriminatory language such as 'savage' to describe Indigenous Peoples in language arts texts. ${ }^{16}$ Addressing the cultural relevancy of provincial curricula involves the integration of Indigenous ways of knowing and engaging with the world into curricular outcomes and instructional resources. Many efforts are being made by professional educators in this area. ${ }^{17}$ For

\footnotetext{
${ }^{16}$ Policy makers at the New Brunswick Department of Education and Early Childhood Development recently addressed this issue with the implementation an instructional policy of critical literacy to address the issue of discriminatory language in approved high school texts. Instead of removing the text, which may have historical significance, educators are encouraged to engage their students in a critical discussion of the historical and geographical context within which the language was used, while teaching students how to decipher when language is power-laden and hurtful, and what word usage is appropriate instead. ${ }^{17}$ Officials at provincial education ministries are working toward curriculum development processes that ensure cultural inclusion as a focal point for the revision of outdated curriculum. For instance, social studies consultants from the Atlantic Provinces worked together in 2013 to integrate Indigenous
} 
instance, the lack of cultural relevancy of traditional mathematics curriculum is improved for example, through the integration of Indigenous knowledge related to geometric planning for the construction of sweat lodges.

However, modifying curriculum and pedagogical resources is pricey, and there are many interests at play, including corporate and political interests. ${ }^{18}$ Often, Indigenous concerns for cultural relevancy are overshadowed by other priorities. ${ }^{19}$ Furthermore, although improved cultural representation in provincial curriculum and resources is beneficial (and possibly emancipatory) to all students and staff, Indigenous and nonIndigenous, it could also be interpreted as assimilative, in that it makes the provincial school system more attractive to Indigenous parents and students. However, one could also make the argument that making traditionally Eurocentric resources more inclusionary strengthens on-reserve schools, considering that the majority of community schools still utilize provincial curricula. Either way, the logic of elimination/assimilation informs each of these policy outcomes, most of which have been the subject of countless reports on the state of Indigenous education since the Residential and Day Schools era.

\footnotetext{
perspectives into new social studies resources (textbooks) under the Foundation for the Atlantic Canada Social Studies Curriculum. (Council of Atlantic Ministers of Education and Training, 1998)

18 In recent years, corporate educational resource companies have begun to heed the absence of culturally relevant instructional resources. Whereas in the past, this was not a profitable market within which to invest, with austerity measures constraining the purchasing budgets at educational institutions, companies such as Nelson are investing in the niche 'Indigenous resource' market as a means of expanding opportunities for accumulation. (Nelson Education, 2013) The creation of these new products is also a result of increasing attention to the importance of cultural relevancy on behalf of educators and provincial ministries.

${ }^{19}$ I have personally experienced provincial budget cuts that target the revision of curriculum and the creation of resources for purposes of improving cultural relevancy while privileging other traditional subject areas (not unimportant) such as literacy, numeracy and science.
} 


\subsubsection{Commodification/Subjectification}

In the settler-colonial logic of commodification/subjectification, Indigenous Peoples are seen as unenlightened and ignorant of how to best organize their societies, governance, and economies. Through commodification of Indigenous land and labour for entry into the capitalist market, colonial social relations are mystified and Indigenous difference, that of inherent and treaty rights to land and therefore sovereignty, is invisiblized. The subjectification logic sees the subjectification of Indigenous Peoples to capitalist rationalities for purposes of commodification. The end goal of this logic is the entry of Indigenous Peoples to the capitalist marketplace. The assumption is that once Indigenous identities are rationalized, their Indigenous difference will eventually be dissolved through their participation in free-market society, as they are ever more reified by market imperatives of individualism, competition and choice. Similar to the abandonment of welfare state provisions under neoliberal society, it is presumed Indigenous Peoples, once immersed in market society, will be more likely to relinquish their collective title to land for engagement with the private property regimes governing the majority of Canadian society. ${ }^{20}$ In this way, the logic of commodification/subjectification aims to provide access to Indigenous labour and land through the entry of both to the capitalist marketplace. Through this process, the goals of elimination/assimilation are also achieved. The mutually reinforcing nature of these two logics strengthens the connectedness of the goals of settlercolonialism and neoliberal capitalism.

\footnotetext{
${ }^{20}$ The problematic aspect of this is not the participation of Indigenous peoples in the market economy, but rather the government's use of market assimilation as a strategy to dissolve Indigeneity.
} 
The logic of commodification/subjectification is enacted in similar ways that tend to reinforce the logic of elimination/assimilation. As previously proposed, a discourse of restructuring surrounds Indigenous education in Canada. Federal rhetoric aligns Indigenous education with the national interest, invisiblizing colonial legacies and the benefit Indigenous control over education would have on community well-being and cultural revival. (Stavenhagen, 2004) In Canada's Federal Framework for Aboriginal Economic Development, a comprehensive restructuring across government is promised to prioritize the creation of improved opportunities for the entry of Indigenous Peoples to market-society. Likewise, in the same plan, the government commits to linking Indigenous educational investments to labour market demands. (Government of Canada, 2009) The subjectification of Indigenous Peoples to neoliberal rationalities is key to the goals of the settler-colonial state. Indigenous Peoples as commodified subjects are assimilated to market-society, rationalized as profit-seeking individuals, and separated from their collective Indigeneity. Indigeneity is veiled and the legacies of colonialism not only left unaddressed, but also re-enacted in the contemporary. Eventually, Indigenous lands are commodified as private property in accordance with the neoliberal marketplace. Capitalist relations subsume Indigenous Peoples and lands (and their myriad interrelations) through these strategies of accumulation by dispossession.

\subsection{Conclusion}

Taking into account the ways in which Indigenous education in Canada is harnessed by the neoliberal state to dispossess Indigenous Peoples of their Indigeneity, the remaining chapters of this thesis will focus on how recent federal educational reform activities were

carried out. With specific attention paid to how the government responds to dissenting 
Indigenous and public expressions, this thesis will analyse how colonial power dynamics are reproduced through federal consultation processes regarding on-reserve education. Additionally, the discourse of restructuring featuring discursive messages linking Indigenous education to economic benefits, will be unpackaged to evaluate how the government subjectifies Indigenous identities for the construction of neoliberal rationalities. Both veins will be explored through the lens of the dispossession and assimilation of Indigenous Peoples for capitalist expansion.

The chapter that follows will describe the current international rights and policy frameworks related to Indigenous education in Canada as a precursor to a detailed illustration of the federal government's recent attempts to introduce federal legislation for on-reserve education. 


\section{Chapter 4: Historical Development of Indigenous Education Policy in Canada}

To contextualize my argument and set a foundation for this thesis, the following chapter will introduce the historical development of First Nations education policy in Canada. Details regarding the supranational legal infrastructure that promotes and aims to protect the rights of Indigenous Peoples to a quality education through self-government will be integrated within.

This thesis focuses on the state of Indigenous education in the post-White Paper era and will not go into great detail of the events prior to the government's 1970s adoption of a policy of partial Indigenous control over education. However, in order to fully contextualize the topic of Indigenous educational reform, this chapter starts with a brief history of Indigenous education in Canada beginning with the first residential school. Section 4.1, titled Indigenous Education as a Tool of Assimilation, details the historical use of education for the assimilation of Indigenous Peoples, as well as the corresponding policies of enforcement. Section 4.2, titled Treaties, Indigenous Education, and the Canadian Constitution, relates Canada's Constitutional and Treaty obligations for the provision of Indigenous education. Section 4.3, titled Indigenous Education in Supranational Rights Frameworks, explores the supranational legal infrastructure promoting human and Indigenous rights to education. Section 4.4, titled Provincial Devolution of Indigenous Education, illustrates the federal strategy to devolve the education of Indigenous Peoples to the provinces. Section 4.5, titled The Struggle for First Nations Control of First Nations Education, illustrates the Indigenous movement for autonomy in education. Finally, Section 4.6, titled The Current State of On-Reserve 
Indigenous Education, outlines the structural impediments to Indigenous educational success in the current on-reserve system. The wealth of information provided throughout this chapter will critically inform my analysis of the recent consultation process related to on-reserve Indigenous education presented in Chapter 5.

\subsection{Indigenous Education as a Tool of Assimilation}

The history of government paternalism over Indigenous education in Canada begins about a century after first contact. Prior to the arrival of Europeans on the continent, Indigenous Peoples had their own flourishing societies built upon a life-long learning continuum. Indigenous societies viewed education as a holistic experience, involving spiritual, emotional, intellectual and physical dimensions of human development. (Battiste \& McLean, 2005) But in the early 1600s, Canada began to use education as a means of oppressing Indigenous Peoples. The participation of Indigenous Peoples in federal education systems was not voluntary in most instances, but instead enforced through the Crown's creation and enforcement of oppressive laws and regulations. From the very beginning, government-sponsored formal education for Indigenous Peoples was unapologetically assimilationist. (Government of Canada, 1996)

Arguably the most infamous and destructive policy of assimilation in Canada is the Indian Residential and Day Schools System. Although some accounts peg the system's establishment to the enactment of the Indian Act in 1876, the first residential school for the education of Indigenous children was actually opened in Quebec in 1620 by The Recollets, a religious order from France. (Legacy of Hope Foundation, 2013, p. 2) Residential schools were operated by religious sects on behalf of the government, 
simultaneously serving the goals of assimilating children to Christian and Canadian mainstream society. At the schools, Indigenous students were punished, often times violently, for speaking their language, practicing their spiritual culture, or wearing traditional hairstyles or clothing. Siblings were forbidden from speaking to one another and "the warmth of the intergenerational Aboriginal family was replaced with sterile institutional child rearing". (Government of Canada, 1996) Many students suffered physical and sexual abuse at the hands of their caretakers, while hard labour and hunger were prominent features of the schooling experience.

As a result, Indigenous societies in Canada are affected by Residential School Syndrome (RSS) due to a combination of historial trauma and posttraumatic stress. RSS affects residential school survivors, their families, friends, and communities and is symptomatic of acute self-conflict, reduced self-esteem, emotional numbing, chronic depression and anxiety, paranoia, heightened irritability, suicidality, and tendencies to substance abuse, among other things. (Rheault, 2011, p. 6)

In the Prime Minister of Canada's 2008 apology to Indigenous Peoples for this violent assault on their autonomy, the government of the day publicly acknowledged that the purpose of residential schools was to isolate Indigenous children from their families for their assimilation, and that this purpose was undertaken with the opinion that Indigenous Peoples were inferior and unequal. (University of British Columbia - First Nations Studies Program, 2009) However, the apology did not acknowledge the intergenerational trauma caused by the Residential and Day Schools System, a legacy 
that continues to impact the well-being of Indigenous Peoples today. ${ }^{21}$ A year later, Indigenous Peoples and allied Canadians questioned the authenticity of the apology when the Prime Minister told an international news conference at the 2009 G20 Summit that Canada had a history free of colonialism. (Rheault, 2011, p. 6)

The Eurocentric, colonial perspective that led to the creation and enforcement of residential schooling for Indigenous Peoples was informed by the political logic at the time, evidenced by the 1857 Act to Encourage the Gradual Civilization of Indian Tribes in this Province. (Province of Canada) The Act created a legal basis for the disenfranchisement of Indigenous Peoples from their inherent rights should they learn to read and write. During this time, mainstream discourses characterized Indigenous Peoples as "childlike" and "in need of wardship". It was believed that by targeting Indigenous children, the cultural ways of Indigenous adults could be phased out of the next generation via assimilative education that isolated them from their cultural identity. (Leeuw, 2009, pp. 128-129)

The Bagot Report, commissioned on the subject in 1875, furthered entrenched colonial perspectives when it positioned the assimilation of Indigenous Peoples through education as a means to enable dispossession of their collective lands. (Ibid.) This is an example of how colonial policies can work to dispossess Indigenous Peoples of their identities and eventually, their lands, creating new space for the production of capitalism.

\footnotetext{
${ }^{21}$ The Indian Residential School Settlement Agreement was signed in 2006 between the federal government, legal representatives of survivors, the Assembly of First Nations, Inuit representatives and churches to compensate residential school survivors and address the legacies of the Indian Residential and Day Schools System. As part of this settlement, a Truth and Reconciliation Commission was launched in 2010 to document the experiences of residential school survivors as part of a healing process toward Indigenous-Crown reconciliation. The TRC completed its work in 2015.
} 
(Harvey, 2004) In other words, the assimilation of Indigenous Peoples to mainstream society was linked to the state's pursuit of their land and resources. (Leeuw, 2009, p. 128) It was the belief of policy makers of the day that by disconnecting Indigenous Peoples from their families, their culture, and eventually their communities, their collective title to land would eventually dissolve, along with their societies.

Enacted in 1876, the Indian Act (Government of Canada, 1985) was anchored in the Act to Encourage the Gradual Civilization of Indian Tribes in this Province. The focus of these two pieces of legislation on Indigenous identity, territory and claims to land, had a direct impact on the development of Indigenous education policy. (Leeuw, 2009, p. 128) The goal of these elements of statecraft was to undermine Indigenous cultural integrity, eliminate their "special status" and separate them from their land and resources. (Godlewska, Schaefli, \& Chaput, 2013, p. 274) The Royal Commission on Aboriginal Peoples, hereafter referred to as RCAP, identified four false assumptions operating in settler-Canada during the Indian Residential and Days Schools era that informed the government's assimilationist/interventionist policies:

1. The first held Aboriginal people to be inherently inferior and incapable of governing themselves.

2. The second was that Treaties and other agreements were, by and large, not covenants of trust and obligation but devices of statecraft, less expensive and more acceptable than armed conflict. Treaties were seen as a form of bureaucratic memorandum of understanding, to be acknowledged formally but ignored frequently. All four areas of policy or action ran roughshod over Treaty obligations.

3. The third false assumption was that wardship was appropriate for Aboriginal peoples, so that actions deemed to be for their benefit could be taken without their consent or their involvement in design or implementation. 
4. The fourth was that concepts of development, whether for the individual or the community, could be defined by non-Aboriginal values alone. This assumption held whether progress was seen as Aboriginal people being civilized and assimilated or, in later times, as resource development and environmental exploitation.

(Government of Canada, 1996, pp. Part 2, Chapter 8)

The Indian Act (Government of Canada, 1985) was the main apparatus for the implementation of these false assumptions. Its purpose was to create a legal basis for the internment and eventual assimilation of Indigenous children, while establishing government control over Indigenous society. (Mendelson, 2008, p. 3) The Indian Act was ammended most recently in 2011 , but in terms of educational provisions, it remains rather sparse. The lack of regulatory provisions related to education contained within the Indian Act is critical to this thesis because the same act is the sole legislation governing education on reserve in Canada today.

Sections 114 - 122 of the Indian Act apply to Schools, defining the terms of Canada's constitutional duty for the provision of education to Indigenous Peoples. Section 114 (1) gives the Minister of Indian Affairs ${ }^{22}$ authority to enter into agreements with provinces, churches, and school boards for the provision of education to on-reserve Indigenous students - with the notable exception of authority to enter into agreement with First Nations governments to run their own schools. (Government of Canada, 1985) Only recently has the Indian Act been amended to allow for two precedent-setting agreements that devolved jurisdiction over education to Indigenous Peoples: The 1998 Mi'kmaq Education Act of Nova Scotia ${ }^{23}$ and the First Nations Jurisdiction over

\footnotetext{
${ }^{22}$ AANDC was previously known as the Department of Indian Affairs or DIA.

${ }^{23}$ See http://nslegislature.ca/legc/statutes/mi\%27kmaq\%20education.pdf for more information.
} 
Education in British Columbia Act ${ }^{24}$ of $2006 .{ }^{25}$ These precedent-setting bilateral agreements (between the Crown and Indigenous nations) returned jurisdiction to Indigenous signatories for the autonomous control of their education systems on reserve, and are often held up as a contemporary model for Indigenous governance of education.

Section 114 (2) of the Act allows for the Minister to operate schools for Indigenous children, while Section 115 says the Minister may make regulations to govern education on reserve. The remaining sections have since been repealed or deal with the required age (7-16) for compulsory attendance at school. (Ibid.) Given the complex educational frameworks in place for the operation of quality, representative education systems at the provincial level, it is clear that these legislative terms are inadequate. Indeed, the sections of the Indian Act pertaining to the provision of education are virtually inoperative, meaning that in practice most education on reserve is left without statutory basis. (Mendelson, 2008, p. 3) The systemic issues affecting the educational outcomes of on-reserve Indigenous students today can be attributed in part to the inappropriateness of the Indian Act as a vehicle to deliver educational services, in large part due to the colonial assumptions it is founded upon, but also due to its lack of educational focus. (Stewart, 2006, pp. 1005-6) Although residential schools for Indigenous children had already been operating in Canada as a prominent feature of assimilation efforts, the Indian Act formalized the Indian Residential and Days Schools System. (Leeuw, 2009, p. 129)

\footnotetext{
${ }^{24}$ See http://laws-lois.justice.gc.ca/eng/acts/F-11.75/page-1.html for more information.

${ }^{25}$ These Crown-Indigenous agreements were formalized in federal legislation, later leading to the creation of supporting provincial legislation.
} 


\subsection{Treaties, Indigenous Education, and the Canadian Constitution}

Under Section 93 of the Constitution Act of Canada, 1867, the responsibility for the provision of education to Canadian citizens is assigned to the provinces, with the exception of on-reserve Indigenous students. (Department of Justice, Canada, 2013) The Constitution, Section 91, maintains federal authority for "Indians, and Lands reserved for the Indians". It was under this section that the Indian Act, Canada's prolific policy of assimilation governing the lives of Indigenous Peoples, was enacted. (Stewart, 2006, p. 1001) In 1982, First Ministers and leaders of Indigenous organizations agreed to amendments to the Constitution that recognize Indigenous rights to self-government under Section 35, among other things. ${ }^{26}$

Indigenous claims to self-government in education as an inherent right, as could be protected under Section 35, have been contested by the government and in 2015, remain unexamined by the Canadian judicial system. In order for education to be determined an inherent right for Indigenous Peoples according to Canadian law, courts would have to determine that education is key to sustaining Indigenous culture and ways of being. (Paquette \& Fallon, 2008, p. 358) Considering the state's historical dependency upon education to acculturate Indigenous Peoples to dominant Canadian society, and the supranational human rights infrastructure connecting self-government in

\footnotetext{
${ }^{26}$ Also included were amendments to Section 37, later repealed, that required that constitutional conferences be convened to discuss constitutional matters that directly affect Indigenous Peoples, with Indigenous representatives invited to participate. Amendments to Section 25 ascertained that the Canadian Charter of Rights and Freedoms does not abrogate or derogate from any Aboriginal, Treaty or other rights and freedoms related to Indigenous Peoples in Canada. (Department of Justice, Canada, 2013)
} 
education to the survival of Indigenous cultures, (Stavenhagen, 2004) the case for education as an inherent Indigenous right seems common sense.

The Canadian government has also disputed to what extent education is included as a provision of Indigenous Treaties. Treaties were signed between Indigenous nations and the British Crown "in the spirit of peaceful coexistence and mutual respect" for the protection of Indigenous inherent rights and rights to self-government, as well as the terms of an exchange of resources (land and 'benefit') to enable an equitable partnership based on cooperation and mutual needs. (Assembly of First Nations, 2014b) Peace and Friendship Treaties in Eastern Canada were entered into before 1779, followed by the Upper Canada Treaties (1764 - 1862), the Vancouver Island Treaties (1850 - 1854), and the Numbered Treaties in Ontario, the Prairies and the Northwest Territories (1871 1921). (Government of Canada, 2010a) Thus, nation-to-nation treaty agreements were signed at the same time as the government's strategies of educational assimilation were carried out through the operation of church-run residential and day schools.

Although an inherent right to education is still debated in Canadian jurisprudence, each Treaty made some level of reference to the provision of education for Indigenous peoples. The terms of education within the Treaties are diverse in scope and detail. In Treaties $1 \& 2$, the terms of agreement specify only that a school will be provided, whereas Treaty 9 outlines a detailed description of teacher compensation, school facilities and educational resources. (Paquette \& Fallon, 2008, p. 357) Though the terms of education under the Treaties vary significantly, it is likely they would be interpreted in the context of what is required in present day to provide for a quality education that enables Indigenous peoples to contribute effectively to Canadian society while 
maintaining their inherent rights. (Paquette \& Fallon, 2008, p. 358) In contemporary Canada, Indigenous peoples still endure social, political, environmental, and economic injustices in their struggle for the full implementation of the terms of the Treaties.

\subsection{Indigenous Education in Supranational Rights Frameworks}

In 1948, the United Nations released its Universal Declaration of Human Rights, (United Nations, 1948) Article 26 of which defined the universal right to quality education for all peoples. In reference to educational rights, the 1948 Declaration stated that:

(1) Education be free and compulsory, with educational advancement based upon merit;

(2) “...[E]ducation be directed to the full development of the human personality and to the strengthening of respect for human rights and fundamental freedoms. It shall promote understanding, tolerance and friendship among all nations, racial or religious groups, and shall further the activities of the United Nations for the maintenance of peace"; and,

(3) Parents be afforded the right to choose the form of education for their children. (United Nations, 1948)

Then, in 1960, the United Nations Educational, Scientific and Cultural Organization adopted the Convention Against Discrimination in Education, (1960) which built upon Article 26 of the human rights declaration in this important area. The convention was enacted to identify the terms for non-discrimination in education, the terms of which advised states against the segregation of school systems on the basis of race, language, or religion without the consent of parents and that presupposed fair and equitable access to quality education for minority peoples, funded and administered comparable to national standards, and that those minority nations be given full and free control over the establishment and maintainence of their education systems. Based upon the agreement of what constitutes a human right, the convention calls upon states to halt any 
discriminatory practices in education and to ensure that state authorities do not engage in unequal treatment in the administration of funding and schools for students of a minority group. (Ibid., p. 4-5)

In 2007, the General Assembly of the United Nations passed a resolution to adopt the United Nations Declaration on the Rights of Indigenous Peoples. (2008) Within the Declaration are many pertinent statements that promote the protection of Indigenous rights to self-government. Indigenous education in particular is viewed as a key instrument for creating respect for cultural diversity and for achieving equitable development. (Stavenhagen, 2004) The Declaration provides specific terms for Indigenous education, demarcated in Box 1.0. 


\section{Box 1.0 Articles pertaining to education in the United Nations Declaration on the Rights of Indigenous Peoples}

Recognizing in particular the right of indigenous families and communities to retain shared responsibility for the upbringing, training, education and well-being of their children, consistent with the rights of the child,

Article 14

1. Indigenous peoples have the right to establish and control their educational systems and institutions providing education in their own languages, in a manner appropriate to their cultural methods of teaching and learning;

2. Indigenous individuals, particularly children, have the right to all levels and forms of education of the State without discrimination; and,

3. States shall, in conjunction with indigenous peoples, take effective measures, in order for indigenous individuals, particularly children, including those living outside their communities, to have access, when possible, to an education in their own culture and provided in their own language.

Article 15

1. Indigenous peoples have the right to the dignity and diversity of their cultures, traditions, histories and aspirations which shall be appropriately reflected in education and public information; and,

2. States shall take effective measures, in consultation and cooperation with the indigenous peoples concerned, to combat prejudice and eliminate discrimination and to promote tolerance, understanding and good relations among indigenous peoples and all other segments of society.

Article 17

2. States shall in consultation and cooperation with indigenous peoples take specific measures to protect indigenous children from economic exploitation and from performing any work that is likely to be hazardous or to interfere with the child's education, or to be harmful to the child's health or physical, mental, spiritual, moral or social development, taking into account their special vulnerability and the importance of education for their empowerment.

Article 21

1. Indigenous peoples have the right, without discrimination, to the improvement of their economic and social conditions, including, inter alia, in the areas of education, employment, vocational training and retraining, housing, sanitation, health and social security.

(United Nations, 2008)

After initially refusing to endorse the Declaration, Canada did so three years later in November, 2010, with the disclaimer that, " $[\ldots]$ the Declaration is a non-legally binding document that does not reflect customary international law nor change Canadian laws”. (Government of Canada, 2010) Pointedly, the government was adamant that Indigenous education was appropriately mandated and provided within the Canadian 
legal jurisprudence and was hesitant to endorse the Declaration if its terms could be used to challenge the authority of the Crown in the future.

\subsection{Provincial Devolution of Indigenous Education}

In the 1940s, Indigenous peoples were politicized through the movement of Indigenous WWI and WWII veterens to resist the discriminatory treatment that greeted them upon return to Canada. Many Indigenous men volunteered for military service (over 3000 in each war) to support their alliance with the Crown, as signified through the Treaties, but

yet faced government policies that threatened enfranchisement for doing so. Indigenous veterens joined the leadership of their communities and spurred inquiry into whether the government's policy of enfranchisement for voluntary military service stood up against the terms of the Treaties. As a result, Indigenous veterens started a movement that stimulated the politicization of Indigenous peoples and marked a change in the relationship between Indigenous peoples and the federal government. (Government of Canada, 1996)

During the same period, public curiousity about the effectiveness of the residential school system was piqued. Moreover, Indigenous communities and parents were enraged that children were dying while in the care of the government's education system. In reponse to these concerns and those of Indigenous veterens, the federal government launched a Special Joint Committee of the Senate and the House of Commons in 1946 to receive public submissions on issues affecting Indigenous peoples. Education represented $92 \%$ of subissions. (Raptis \& Bowker, 2010, p. 2) 
At the time, the population of Indigenous peoples was burgeoning, not unlike the situation today, and the federal government found itself in search of efficiencies to manage its constitutional responsibilities. The large majority $(90 \%)$ of submissions to the Joint Committee were made by Indigenous peoples calling for the attainment of qualified teachers for their schools, the construction of new schools on reserve so that students need not travel great distances, and proper maintenance of current facilities. (Ibid.) Indeed, the evidence recorded in the report highlights chronic underfunding of schools, a deficit in funding compared to provincial education systems, and poorly-constructed and marginally-equipped schools, with high teacher turnover due to insufficient wages for the trade. (Stewart, 2006, p. 1003)

However, the recommendations of the Joint Committee did not reflect Indigenous voices, instead making a final recommendation for a shift from segregated schooling to integration. Raptis and Bowker show that this decision was made, not based upon the façade of consultation meant to give the illusion of democratic participation, but intead the government's desire to find cost-effective measures to reduce the burden of its constitutional duty for Indigenous education. (Raptis \& Bowker, 2010, p. 17) This event has particular relevancy as it establishes precedence for the government's historical practice of using the illusion of consultation to implement unilateral policy decisions, which often prioritize cost-saving measures, in the area of Indigenous education.

The government's shift to a policy of integration would have an enormous impact on the education of Indigenous peoples, still felt today. In 1949, the Report of the Special Joint Committee would be used by the government to introduce conditions of 
comparability to provincial systems for Indigenous education in residential schools. (Legacy of Hope Foundation, 2013, p. 5) This meant that residential schools were legislated to abide by provincial curriculum standards. Then, in 1951, the Indian Act was ammended to allow for Indigenous students to attend provincial schools, thereby devolving partial responsibility for Indigenous education to the Provinces. (Raptis \& Bowker, 2010, p. 2)

By 1958, pressure on the government to eliminate residential schools was mounting as even more Regional Indian Affairs Inspectors called for the closure of the Indian Residential and Day Schools System; however, over 10,000 students still attended two years later. Finally, in 1969, the federal government terminated its partnership with Christian churches for the management of residential schools. Although 1969 marked the beginning of partial devolution of control for education to Indigenous peoples, the last residential school did not close until 1998. (Legacy of Hope Foundation, 2013, pp. 4-7)

The year 1969 saw more than one significant change to the political economy of Indigenous-state relations in Canada. The Department of Indian Affairs, led by future Prime Minister Jean Chrétien, drew upon ideas from the equal rights movement to propose a new way forward for Indigenous peoples in Canada. The White Paper proposed that the "special treatment" of Indigenous peoples due to their inherent and treaty rights, caused them to be "disadvantaged and apart" - marginalized in mainstream society. Moreover, authors of the White Paper suggested that to be free, Indigenous peoples should abandon their inherent rights and integrate themselves to Canadian settlersociety. (Government of Canada, 1969, p. 1) 
The White Paper advocated that the termination of Indigenous 'special' rights was the way for Indigenous peoples to reassert their rights as free citizens. Ironically, this was a complete reversal from the position of the Indigenous rights movement of the time, which was concerned with advocating for Canada to honor its treaty obligations by recognizing Indigenous rights to self-government. Through vocal opposition and lobbying of the Crown and the United Nations, Indigenous peoples were able to force the rejection of the policy in favor of resuming their struggle for the protection of their collective rights. This historic success of Indigenous agency to impact government policy was a catalyst for change in Indigenous-settler relations. (Manuel \& Derrickson, 2015)

\subsection{The Struggle for Indigenous Control of Indigenous Education}

A turning point in the history of Indigenous education in Canada, the National Indian Brotherhood (NIB) put forth a policy statement on Indigenous education in 1972 titled Indian Control of Indian Education. (National Indian Brotherhood, 1972) The national representative body comprised of First Nations Chiefs from across Canada had evolved over time from separate initiatives and alliances of First Nation groups, and today it is known as the Assembly of First Nations. The NIB had been active opposing the 1969 White Paper and had travelled to the United Nations and Great Britain to lobby for protection of Indigenous Constitutional rights. (National Indian Brotherhood, 1980)

Still incredibly relevant today, Indian Control of Indian Education remains one of the most crucial policy documents ever created by Indigenous peoples in Canada regarding their right to self-government in education. Indian Control of Indian Education points out that Indigenous tradition stipulates that each adult is responsible for 
each child, and that it takes a communal effort to raise a child. The policy stresses the importance of education to the long-term success of Indigenous peoples, and that education must consist of teachings that enable positive self-esteem and cultural identity, while enabling the development of the skills required to engage with the broader world around them. Further, the document acknowledges a gap in understanding between settler-Canadian and Indigenous cultures, and that in order for this to be overcome, “...Canadian children of every racial origin must have the opportunity during their school days to learn about the history, customs and culture of this country's original inhabitants and first citizens.” (National Indian Brotherhood, 1972, p. 2)

Indian Control of Indian Education suggests that in order to correct past policies, colonial in nature, that have resulted in withdrawl and failure, Indigenous parents must be given the same rights as other Canadians: full authority to choose and participate in the education of their children. There are two crucial principles an Indgenous education system must be founded upon: (1) local control, and (2) parental responsibility. The NIB points to the Crown's constitutional and treaty obligation for the provision of quality education to Indigenous peoples, and maintains the federal government has an obligation to properly fund Indigenous education systems. (Ibid., p. 3)

Indian Control of Indian Education provides a detailed framework within which an exceptional education system for Indigenous peoples could be created. In terms of control, the authority for education would rest with local First Nation government governments, whom would form regional education authorities for the delivery of centralized services similar to what a school board or provincial ministry of education 
would provide. Complete jurisdiction over education would be devolved to First Nation governments gradually as their adminsitrative and managerial capacity related to education improved. Indigenous peoples would be consulted by their educational authorities regarding the education of their children at the school, school board (or district) and educational authority (ministerial) level. For those parents that chose to send their children to public schools, Indigenous participation would be remedied by enabling proportional representation of Indigenous peoples on provincial school boards, curriculum development commmittees, and as teachers in provincial classrooms. The implementation of the Indian Control of Indian Education framework would mitigate the educational oppression Indigenous peoples encountered as wards of the state by ensuring that decisions related to Indigenous children were no longer implemented without the proper consultation and approval of their families.

Provisions would be made so that qualifications related to fluency in an Indigenous language and experience with the culture of the community would come into consideration when hiring decisions for teachers were made. Language and culture programming would be offered in every school, and each community would have the authority to create curriculum and determine pedagogical approach. School facilities would be upgraded to regulation and new schools built so that children could attend school in their communities. ${ }^{27}$ Integration with the provincial system would not be imposed but would be discussed among equal partners to determine its benefits and disadvantages. (Ibid., pp. 27-31) Although for most critical thinkers, these ideas may

\footnotetext{
${ }^{27}$ A large number of new schools have been constructed on reserve since the 1970 s, and many old residential schools repurposed as colleges.
} 
seem like common sense today, in the 1970s, with residential schools still in operation and the memory of the colonial assault on Indigeneity still very fresh, this policy statement represented not only a radical act of Indigenous resistance to colonialism, but also a strong display of Indigenous self-government.

Indian Control of Indian Education was put forward in a climate of political upheaval in Indigenous-state relations. At the time of its release, the White Paper had been adamantly opposed, the United Nations had released its Universal Declaration of Human Rights, (United Nations, 1948) Article 26 of which defined the universal right to quality education for all peoples, and Indigenous groups were organizing at the local, regional, national, and international level to lobby for their collective rights. In a shocking reversal of its position, the federal government announced its acceptance of the NIB's policy and within a few years, had adopted a hands-off stance related to education on-reserve. (Mendelson, 2008)

Unfortunately, this role reversal was undertaken without due regard for the implications associated with transferring jurisdiction to local First Nation governments without adequate funding, training or planning. (Mendelson, 2008, pp. 3-5) Without satisfactory guidelines or processes governing education on reserve, and based solely on the sparse terms regarding education outlined in the Indian Act, the roles and responsibiltiies to enable the transition to Indigenous control were blurred.

Under the (partial) implementation of Indian Control of Indian Education, the role of the federal government has been hardly more than to administer funds and manage reporting regimes, placing high value on expense reporting rather than on conditions of 
student improvement and performance. (Mendelson, 2008) Regrettably, discourses of Indigenous self-government and autonomy can be used to reduce the administrative costs and constitutional accountability of the government, while downloading inadequate funding (and exacerabting administrative burdens) onto nations that lack the jurisdictional authority and organizational capacity to properly implement selfgovernment. (Godlewska, Schaefli, \& Chaput, 2013, p. 275)

First Nations communities in Canada now administer up to $85 \%$ of their federal education funding through generic funding agreements with the state. Education funding is granted across a wide variety of categories, ranging from teacher salaries to high-cost special education to guidance and counselling. However, First Nation government s still lack the authority to control their education systems, shackled as they are to the Department of Aboriginal Affairs and Northern Development Canada (AANDC). (Stewart, 2006) The Indian Act, which continues to present day to be the sole legislation governing education on-reserve, does not provide any mechanism for Indigenous parents, educators, or students to appeal mistreatment or a lack of quality educational programming, while simultaneously requiring only that the government enable education instead of providing it. (Paquette \& Fallon, 2008, pp. 353-354) A perspective from legal scholars Paquette and Fallon says it all:

It would be unthinkable, within either contemporary societal mores or within the political and social-value realities of the twenty-first century, for a Canadian province or territory to offer students and parents within its jurisdiction only the educational-rights vacuum that currently exists within the Indian Act. (Ibid., p. 349) 


\subsection{The Current State of On-reserve Indigenous Education}

Critics of the government's administration of the on-reserve education system, or the lack thereof, have raised several significant concerns. In particular, chronic underfunding proves a major source of contention. AANDC funds First Nation governments based upon a count of school-age students living in their communities. Recall that the Nominal Roll is the main data used to inform federal administration of on-reserve education.

An internal evaluation of AANDC's Band-Operated and Federal Schools (BOFS) program found that per-capita student funding of $\$ 5500$ - $\$ 7500$ is made available for students attending schools on reserve, while the per-capita average funding for on-reserve students attending provincial schools is $\$ 6800$ - $\$ 8400$. (Indian and Northern Affairs Canada, 2005) For an Indigenous community school of 120 students, that amounts to a comparable deficit of $\$ 156,000-108,000$, enough to hire two-three aditional staff. Furthermore, the audit found that due to the high-cost factors of operating schools in isolated environments and disproportionate levels of high-risk special needs students (a direct result of the inter-generational trauma affecting community development), actual per student costs for Indigenous students would likely exceed provincial averages. (Ibid.)

In spite of these facts, the federal government has placed conditions of provincial comparability upon Indigenous communities for the receipt of education funding. (Mendelson, 2008, pp. 6-7) Not only do First Nation governments not have the autonomy to control their own education systems, but they must attempt to replicate provincial education systems or risk losing their funding, insufficient though it is. Futhermore, there is absolutely no evidence of a link between budget setting and the 
condition of comparability in the policies and practices of the federal government.

(Mendelson, 2008) In fact, the federally-sponsored evaluation of the effectiveness of the on-reserve school system found that " ...the formal statement of program objectives does not fully support the priorities due to an overemphasis on eligibility and provincial system comparability to the detriment of essential attributes of a linguistically and culturally relevant education system". (Indian and Northern Affairs Canada, 2005, p. ii) The condition of comparability is required for receipt of funding, however, there is no follow-up mechanism to remedy deficiencies or to reward successes. (Mendelson, 2008) There is a complete lack of accountability concerning how the federal government funds First Nation governments for education on reserve. (Auditor General of Canada, 2011)

The Auditor General of Canada took up the issue of on-reserve education in the year 2000 and has since reported on the Elementary and Secondary Education Program for students living on reserve in 2004, 2006, and 2011. Each evaluation found that the AANDC made unsatisfactory progress toward the recommendations of prior reports and that the index of well-being for First Nations people had not improved. (Auditor General of Canada, 2011) In particular, the Auditor General identified four structural impediments to the delivery of public services to Indigenous communities:

1. Lack of clarity about service levels;

2. Lack of a legislative base;

3. Lack of an appropriate funding mechanism; and,

4. Lack of organizations to support local service delivery. (Ibid.)

Regarding the lack of clarity about service levels, the Auditor General reported that “...it is not always evident whether the federal government is committed to providing services on reserves of the same range and quality as those provided to other communities across 
Canada.” (Ibid.) The lack of a legisltative base was criticized for creating ambiguity about jurisdiction and responsibility, as well as creating a void in program accountability. In terms of funding, the Auditor General detailed the difficulty First Nations experience because of the unreliability (funding is not dispersed in a timely, planned manner) and the uncertainty of funding dispersement (funding must be applied for year after year, with no guarantee it will be awarded).

Indeed, the lack of funding security makes it challenging for First Nations to adequately strengthen their capacity and conduct long-term planning, two crucial elements for any system to succeed. Funding was also found to be inadequate, as the formula for funding dispersement to communities for the operation for a community school had not been updated since the 1980s. In fact, the Auditor General noted that the government has no mechanism in place to determine the appropriateness of funding levels to the needs of First Nations, and that the condition of comparability is in no way enforced. Additionally, the excessive reporting required of First Nations by the federal government causes precious financial and human resources to be wasted on the submission of countless reports, while the Auditor General found that the reports were never reviewed by the government and served no purpose. (Ibid.)

In response to concerns from First Nations about their inability to provide quality education to their children because of the inadequacy of funding, the government's response was that its role is to provide funding, not to ensure delivery. Recognizing this gap in responsibility, the Auditor General recommends that First Nations and the federal government work together to develop standards and service delivery agencies, as well as 
collaborate on how the standards will be enforced and monitored. (Ibid.) Clearly, the successful implementation of significant changes to the way Indigenous education is delivered would depend upon the improvement of the funding regime.

The government has been slow to respond to these critical recommendations. But in 2008, it launched its most recent effort to reform the Elementary and Secondary Education Program for students on reserve. The creation and implemention of federal legislation to govern education on reserve was the end goal of the federal government. The reform process is described below, and Chapter 5 details feedback the state received through consultation.

\subsection{Conclusion}

This chapter included the assimilative history of Indigenous education in Canada, a description of the supranational rights infrastructure related to education, the constitutional and treaty implications for Indigenous education in Canada, the vision First Nations have for an autonomous education system, and the federal strategy for provincial devolution. Finally, the last section gave an overview of the current state of First Nations education in Canada. I sought throughout to present this information as objectively as possible. Chapter 5 will describe the recent federal consultation process meant to inform the creation of legislation to govern education on reserve. Critical analysis will reveal the power dynamics at play and the government's discursive framing linking Indigenous education to economic benefit. 


\section{Chapter 5: Analyzing State-Sponsored Reform of Indigenous Education}

The education of our children is a fundamental and sacred responsibility, and both a right and a duty of our Nations. The residential schools era is a deep scar on the national soul of this country. Every day, our families bear the trauma of this past. Honouring this reality, respecting our rights as Nations and as peoples demands clear actions to achieve reconciliation. First Nations are resolute and determined to resume our responsibility fully to First Nation education. While our ways, our rights and our responsibilities were pushed aside by the federal government in the residential schools era, we have been fighting back ever since to take back this responsibility. Today, we are acting to achieve this better day for our children now. (Atleo, 2013)

The words of the Assembly of First Nations National Chief in the passage above reveal the passion surrounding the complex issue of Indigenous education. The complexity of the relationships amongst First Nations and between First Nations and the government are underpinned by entrenched mistrust for federal education systems and the uniqueness of each Nation's particular situation. The duplicitous actions of the settler-colonial government throughout the long history of federally-sponsored education for Indigenous peoples tarnishes Canada's legitimacy in the present. At the same time, the individual experiences of each First Nation inform their opinions regarding whether First Nations autonomy can be recognized and enacted within Canadian systems, or whether the true means of Indigenous control can only be found through sovereign separation from the government.

It is the classic philosophical divide Harvey refers to when he speaks of the 'political and social struggles and vast swaths of difference' that arise from processes of accumulation by dispossession that involve creation destruction. While some people will buy-in to new opportunities made available by the reproduction of space, in the belief 
that social progress can be achieved therein, others will struggle against co-optation to maintain their traditional systems. Still, others will fight against co-optation, not in the defense of tradition, but for the right to define a progressive alternative to the expansion of capitalist relations. (Harvey, 2003, pp. 162-164)

In regard to Indigenous educational reform, political dissonance is sparked by questions such as: Can educational reform solutions be found within the current system to enact autonomy and enable systemic transformation toward reconciliation? Or is complete liberation from a system historically constituted upon oppression necessary to obtain real change? These fundamental questions were a vein throughout the consultation process related to on-reserve educational reform. Although some Nations rejected the reform process completely, arguing that any government-sponsored education system interferred with their right to self-determination, others participated in the hopes that progress toward Indigenous goals of educational autonomy could be progressed with incremental change. As the evidence that follows will show, although there are many similarities among Nations, there are also vast differences, and the complex landscape of Indigenous-state relationality in Canada drastically affects the way forward on Indigenous educational reform.

Although the federal government has sponsored several reform initiatives in the recent past, this thesis focuses on the recent consultation process to inform the creation of federal legislation to govern education on reserve. This chapter will present the evidence related to the reform consultation process accompanied by some brief analysis. Section 5.1, begins with an overview of the federal government's Reforming First Nations 
Education Initiative. Then, Section 5.2, titled Consultations, Interpreted introduces the recent federal consultation process, detailing what was heard during face-to-face consultations in cities across the country. The concept of consultation as it relates to Indigenous peoples is explored through the views of Indigenous groups and some public stakeholders, as expressed in consultation documents. This section is further sub-divided into the three major themes that emerged through this analysis: Funding, Consultation, and First Nations Control. The rest of the reform process, from the end of face-to-face consultations, to the tabling of Bill C-33 in the House of Commons, will be detailed in Chapter 6, along with a discourse analysis of how the government frames Indigenous education as related to national economic benefit.

\subsection{Reforming First Nation Education Initiative}

In 2008, Aboriginal Affairs and Northern Development Canada (AANDC) announced the lauch of the Reforming First Nation Education Initiative. (Government of Canada, 2013) The initiative includes an investment in three project-based funding programs to supplement the Elementary and Secondary Education Program for students ordinarily resident on reserve. The programs include the Education Partnerships Program (EPP), (Government of Canada, 2015) which features collaborations between provincial governments and Indigenous educational organizations for students in public schools; the First Nation Student Success Program (FNSSP), (Government of Canada, 2015a) which supports projects that supplement the services provided in community-operated schools; and, the Education Information System (EIS), (Government of Canada, 2013) which aims to create a federal database to streamline reporting and host education statistics, as well as to train communities across the country in its population and use. 
The eligibility criteria for the EPP and the FNSSP states that only Regional Management Organizations (RMO), incorporated education groups representing more than one school, may apply. RMOs must have structures that include an executive director, a finance manager and a board of directors, or an equivalent. Both programs are project based, where eligible RMOs must submit a new proposal annually - multi-year proposals for long-term projects are not accepted. The EPP promotes the establishment and advancement of provincial partnerships through project categories that link the onreserve and public school systems. The FNSSP promotes literacy, numeracy and student retention initiatives, as well as performance measurement and school success planning. (Ibid.) Available under both programs is the Structural Readiness category, which promotes the development of organizational capacity for RMOs in preparation for educational reform.

These funding programs were launched in 2008 as a precondition to the development and implementation of federal legislation, although the government's intention to legislate on-reserve education had not yet been made public. The categories of supplementary funding made available to Indigenous communities under these funding programs require them to form incorporated organizations, to develop expertise-sharing partnerships that improve opportunities for student transition between the public and First Nation-operated school systems, and to implement data-driven practices into the school environments. The establishment of bilateral and trilateral agreements between the provinces, First Nations and the government, are a major focus of the EPP. This is indicative of the federal government's desire to strengthen the capacity of provincial governments in preparation for further devolution of Indigenous education to the 
Provinces. Although alliances between Indigenous nations and provincial governments are important, the federal government neglects the dire state of the on-reserve school system and further promotes the attrition of Indigenous students to provincial schools by concentrating on Indigenous-provincial partnerships.

The interest of the government in introducing data-driven processes for evidencebased decision making in the on-reserve school system fails to recognize Indigenous knowledge and autonomy in guiding and measuring the educational success of Indigenous students. As on-reserve schools are required to maintain provincial comparability, using provincial curriculum to accomplish this due to a lack of adequate funding to enable the production of locally-created instructional resources, the autonomy of Indigenous peoples to set their own criteria and indicators for measuring student success is constrained. Additionally, the requirement to report unilaterally defined data measures to AANDC limits the time and human capacity Indigenous educators have to focus on Indigenous-led solutions. Although supplementary funding for First Nationoperated schools allows First Nation groups to provide for critical support services, the use of project-based funding programs further entrenches the structural impediments to quality education on reserve and does nothing to mitigate the real issue of a completely inadequate funding regime.

In December of 2010, when the EPP and FNSSP had been operating for two fiscal years, the federal government and the Assembly of First Nations announced the creation of a national panel to evaluate, through consultation and research, the options for onreserve educational reform, including legislation. (Government of Canada, 2013) At the 
same time, the Standing Senate Committee on Aboriginal Peoples was conducting a cross-country audit of on-reserve education. (2011) Between June and November 2011, the national panel hosted eight regional and one national roundtable discussions, met with various stakeholders and visited communities to discuss Indigenous educational priorities. In December 2011, the Standing Senate Committee tabled its report, which illustrated the dire condition of Indigenous education on reserve. A short time later, in February of 2012, the national panel tabled its report, which featured strong recommendations for the co-creation of federal legislation based upon a new political relationship founded in principles of reconciliation and cooperation. (The National Panel on First Nation Elementary and Secondary Education for Students on Reserve, 2012)

The national panel stated that reform,

[...] cannot come from a place of unilaterally imposing the government's will on First Nations, which tragically marred education during the residential school experience. Nor can it be an "off-load" onto struggling communities of the full imperative of improvement without meaningful partnership, support and collaboration in building the systems required. (Ibid.)

Both reports recommended the full inclusion of Indigenous peoples in the development of reform solutions and harked against unilateral reform solutions.

\subsection{Consultations, Interpreted}

Before any Indigenous peoples were consulted by the federal government regarding the creation of legislation, Economic Action Plan 2012 directly committed to:

... [E]nsure readiness for the new First Nations education system to be outlined in legislation, with funding used to provide early literacy programming and other supports and services to First Nations schools and students, and to strengthen their relationships with provincial school systems. (Wilkinson \& Leclair, 2013) 
The Government of Canada has an obligation to consult with Indigenous peoples when a government decision could impact Indigenous inherent or Treaty rights. This obligation was formalized by the Supreme Court of Canada in the 2004 Haida and Taku River decisions:

The Supreme Court of Canada concluded that where the Crown, federal or provincial, has "knowledge, real or constructive," of the potential existence of an Aboriginal right, title or a treaty right, and contemplates conduct that might adversely affect that right or title, the honour of the Crown requires the Crown to consult and in some circumstances accommodate that interest. (Tzimas, 2005)

The Court explained that:

... [T] he duty to consult is a constitutional duty; [it] applies in the context of modern treaties; officials must look at treaty provisions first; and where treaty consultation provisions do not apply to a proposed activity, a 'parallel' duty to consult exists. (Government of Canada, 2011)

The Government of Canada asserts that public consultation is a part of good governance and policy-making related to all Canadian citizens. However, in relation to Indigenous peoples specifically, the Crown has "statutory, contractual, and common law obligations to consult". (Ibid.) To assist the Crown in meeting these obligations, the federal government has identified a series of principles that its officials should turn to when judging whether or not a decision requires consultation with Indigenous peoples. Within these guiding principles is a definition of what determines meaningful consultation:

\section{Guiding Principle No. 4}

Consultation and accommodation will be carried out in a manner that seeks to balance Aboriginal interests with other societal interests, relationships and positive outcomes for all partners. A meaningful consultation process is one which is:

- carried out in a timely, efficient and responsible manner; 
- transparent and predictable;

-accessible, reasonable, flexible and fair;

- founded in the principles of good faith, respect and reciprocal responsibility;

- respectful of the uniqueness of First Nation, Metis and Inuit communities; and,

- includes accommodation (e.g. Changing timelines, project parameters), where appropriate. (Ibid.)

The consultation process carried out by the federal government regarding Indigenous educational reform is criticized by participants for not adequately meeting these guiding principles (as will be revealed through first-hand accounts in the following pages). Importantly, these principles of consultation were shaped by the government. Indigenous peoples may have different interpretations about what entails 'meaningful' and adequate consultation. Additionally, there remains a definitional difference between 'consulting' with stakeholders and 'collaborating' with them. One concept implies only listening to concerns, without required action, while the other implies coordinating with stakeholders to address concerns. The feedback from consultation participants evidenced in the following paragraphs reveals the thoughts of stakeholders on the issue of consultation related to educational reform.

A few months after the promise of on-reserve education legislation communicated in Economic Action Plan 2012, the federal government announced the start of "intensive consultations" with Indigenous peoples regarding the reform of education on reserve in December, 2012. The ambitious goal provided was the implementation of federal legislation for the start of the 2014 school year. (Wilkinson \& Leclair, 2013) As will be apparent through this research, the push for the introduction of legislation in time for 
September, 2014, would underpin every step of the so-called 'intensive' consultation

process. With only a year and six months, at the latest, until draft legislation would need to be introduced in the House of Commons in order to meet the deadline for implementation, the public engagement process was short and quick. Indeed, the government initially aimed to have draft legislation in the House of Commons by September, 2013. (Wilkinson \& Leclair, 2013) To this end, federally-sponsored consultation sessions were held in the following cities:

1. January 22,2013 - Halifax, Nova Scotia

2. February 8, 2013, Saskatoon, Saskatchewan

3. March 8, 2013 - Vancouver, British Columbia

4. March 12-13, 2013 - Winnipeg, Manitobs

5. March 27, 2013 - Wendake (Quebec City), Quebec

6. April 11, 2013 - Thunder Bay, Ontario

7. April 12,2013 - Kenora, Ontario

8. April 16, 2013 - Calgary, Alberta

After each session, the government followed up with participants using three form letters - one for Chiefs that attended, one for Chiefs that did not, and one for general participants. As these were form letters, they were not tailored to address or summarize any of the feedback received during the sessions. Each letter thanked the recipient and encouraged them to continue a dialogue throughout the reform process, as AANDC officials would make themselves available through video or teleconferencing. (Stephen Gagnon, 2013)

The eight consultations hosted by the government in cities across the country (not in First Nation communities, and predominantly in urban centres) were informed by a 'Discussion Document' based upon the national panel's report. These 'intensive consultations' took place over a five-month period. Just 440 individuals participated. 
(Wilkinson \& Leclair, 2013) With the conclusion of in-person consultations on April 16, 2013, the government released a 'Blueprint' document containing an annotated outline of proposed federal legislation. (Government of Canada, 2013) The July 12, 2013 release of this blueprint was in response to concerns raised during consultation about a lack of information and transparency in the reform process. Stakeholders were encouraged to submit feedback on the blueprint via video and teleconference calls with AANDC officials or through the online portal. The consultation phase included over 30 teleconferences with interested groups (in which 200 individuals participated), foremost Indigenous communities and organizations, and an online survey to enable the submission of public feedback through an online portal (through which 467 responses by May 17, 2013 were received). (Wilkinson \& Leclair, 2013) The government hosted no further face-to-face consultations.

For the purposes of this research, the bulk of feedback received from First Nations during the face-to-face consultation sessions can be organized into three major themes: Consultation; Funding; and First Nations Control. Other, less common themes were related to how education legislation would affect self-government; the importance of language and culture programming; and school infrastructure development. What follows is a synopsis of what was said in relation to the three major themes. Where possible, Indigenous voices from direct feedback submissions is used in place of government summaries of consultation sessions. As this thesis has already explored the historical inadequacy of the funding regime for Indigenous education and the paternalistic nature of the government's relationship to First Nations people in this policy 
area, feedback that relates the past situation will not be detailed. Only comments regarding the current reform process will be shared. ${ }^{28}$

\subsubsection{Funding}

At every in-person consultation session, funding was a key concern. Many participants in the consultation process suggested that addressing funding inadequacy was the most crucial issue, and that legislation could be considered once an appropriate funding regime was in place. Stakeholders at the Halifax session suggested that providing the funding required to enable First Nations to develop the capacity they require may be more beneficial than launching legislation at this current time. (AANDC Atlantic Regional Office, 2013)

Elsipogtog First Nation School's report requested that a new funding formula address important components of a quality school, such as: school staff paid on par with the provincial system; renewal of curriculum and resources every five years; special needs staffing and resourcing, including for the transportation of disabled students; fulltime support staff including a guidance counsellor, child advocate or outreach worker to engage with parents; at least one literacy and one numeracy clinician; healthcare practitioners such as a child psychologist, a speech and language pathologist, and an occupational therapist; and, much more. (Elsipogtog First Nation School, 2013) Although these are eligible categories for school expenditures under the operational funding schools receive, often the inadequacy of the funding regime does not make it viable for

\footnotetext{
${ }^{28}$ The evidence utilized for this analysis is in the form of consultation summaries produced by AANDC and Indigenous submissions to the online feedback process. Therefore, in the case of the consultation summaries, quantifying the number of participants that gave certain feedback is not possible.
} 
schools to afford these services. Importantly, Elsipogtog First Nation School also related the need to,

[...] clearly define areas requiring funding, so AANDC and other federal legislative staff clearly understand what items will need to be budgeted for the Act to be fully and successfully enacted across schools and communities, especially those with severe economic issues. (Elsipogtog First Nation School, 2013)

The school was especially concerned that new per-capita funding for on-reserve students meet or exceed the federal tuition paid for Indigenous students attending provincial schools.

The Miawpukek Mi'kamawey Mawi'omi, the Government of the Conne River Mi'kmaw of Newfoundland, submitted a letter of support for the creation of federal legislation. The letter notes that, "[1] egislation to set minimum standards to ensure quality education that provides a smooth and successful transition between First Nation and provincial schools and school systems is definitely viewed as a positive." (Miawpukek Mi’kamawey Mawi’omi, 2013)

The Mi'kmaw Nation suggests that regulation is a necessity, as is legislation that properly defines financial accountability between First Nations and the Government of Canada. However, although generally supportive of the creation of legislation, the Conne River Mi'kmaw do have concerns about the lack of detail provided concerning the proposal of a new funding regime enforced by legislation. The community states,

[...] it is often said that money is not everything, but experience in the educational system shows that it certainly is a great equalizer. Without adequate funding to First Nations schools, its students are disadvantages when it comes to improving educational outcomes. (Miawpukek Mi’kamawey Mawi’omi, 2013) 
The Director General of the First Nations Education Council (FNEC) is highly critical of the government's proposal to enact federal legislation, and also of the consultation process. FNEC grounds its own reservations in the "... absence of an agreement that guarantees respect of First Nations' rights and aspirations in education.” (Bastien, 2013) According to Bastien, Executive Director, FNEC has advocated tirelessly for the revision of the federal funding formula for schools on reserve. In her opinion, the government has been too complacent about the state of the current system for far too long. She states:

Even in the absence of such legislation, the government has all the authority needed to bring the funding formula up to date [and] create support systems for the schools...If the federal government's real objective is to implement means for improving school success, it certainly would have had the opportunity to do so in recent years, which would have improved its relations with First Nations and overcome their objections towards this consultation. (Bastien, 2013)

When concerns were raised during consultations that related to funding, whether regarding the lack of an adequate regime or the proposal that funding should be in place before legislation is discussed, AANDC officials consistently responded that they "recognized the need for stable and predictable funding", but that the development of legislation was required before a modified funding regime would be discussed. For instance, the government offered this response to concerns about inadequate funding raised at the Halifax consultation session:

... [T] he Government of Canada has committed to legislation and [...] a discussion of funding without a discussion of the development of education systems is beyond the mandate officials have been given. The purpose of the consultation at this point was to examine systems. There [will] be time to look at related funding issues once there is a better sense of what the system [will] look like. (AANDC Atlantic Regional Office, 2013)

Additionally, government officials state that the only way statutory funding could be made available is through legislation. (Ibid.) 


\subsubsection{Consultation}

Several stakeholders raised concerns about the lack of authentic consultation opportunities throughout the reform process. In addition to the lack of adequate timing to engage with their communities at the grass-roots level, several First Nation participants felt that the provision of online methods that were open to the general public were inappropriate for an issue related solely to Indigenous peoples and which affected Treaty rights and First Nations autonomy. In an internal document, the federal government refers to the fact that cost-saving measures were taken to limit the cost of the consultation process. At the expense of face-to-face consultations, of which there were only eight across the entire country, in major cities no less, the government depended upon a website whereby interested parties could submit feedback. (AANDC, 2013a)

At the federal consultation session held in Vancouver, British Columbia, federal representatives encountered resistance to the use of the term 'consultation' to describe the meeting. The First Nation Education Steering Committee (FNESC) of British Columbia is an educational alliance representing approximately 104 communities that individually obtained jurisdiction over education beginning in 1992. (FNESC and FNSA, 2014) FNESC, the co-host of the Vancouver session, was

\section{[...] unwilling to call the consultation session 'consultation', whereas the Government of Canada was of the view that it was. The parties eventually agreed to call it an 'engagement', however the Government of Canada still asserts that the session constitutes 'consultation'. (AANDC, 2013b)}

The stance of the federal government on this issue is clearly juxtaposed to that of the Vancouver First Nations participants - a common ideological divide that will be evidenced throughout this analysis. Still, while some participants at the Vancouver 
session expressed doubt that legislation was even needed, others called for a joint effort to drafting legislation. Participant feedback on consultation recommended "meaningful and direct consultation with all communities, and adequate time to allow for dialogue on complex issues". (AANDC, 2013b)

First Nations that attended the Calgary session also asserted strongly that they did not consider it to be consultation, but that authentic consultation would be between the leadership of First Nation communities and the leadership of government, not mid-level AANDC officials. Participants were often frustrated that the AANDC officials facilitating consultation sessions were unable to answer questions with authority, instead repeating pre-determined statements. AANDC's positioning in relation to concerns raised at consultation sessions is consistent and matches internal communications briefings on key messages to relay when speaking with the public and First Nations. (Wilkinson \& Leclair, 2013)

Calgary participants denounced the use of an online survey to collect feedback from interested parties. The Chiefs that attended the Calgary session were critical of the ambitious timeline the government had set for the introduction of federal legislation, and asserted that the government was taking a unilateral approach to reform. (AANDC, 2013) Participants to the Kenora session also disagreed with the use of an online mechanism for providing feedback, the lack of time to adequately prepare for the session, and the lack of a Treaty-informed process. Most participants in Kenora were opposed to legislation, believing that it would diminish their rights and control over education. (AANDC, 2013d) 
Participants in the Halifax consultation session raised numerous concerns about the consultation process, including the fact that the sessions are separated into two events, one for Chiefs and First Nations leadership, and the other for educators and community members. (AANDC Atlantic Regional Office, 2013) I recall that this was a particular sore point for several First Nations from New Brunswick, as they felt it was a strategy to 'divide and conquer' through the creation of ambiguity and mixed messages between the two groups. Participants also raised the need for additional sessions and sessions directly with communities for consultation to be adequate and effective.

The Assembly of First Nations of Quebec and Labrador (AFNQL) called the consultation process 'superficial'. Furthermore, of the later changes made to the draft legislation in coordination with the National Chief, the AFNQL stated that the modification amounted to "nothing more than a shameful cosmetic name change." (AANDC Atlantic Regional Office, 2014)

The government's attempt to host a consultation session in Quebec City for First Nations in Quebec was thwarted when the 40 participants arrived, two Chiefs presented, and then the entire group immediately took its leave. An orchestrated display of power, the Quebec Chiefs were led by Grand Chief Konrad Sioui and Regional Chief Ghislain Picard, the two presenters. (AANDC, 2013g) AANDC's internal documents show that the government had been expecting to present an orientation on the proposed legislation, but were not given the chance.

The Chiefs strongly rejected the consultation process and briefly spoke to their concerns before taking their leave from the session room. The AFNQL advocated a 
nation-to-nation negotiation process instead of a unilateral approach to the creation of legislation. They wholly rejected any top-down, legislation or any federal policy that would interfere with their control of education. The Chiefs argued that the proposed act conflicted with First Nation jurisdiction, and that they would continue to advocate for authentic First Nations control. As many other stakeholders had before them, they requested the government make a formal commitment to an adequate funding regime for on-reserve education. Finally, they accused the government of failing to meet its constitutional duty to consult because of the inappropriate means by which the consultation process had been carried out. (AANDC, 2013g) The AFNQL has since launched a federal court suit to challenge the federal consultation process for its failure to properly consult and accommodate. (Bastien, 2013)

In Manitoba, consultation participants raised similar concerns regarding the inadequacy of consultation, stating the need for "grassroots consultation sessions in communities, especially with parents", and that ample time was required, but not provided, for direct engagement with communities. (AANDC, 2013e) Several of the attendees noted that First Nations should be leading the consultation sessions, and still others took the position of observer, saying they did not want to participate to give legitimacy to the insufficient consultation process. Those that participated in the Thunder Bay consultation also felt that consultation was inadequate. (AANDC, 2013f)

The Honorable Dominic LeBlanc, a Liberal party Member of Parliament from New Brunswick, was critical of the consultation process, writing that 
I voted against Bill C-33...specifically because your government chose to impose this new education policy on First Nations without their consent and approval, all the while withholding the funding which it would have necessitated. I believe that by working with groups such as the Three Nations Education Group, you will have much better success to finding a consensual solution, than working against them. (LeBlanc, 2014)

LeBlanc accused the reform process of dividing communities, although he gives no other context, except to say that AANDC has a responsibility to consult and cooperate with all communities. (LeBlanc, 2014)

The Canadian School Boards Association (CSBA) submitted feedback via the online consultation mechanism, communicating its disdain for the federal consultation process and its desire to work with First Nations to build solutions, as opposed to being a part of the imposition of reform. (Canadian School Boards Association, 2013) The CSBA took the position that, "[t]he Canadian School Boards Association understands and concurs with the need to recognize the importance of local decision-making when it comes to children's education and would support an alternative process that is based on local engagement." (Canadian School Boards Association, 2013) As well, the CSBA found that the Discussion Guide used to spur discussion at consultation sessions, "reveals a 'command and control' approach with a heavy emphasis on standards, structures and accountability..." and "...do[es] not give prominence to the central importance of the child or to the aspirations of First Nation parents and communities for the future of their children as First Nation peoples”. (Canadian School Boards Association, 2013)

An internal briefing document on the CSBA's submission reveals the government's response to their concerns about a lack of authentic consultation: "The Canadian School Boards Association response does not consider opportunities for First 
Nation stakeholders to provide input, in person or through web-based tools and teleconference briefings." (AANDC, 2013c)

Government officials consistently responded to concerns about a lack of adequate consultation by reiterating that legislation would not be drafted until the completion of the eight regional consultation sessions. AANDC also directed those concerned to the online feedback portal on the Department's website, and encouraged interested parties to video or teleconference with AANDC. (AANDC, 2013f) Furthermore, government officials consistently said that First Nations 'input' would be 'taken into consideration' in the drafting of legislation, but never stated that 'input' would be integrated for accommodation. AANDC writes: "The Government of Canada remains committed to sharing what has been heard to date through consultations on a proposed First Nations Education Act; and to continuing to listen to the feedback of First Nations and stakeholders." (Wilkinson \& Leclair, 2013, my italics)

\subsubsection{First Nation Control}

Concerns regarding Indigenous autonomy over education were related to Treaty rights, consultation and accommodation, and the unilateral nature of the reform process. First Nations made requests that a joint approach to reforming education be adopted, rather than the imposition of federal solutions onto Indigenous educational priorities.

In its Response to AANDC-Initiated Consultations on Proposed First Nations Education Legislation, the CSBA called the federal consultation process "unilateral". (Canadian School Boards Association, 2013) The CSBA suggests that the approach to consultations required First Nations to comment on and provide input on proposed 
legislation, the contents of which was already decided by the federal government.

Indeed, this observation astutely corresponds to the federal government's key messaging regarding consultation, outlined above.

Along the same lines, the Union of BC Indian Chiefs put forth a resolution that called for joint drafting of legislation; authentic respect for First Nations control and Treaty rights; recognition of the Indigenous right to language and culture education; respect for diversity and uniqueness among Indigenous nations; and, “...sustained, secure and adequate funding”. (AANDC, 2013b) Appropriately, Indigenous stakeholders in British Columbia were concerned that federal legislation might disrupt their federal and provincial jurisdictional agreements, and that authority over Indigenous schools might be transferred to the province. The federal government responded to these concerns accordingly:

... [L] egislation is not intended to take away from what has been done in $B C$. There is no proposition to have a 'one-size-fits-all legislative approach. Diversity among regions and First Nations is recognized. Further, the legislation would not apply to self-governing First Nations that have implemented their own education laws. There is not intent to undermine Aboriginal rights; nor is there any intent to take control or authority for education away from First Nations. Provinces would not have authority over First Nation schools on reserve. (AANDC, 2013b)

Meanwhile, the Chiefs present in Calgary felt strongly that the federal legislation imposed upon their Treaty rights and suggested that any work toward reform in education be Treaty-based. (AANDC, 2013) The participants to the Manitoba consultation were divided on whether legislation was required to improve the on-reserve school system or not. Some participants felt that education was a Treaty right and could not be legislated; others felt that the implementation of standards at the local level would require federal 
legislation. Manitoba First Nations also felt that “...there is a need to honour current systems that have been developed by First Nations and continue pilot projects that are making a difference". (AANDC, 2013e)

An on-reserve school's direct perspective on the Act was laid out in Elsipogtog First Nation's Recommendations for Improving the First Nations Education Act. (Elsipogtog First Nation School, 2013) The school felt that the act was rather general and needed to "[...] be expanded to contain specific details that make the roles of the schools, education authority and province clear and transparent to all educational staff as well as to ensure administrative accountability." (Elsipogtog First Nation School, 2013)

AFNQL Chief Ghislain Picard argued that Bill C-33 simultaneously strengthens government control while allowing government to escape its responsibility. (AANDC Atlantic Regional Office, 2014) His observations are indicative of the neoliberal imperative of a state that 'governs from afar". (Larner, 2000) Chief Picard also accused the government of denying the existence of underfunding as an issue. (AANDC Atlantic Regional Office, 2014) Regarding the lack of adequate First Nations inclusion in the reform process, he stated:

How can the Minister pretend that this bill will give the First Nations the control of their education, while imposing criteria and the model of School Boards, his bill does not allow us to develop our own criteria and our governance model? (Picard, quoted in AANDC Atlantic Regional Office, 2014)

Later in the process, the Assembly of First Nations Senior Manager of Mi'kmaq called the bill a failure, citing a “... 'complete absence of reciprocity' whereby the Minister will be able to choose to ignore the advice of the future Joint Council, and set funding regulations unilaterally.” (AANDC Atlantic Regional Office, 2014) 
In response to criticisms that it was acting unilaterally, the federal government maintained the following throughout the process:

I would like to assure you that First Nations are involved at multiple stages of the legislative development process. In the initial phase of consultation, the Government provided the Discussion Guide prior to developing legislation in order to facilitate a constructive discussion and seek input on elements that could potentially be included in a First Nations Education Act. [...]

The Government has committed to take into consideration the input received from all stakeholders during this phase of the consultations, including formal submissions and reports by First Nations organizations. This will inform the drafting of legislation. (AANDC, 2013i)

These glimpses into the consultation sessions and feedback received from Indigenous groups and the public, reveal the back and forth between consultation participants and government officials. Most participants to consultation expressed concerns regarding the process itself, while the government often responded with pre-determined media lines in the style of political posturing. The interplay of these stakeholders is crucial to understanding the nature of the Indigenous-state relationship in regard to educational reform.

In the next chapter, I will continue to unpack the federal consultation process, picking the story up after the close of face-to-face consultations, in the summer of 2013. The latter part of Chapter 6 will examine how the whole process of Indigenous education reform was framed by the government as crucial to the economic interest of the country. 


\section{Chapter 6: Reforming Education or Reframing Indigeneity?}

This chapter will detail the consultation process from the May, 2013 close of in-person consultations to the April, 2014 tabling of Bill C-33 in the House of Commons. Section 6.1, Engagement is a Quick Fix?, will describe the community engagement process the government launched in response to concerns about inadequate consultation. Section 6.2, titled The Assembly of First Nations Gets Involved, will examine the role of the Assembly of First Nations in educational reform, and lay bare the juxtaposition of the government and Assembly of First Nations' ideologies related to education. Section 6.3, Historic Agreement or History Repeated?, will relate the final hours of Bill C-33's journey to the House of Commons. Finally, Section 6.4, titled Indigenous Education Reform as Economic Benefit, will explore the government's economic framing of Indigenous education and relate the implications of such a discourse for Indigeneity.

\subsection{Engagement is a Quick Fix?}

In August of 2013, the government announced the launch of a community engagement process, stating the following as their impetus: "First Nations expressed a desire for greater support to meaningfully engage in community dialogue on the legislative proposal for education reform". (Aboriginal Affairs and Northern Development Canada, 2013, my italics) Indigenous educational organizations were offered pre-determined funds to:

1) share and review the Blueprint document with their Board of Directors;

2) draft a plan to engage communities, using the Blueprint as a planning tool to focus discussions;

3) implement the community engagement plans once draft legislation is released; and,

4) provide feedback on the draft bill. (Ibid.)

Importantly, Indigenous groups that accepted the funding for conducting engagement sessions were required to submit a final report of their activities. In the experience of 
Three Nations Education Group Inc., a three-community alliance from New Brunswick, the invitation to participate in the government's community engagement strategy was received July 31, 2013. (TNEGI, 2014) On September 23, 2013, TNEGI was asked to revise their proposal to reflect a reporting deadline of October 15, 2013. AANDC also added a stipulation that government officials be present at all engagement activities.

TNEGI would be harassed numerous times to revise their two-page proposal between August 23, 2013 - and January 17, 2014, even though the funding allocated and the activities proposed were already pre-determined by the government. An excerpt from

TNEGI's final engagement report, below, reveals their frustration with the process:

Not surprisingly, these new directions come as a shock to TNEGI. It responds [to the government] by asking how the deliverables might be completed when the very draft legislation consultations are to be undertaken about has not been released, and how free, prior and informed consultations could possibly take place (and a full report written) within three weeks (especially considering the building intensity of Indigenous resistance to Province of New Brunswick and industry efforts to develop on Crown land without consulting with Elsipogtog First Nation and others). TNEGI also indicates that a requirement to have AANDC at all consultations would likely impact the dynamic of engagement activities, creating a climate of discomfort not conducive to sharing. Over the next few days, AANDC Regional pressures TNEGI to modify its proposal to reflect these changes and firmly denies TNEGI's request for an extension to November 15th, stating that this response comes directly from AANDC headquarters. [The government] affirms that AANDC must be present at all consultations to ensure a "two-way conversation" takes place. AANDC Regional acknowledges that the draft legislation is notably absent, stating that First Nations should now just "roll with the Blueprint" to inform their engagement sessions, with promises of other possibilities to consult on the draft legislation when it is introduced. This was the first time TNEGI had been made aware the draft legislation was delayed and the organization was not only confused, it felt purposely excluded from the very process that was meant to "meaningful consult" with it. (TNEGI, 2014)

This passage illustrates how federal government directives are received and interpreted at the local level. Clearly, TNEGI's experience evidences the dissonance between First Nations and the state regarding concepts of 'meaningful consultation'. 
The draft legislation was released by AANDC on October 22, 2013, seven days past AANDC's stated deadline for engagement reports to be submitted. After intense pressure through several phone calls and e-mails from AANDC Atlantic Regional Office, TNEGI arranged for its three schools to have teleconference calls with AANDC the following week. (TNEGI, 2014) Not only was there inadequate time (three-five business days) for any of the school participants to review the 31-page, onerous document (heavily laden with legal language), but the communities were also in turmoil after RCMP snipers entered a protest camp at Elsipogtog to fulfill an injunction over shale gas development in the province. On November $8^{\text {th }}, 2013$, AANDC regional contacted TNEGI and moved the deadline for submission of the final engagement report to March $31^{\text {st }}, 2014$. Even so, the government continued to harass the group for edits to their two-page engagement proposal through the month of January, six months after TNEGI had been invited to take advantage of the $\$ 15,000$ targeted for them to conduct engagement activities with their three schools. (TNEGI, 2014)

\subsection{The Assembly of First Nations Steps In}

In the interim, the Assembly of First Nations (AFN) created and circulated A framework to achieve success in First Nation education in response to the government's reform process. (Assembly of First Nations, 2014a) The framework stipulated five conditions the AFN felt needed to be addressed before legislation could possibly receive endorsement from the AFN general assembly. The five principles (jurisdiction, funding, language and culture, reciprocal accountability and transparency, and meaningful dialogue) are defined as follows: 
1. Jurisdiction - Respects and recognizes inherent rights and title, Treaty rights, and First Nation Control of First Nation Education jurisdiction. First Nations must retain all options to advance their education and all such agreements must be fully respected, enabled and supported;

2. Funding - Provides a statutory guarantee for funding of First Nations education as a precondition that is sustainable and reflects needs based costs consistent with Canada's obligation;

3. Language and Culture - Enables and supports systems to provide full immersion and grounding of all education in Indigenous languages and cultures;

4. Reciprocal Accountability and Transparency - Develops mechanisms to oversee, evaluate, and for reciprocal accountability and ensure there must not be unilateral federal oversight and authority;

5. Meaningful Dialogue - Ensures a meaningful support process to address these conditions through a commitment to working together through co-development, fully reflective of First Nations rights and jurisdiction. (Assembly of First Nations, 2014a)

National Chief Shawn A-in-chut Atleo elaborated on these conditions in a November 25, 2013, open letter addressed to the Minister of AANDC. ${ }^{29}$ After asserting that the current draft of the proposed legislation was not acceptable to First Nations, he noted that First Nations control over the education of their children must be the fundamental principle upon which an education system is built. He stated that First Nations control "...is at the core of reconciliation and, furthermore, is key to achieving improved outcomes and success for our students." (Atleo, 2013) Atleo stressed the consistent efforts of First Nations to advocate for fundamental transformation of the way Indigenous education is funded, citing as evidence the participation of the Assembly of First Nations in federal pre-budget consultation processes every year. The open letter sought “....meaningful engagement including through commitment to co-development and shared oversight including evaluation". (Ibid.) The National Chief expressed his disinterest for

\footnotetext{
${ }^{29}$ Provided as Appendix A to this thesis.
} 
“...unilateral federal oversight and authority vested in the Canadian bureaucracy”. (Ibid.)

National Chief Atleo's impassioned letter displayed the resolute determination of the Assembly of First Nations:

We seek clear commitment to these conditions and we will be relentless in our advocacy and actions expressing our full support for our children to achieve this change now. We must remove every reason and every excuse to not act - but rather create the proper and rightful environment to act now together for our children today and tomorrow. (Atleo, 2013)

The Minister responded to the letter on December 13, 2013. In response to Chief Atleo's concerns regarding First Nations control, he stated that the government was in agreement that "First Nations must have control over their education" and that the proposed legislation he put forth was "intended to empower those who knew best what their children need - First Nations parents, communities and administrators - to determine what is most affective for their success". (Valcourt, 2013) The Minister further stated that, "we remain ready to consider options to further ensure that this principle is embodied in the legislation". (Ibid.) In response to the concerns Chief Atleo referred to about fundamental changes to the way education is funded, the Minister stated that the draft legislative proposal "would commit the Minister in law to sustainable, stable and predictable funding to students and schools" and that he "look[s] forward to continuing the discussion regarding structures and standards so that we can then determine adequate, stable and predictable funding". (Ibid.) Interestingly, the government never used 'statutory' as a descriptor - statutory funding being the vast difference between reliable, core funding and insecure, inconsistent, project-based funding. Regarding the recognition of language and culture as crucial to Indigenous education systems, the Minister wrote: "[...] if there are ways to improve the proposal with regard to language 
and culture, I welcome the opportunity to discuss your ideas". (Ibid.) In response to National Chief Atleo's concerns about the unilateral authority of the federal bureaucracy, the Minister wrote:

I accept that First Nations schools must be responsible to their communities for the evaluation of student outcomes. Now is the time to sit together and determine how this accountability would best be structured. I would welcome a proposal from the Assembly of First Nations in this regard. (Ibid.)

Considering the rhetoric the government exercised to describe its 'intensive' consultations, and that it consistently stated that First Nations input would be 'considered' in the drafting of legislation, as opposed to adopting from the onset an approach of co-creation, the Minister's invitation 'to discuss' the National Chief's concerns seems patronizing, especially so late in the game, and particularly with the government's ambitious deadline for September 2014 implementation looming. However, between the release of the Minister's open letter and February, 2014, something revolutionary must have happened.

\subsection{Historic Agreement or History Repeated?}

On February 7, 2014, the Prime Minister and the National Chief, together, announced that "an historic agreement" had been reached and that legislation to reform on-reserve education in Canada would soon be tabled in Parliament. (Government of Canada, 2013) At this critical juncture, the bill was renamed to the more palatable, but yet considerably ironic, First Nations Control of First Nations Education. The legislative draft was revised to address the concerns of the AFN, as communicated to the National Chief in the Minister's open letter. To address concerns of unilateral control, the revised proposal 
included the establishment of a joint oversight body of educational professionals.

Government internal media lines state:

The Joint Council of Education Professionals will have a robust oversight role ensuring that ministerial powers are used as a last resort, with the benefit of the Joint Council's expert advice. The Joint Council will lead the five-year review of the legislation and advise the Minister on: the designation of First Nation Education Authorities; how to respond to findings of school inspections; and whether to appoint a temporary administrator in cases where this option might be necessary. (AANDC, 2014)

To address concerns about funding, the revised legislation includes terms related to statutory, core, sustainable funding. However, importantly, the new core funding would not come into play until the legislation is passed and fully implemented. The government describes the newly determined funding regime as follows:

This approach will consolidate the nine existing sources of funding into three sources: core transfers; transition funding; and funding for school infrastructure. The new funding under the core transfers will be implemented through statute, thereby providing a stable and predictable base that enables better planning and resource management.

Transition funding will be used to support new systems and early adopters of new governance models as well as promoting partnerships and encouraging innovation in education practices in the longer term.

The infrastructure funding will be used to support construction and renovations to schools and gain efficiencies in the way they are designed, procured, financed and constructed. (Ibid.)

Interestingly, when compared to the piecemeal approach to funding that exists currently, the core funding stream under the new model would be represented by the amalgamation of all current programs: Instructional Services; Student Support; First Nation government Employee Benefits; Operation and Maintenance and Minor Capital; New Paths (a remnant of the last attempt at educational reform); Special Education; and, the FNSSP. 
The Structural Readiness would become the Enhanced Education Fund for building capacity and innovation, and the Education Infrastructure would remain the same. (AANDC, 2014c)

The government's habit of rebranding existing funding in order to funnel it through a different channel, labelling it "new" funding, is not uncommon. In this instance, the rebranding only becomes problematic if, upon implementation, the amount of funding is not enhanced to reflect a more adequate funding regime. However, the government's rebranding of existing funding as 'historic' and 'new' is evidence of the rhetoric it utilizes in the construction of discourse. Additionally, the government's commitment to increase the efficiency of how schools are "designed, procured, financed and constructed" is indicative of an intrusion of capitalist relations into on-reserve school insfrastructure development.

According to the government's internal public relations messaging, the core stream would include "appropriate funding supports" for language and culture programming. (Ibid.) Few other details are provided, although potential media questions on all sorts of other issues, from government liability, to the AFN's internal dynamics, are internally anticipated (with answers prepared in advance). Consider this: in the past, the government maintained that language and culture is supported through operational and supplementary funding streams (Wilkinson \& Leclair, 2013), when in reality, the underfunding of on-reserve education did not allow for schools to hire enough support staff, let alone invest in curriculum development. As such, this half-hearted commitment to support language and culture is indicative of a government tactic whereby First 
Nations' dissent is silenced and the issue is left unaddressed. The issue of core funding being made available to support language and culture in on-reserve schools is of particular concern because of the strong links between cultural identity and Indigenous well-being.

Following the February 7, 2014 announcement of the government's commitment to collaborate with the AFN to integrate their concerns into a new draft of the proposed legislation, stakeholders in the Atlantic region reacted positively. Chief Morley Googoo, the Assembly of First Nations Regional Chief for Nova Scotia-Newfoundland (and also Chair of the AFN's Chiefs Committee on Education) felt that a new commitment to address First Nations concerns in legislation was the right way forward, and that it would lead to "a new era in First Nations education". (AANDC Atlantic Regional Office, 2014) However, considering his role as Chair of the AFN Chiefs' Committee, political interests could have played a role in the opinion he shared.

The executive director of the Mi'kmaw Kina'matnewey, the alliance of First Nations in Nova Scotia that obtained jurisdiction over education on reserve in 1998, was not willing to be quite as resolute, but did acknowledge that positive improvements were being made. Eleanor Bernard noted that the commitment to work together going forward was a "step in the right direction", but that many Nova Scotian schools would still not adopt the plan, as they felt the new funding would continue to be sufficient. (AANDC Atlantic Regional Office, 2014)

Shortly after the joint announcement that 'historic agreement' had been reached, internal power struggles at the AFN came into the spotlight. In a radical turn of events, 
National Chief Atleo resigned on April $2^{\text {nd }}$ amid controversial accusations that he was too close to the government. (Kraus, 2014) While his supporters felt that his collegial relationship with the federal government was a positive dynamic toward reconciling Indigenous-state relations, Atleo stated that he was tired of being a "lightening rod" for criticism from his opponents. (Ibid.) Of his relationship with the government, he insisted: "[T] he current proposal on education is the latest attempt and a sincere, constructive effort on the part of Prime Minister Stephen Harper to take a step forward". (Ibid.) Atlantic Regional Chief Roger Augustine pronounced his support of Atleo, saying that opponents to Atleo were insincere and just after power. (AANDC Atlantic Regional Office, 2014) In her blog of May 3, 2014, Mi'kmaw lawyer Pam Palmater, the runner-up to Atleo in the 2012 election for National Chief, wrote:

With regards to Prime Minister Harper and National Chief Shawn Atleo's education "deal", this was not made in a good way, nor in the spirit of unity. In fact, the countless secret meetings, lack of information, and surprise announcements are counter to our traditional ways of building consensus and capitalizing on our strengths and differences in unity.

The biggest problem is that no space was ever made for the possibility that there would be no unity on this deal - the deal was made for us without us at the table. The result is wide-spread distrust, anger and reaction - all justified. Now, our leaders are forced to account to their citizens for decisions of which they had no part, causing even further disharmony amongst our Nations. Yet, none of this had to happen. (Palmater, 2014)

National Chief Atleo resigned April 2, 2014. Bill C-33, First Nations Control of First Nations Education, was tabled in the House of Commons April 10, 2014. Considering that First Nations' reports from the government's community engagement strategy were due March 31, 2014 from stakeholders across the country, it is highly unlikely any of the feedback obtained through those sessions were actually considered and integrated into the 
draft. Bill C-33 remained in the House until second reading debate concluded on May 2, 2014 when the vote was deferred. (Government of Canada, 2013) Three days later, the government announced the bill was on hold until the leaderless Assembly of First Nations clarified its position. (Kraus, 2014) Bill C-33 remained on hold until it died with the dissolution of Parliament over a year later on August 2, 2015.

After all of its efforts, the federal government failed to have First Nations education legislation implemented for the start of the 2014 school year. A commitment tied to the federal budget, Economic Action Plan 2012, the promised investments remained uncertain as the reform process stalled. Considering the government's inclusion of Indigenous education reform as part of Canada's economic plan, the next section will explore the state's discursive framing of Indigenous education as national economic benefit.

\subsection{Framing Indigenous Education Reform as Economic Benefit}

This thesis has proposed that the neoliberalization of Indigenous education effectively distances the government from its constitutional obligations through the enhancement of Indigenous control. Furthermore, the state frames Indigenous education reform as key to the economic interests of all Canadians, in an effort to elicit support for reform from the general public, political and corporate interests, and Indigenous peoples and communities. This 'discourse of restructuring' will be explored in the following section through a critical examination of government communications briefings and media releases. 
The government's overarching goal for the reform of First Nations education onreserve, is not First Nations sovereignty, but:

... [T] o provide First Naton students with quality education that will strengthen First Nations and a strong Canadian society, and will afford First Nations the opportunity to acquire the skills needed to enter the labour market and be full participants in the Canadian economy. (Wilkinson \& Leclair, 2013)

Examined critically, this framing invisiblizes Indigenous societies and forms of economic production by relating solely to the broader, mainstream 'Canadian' society and economy. Further, the education of Indigenous students is equated to their participation in the labour market (and thus Canadian society), as opposed to contributing to the futures of their own communities. First Nations are represented as being weak and in need of strengthening, without any regard for the contribution legacies of colonialism and the structural impediments of state-sponsored education systems have had on First Nations well-being. The use of the word 'full' seems to imply that Indigenous peoples can be considered less than whole until they integrate to the Canadian economy.

Similarly, the passage shows that First Nations are an important labour pool that must be prepared now to be tapped into in the future:

The proposed First Nation Education Act would help ensure that First Nations youth, who represent the youngest, fastest growing segment of the population in Canada, get a quality education which will allow them to pursue a college or university degrees, get skills training, or secure a job. (Wilkinson \& Leclair, 2013)

Legislation over First Nations education is framed as being the means through which Indigenous youth will accomplish their lifelong learning goals. Although this in itself is not a bad thing, the use of this framing makes invisible the dissonance regarding First 
Nations' opinions on legislation, and the struggle for Indigenous nations to maintain control over their education.

The government links Indigenous youth to the economy even more explicitly in the following statement: "With more than 400,000 Aboriginal youth projected to be ready to enter the labour market over the next 15 years, helping Aboriginal youth to succeed in school and graduate will be critical to increasing their participation in Canada's economy." (AANDC, 2014)

Comparably, the government relates its investment in post-secondary education to ensuring that students "have access to an education that encourages them to stay in school, graduate, and get the skills they need to enter the labour market" (Wilkinson \& Leclair, 2013) Indigenous students are framed as potential labour, in need of investment now for their future use in the capitalist system. For instance:

Meeting the needs of today's labour market requires an approach that helps more First Nation and Inuit students to access and complete post-secondary education, and participate in the labour market through a range of active measures and skills development opportunities. (Wilkinson \& Leclair, 2013)

Again, by equating the education of Indigenous students with their entry into the labour market, the government ignores the colonial assault on their Indigeneity. However, one key passage does touch on community well-being:

A stable and strong system for First Nation education needs to help enable students to graduate, pursue further education and to prosper in their communities and in the broader economy and society. (AANDC, 2013h)

This framing of Indigenous students as sources of future labour is juxtaposed against the Assembly of First Nations' perspective on the purposes of education: 
We want education to give our children the knowledge to understand and be proud of themselves and the knowledge to understand the world around them. We believe in education: as a preparation for total living as a means of free choice of where to live and work; and as a means of enabling us to participate fully in our own social, economic, political and education advancement. (National Indian Brotherhood, 1972)

This perspective on education compares starkly to the government's stance that:

"Improving First Nations education is about more than funding, it requires transformative reform so First Nations youth can reach their full potential and become full participants in the Canadian economy." (AANDC, 2014b) The government framing purports that Indigenous students are whole only when they enter the Canadian economy, whereas the Assembly of First Nations, in the statement italicized, above, values education for the confidence and knowledge it affords students to make the best decisions for themselves and their communities, whatever those decisions may be.

The government links on-reserve educational reform as beneficial to the nation: "The First Nations Control of First Nations Education Act is good for First Nations, and it is good for Canada." (AANDC, 2014b) Similarly, the legislation represents "....an investment in our future prosperity". (AANDC, 2014) Indeed, the reform of First Nations education will result in better outcomes for First Nation students, "opening the door to more opportunities and jobs”. (AANDC, 2012) Framing Indigenous education in this way isolates the education of today's Indigenous students from the government's historical use of education as a tool of aggressive assimilation. Ignoring the history of Indigenous-state relations in education promotes the advancement of a Whitened history and closes the spaces for decolonial discussion regarding the colonial legacies stratifying today's provincial and First Nation-operated school systems. 
This discourse of restructuring is used by the state to connect Indigenous education to Canadian prosperity as opposed to the benefit of Indigenous nations. Notably, the state links better educational outcomes for Indigenous students to jobs, as opposed to social, cultural, economic and political well-being of Indigenous nations. Through this discursive framing, Indigenous claims to sovereignty are invisiblized and Indigenous peoples are Whitened, recognized only as participants in Canadian market society.

Ironically, the National Chief of the Assembly of First Nations views the legislation of Indigenous education in a different light:

The approach we are announcing today embraces the essential and connected components of First Nations control of First Nations education founded on our rights, jurisdiction and Treaties; and secure, sustainable and fair funding that supports our students' success and strengthens their languages and cultures. First Nations control of First Nations education as envisioned by our leaders and educators for many decades will enable and support the systems and standards necessary to ensure our children are nurtured to achieve their goals through full access to quality education. (Assembly of First Nations, 2014)

The Assembly of First Nations views education as a means of strengthening Indigenous rights and supporting Indigenous systems. This ideological divide between the government and Indigenous nations is a chasm into which Indigenous students have fallen before, lost in jurisdictional ambiguity, somewhere near Indigenous autonomy, but not far enough from state paternalism. With the rejection of Bill C-33 by the Assembly of First Nations and the resignation of National Chief Atleo, the future impact of this particular legislative proposal remains unknown. 
This concludes the presentation of primary source data for this research. Final arguments in Chapter 7 will link to the research questions and theoretical framework, and limitations and contributions will also be discussed. 


\section{Chapter 7: Theoretical Explorations and Further Reflections}

The textual and discursive analysis conducted in Chapters 5 and 6 reveal the multifaceted perspectives of First Nations and the government related to Indigenous educational reform, and in particular, contestation over what denotes adequate consultation with Indigenous peoples on issues affecting inherent and Treaty rights. This chapter will link the critical analysis of Chapters 5 and 6 to the research questions laid out in Chapter 1 and the theoretical framework conceptualized in Chapter 3. Section 7.1, Unpacking the Consultation Process, will explore the research findings related to the consultation process. Section 7.2, Linking Practice to Theory-Consultation, will explore how these findings relate to the broad conceptual framework proposed in Chapter

3. Section 7.3, titled Delineating Discursive Findings, will briefly examine the discursive framing that dominated the reform process, while section 7.4, Limitations and Future Lines of Inquiry, will relate the limitations of this research and suggest some possibilities for future work. Section 7.5, Dissemination of Findings, will identify opportunities to share the findings herein, and finally, Section 7.6, titled Personal Reflections, will wrap up this paper on an intimate note.

\subsection{Unpacking the Consultation Process}

Recall the research questions regarding the consultation process related to Indigenous educational reform:

1. How is Indigenous sovereignty suppressed through government methods of public and Indigenous consultation that reproduce settler-colonial power relations and invisiblize Indigenous difference?

2. How did the government respond to feedback from public and Indigenous consultations regarding on-reserve education reform and the federal legislation tabled as Bill C-33, First Nations Control of First Nations Education Act? 
The majority of feedback expressed by Indigenous and public participants characterized the government's consultation process as inadequate and failing to meet the Crown's duty to consult (and where applicable, accommodate) Indigenous peoples. As Ballamingie suggests in her essay regarding the democratization of public consultation processes, there are several key considerations policy makers should take to advance the continuum of consultation toward the inclusion of historically marginalized voices, such as those of Indigenous stakeholders. (Ballamingie, 2009) Following from Ballamingie's recommendations, analysing who did the consulting, who was consulted, what was asked, and how it was asked, is a useful way for interpreting the outcomes of consultation and how the consultation process might be improved upon in the future. For the remainder of this section, each of those questions will be explored in turn as a means of outlining the findings of this thesis.

\subsubsection{Who should do the consulting?}

The biases of the person(s) facilitating the consultation process can greatly impact the outcomes of public engagement. Ballamingie suggests that the consultative body(ies) be representative of the population being consulted and transparent about their backgrounds and any potential biases. The consultative body should be have the authority and critical capacity to conduct effective engagement activities and to raise questions should there be a gap between the outcomes of consultation and the interpretation and implementation of recommendations by the public institution. As well, an oversight mechanism should be in place to ensure the terms of reference of the consultation are carried out. (Ballamingie, 2009, p. 11) 
The federal consultation process regarding Indigenous educational reform did not adhere to these principles. The process was unilaterally determined by the Department of Aboriginal Affairs and Northern Development Canada. The very same government officials that manage the Elementary and Secondary Education Program on a daily basis, corresponding with Indigenous schools, communities, and organizations regarding proposal writing, funding applications, reporting requirements, the nominal roll, and more, were the very officials coordinating and facilitating the in-person consultations sessions and video and audio teleconferences with Indigenous stakeholders. The bias that this brings to the process is significant. In fact, internal government summaries of each consultation session show that government officials rebutted Indigenous concerns/questions consistently using internally determined responses.

Furthermore, First Nations protested that the government officials hosting consultation sessions had no authority to broaden the conversation outside the realm of what had been pre-determined by the government's discussion guide, and that First Nations leadership expected to meet with their counterparts in government (such as executive level officers like Ministers) instead of with mid-level officials with whom they work with on a regular basis for program implementation. Consultations were not led by an independent body meant to engage with stakeholders and report back to government, and Indigenous peoples were not represented among those doing the consulting. Instead, the format, conversation, and dynamic of consultations was shaped by the interests of the very administrative structure educational reform was intended to transform. In other words, the government was consulting with First Nations because there was a legal precedent to do so, but it was not interested in ensuring a deliberative, democratic 
process. (Ballamingie, 2009) There was an inherent bias to government interests throughout the so-called 'consultation'.

\subsubsection{Who should be consulted?}

It is not only crucial to ensure the plurality of the consultative body, but also to consider carefully what part of the citizenry needs to be consulted. For instance, certain stakeholders hold privilege over others in some cases, such as where Indigenous inherent or Treaty rights trigger the Crown's duty to consult. The proximity of different groups to the issue, both tangibly, discursively or geographically, will affect the depth of their engagement. Measuring the level of awareness of the general public can be a useful tool to judge whether consultation efforts are effectively reaching the public, and specific attention should be taken to ensure the inclusiveness of the process through the recognition and invitation of dissenting or silenced voices. (Ballamingie, 2009)

One criticism of the on-reserve educational reform process was the government's provision of an online mechanism to enable the participation of the general public in the reform process. Indigenous resistance to the involvement of the general public was substantial because education is considered by many to be a protected Treaty and/or inherent right. Many Indigenous stakeholders sought a nation-to-nation or Treaty-based process of consultation regarding Indigenous education, which would automatically privilege Indigenous perspectives, limiting the involvement of the broader public.

In terms of the inclusivity of who was consulted, feedback from stakeholders indicates the process inadequately enabled the participation of local Indigenous peoples, such as parents, families, and community members. In spite of the government's rhetoric that the proposed legislation put forth was "intended to empower those who knew best 
what their children need - First Nations parents, communities and administrators - to determine what is most affective for their success" (Valcourt, 2013), only eight face-toface consultation sessions were held, all in urban areas, and none in Indigenous communities. The government's attempt to engage communities at the local level through the hasty, ill-informed Community Engagement Strategy in the fall of 2013 proved an insufficient effort to respond to Indigenous concerns about a lack of grassroots involvement. Additionally, the format of consultation sessions interfered with the transparency of the process when it isolated First Nations leadership from First Nations educators. Segregating community representatives in this way can lead to mixed messages and antagonistic interpretations of what was said, creating internal dissonance among participant groups. This strategy may have been used to separate the First Nations leadership, who would be voting on the reform proposal at the AFN, from the First Nations educators, who, because of their profession, would generally have more knowledge (and therefore more questions and concerns) about the implications for reform at the grassroots level.

In the end, the AANDC Minister and the Assembly of First Nations (AFN) National Chief negotiated behind closed doors to integrate terms to address Indigenous concerns into the legislative draft. Considering that there are over 600 First Nations governments in Canada with a myriad of perspectives on the need for legislation, Indigenous rights related to education, and what determines adequate consultation with the government, the announcement of a historic agreement between First Nations and the federal government on February 7, 2014, was not well-received by many First Nations leadership. Indeed, in terms of who was consulted, the government and the AFN failed to 
consider the fact that First Nation governments did not feel the AFN was an appropriate body to represent their varied and unique educational interests. Given this, the AFN is also not an appropriate mechanism to attempt to negotiate on behalf of local perspectives and should not have been substituted for authentic engagement with Indigenous peoples. Most First Nations participants sought direct engagement with the government on a nation-to-nation basis versus a negotiation between the leaders of high-level, bureaucratic institutions.

\subsubsection{What should they be asked?}

The breadth of the consultation discussion should be carefully managed in order to ensure the inclusion of all relevant perspectives and the coverage of all potential outcomes. Ballamingie suggests that a social justice lens be adopted to ascertain the critical issues that should be addressed through consultation. To ensure democratic conversation, terms of reference should be set to keep consultation sessions on track, but the limits of discussion should not be dictated. Otherwise, the consultation runs the risk of being exclusionary to innovative ideas, subaltern perspectives, and critical voices.

(Ballamingie, 2009)

From the beginning, the conversation regarding Indigenous educational reform was undemocratically constrained by the government. The reform process and consultation strategy were delineated without First Nations input, while Economic Action Plan 2012 committed to implementing federal legislation over on-reserve education before the government directly consulted with Indigenous peoples on the issue. ${ }^{30}$ By

\footnotetext{
${ }^{30}$ The National Panel, a joint effort by the federal government and the AFN, did include federal legislation as a recommendation in its final report, but it advocated a joint-approach to reform. The work of the National Panel is not considered to be a part of the Crown's duty to consult on educational reform.
} 
narrowing the confines of discussion the state silenced discourses related to Indigenous sovereignty, even though Indigenous requests for a Treaty-based or nation-to-nation negotiation process were brought up consistently throughout consultation (and rebutted by government officials just as consistently).

The Indigenous preference for a joint approach to reform was further invisiblized by the state's use of discourse that rhetorically positioned the reform process as one of First Nations control (evidenced strongly by the title of Bill C-33: First Nations Control of First Nations Education). State efforts to reduce the conversation to legislation, remediating the space to discuss how Indigenous well-being could be advanced through authentic autonomy over education, are indicative of the settler-colonial logic of elimination/assimilation.

\subsubsection{How should they be consulted?}

The logistics of how consultation is planned and carried out has a significant impact on the inclusionary participation of the public and the consultation outcomes. Several methods for participating should be made available, such as through in-person sessions, online mechanisms, over the phone, and in print. Special consideration should be given to how persons with disabilities, persons that speak other languages, or persons without access to telecommunications might be properly engaged. Ample time and space must be given for the conversation to run its course, and in-person sessions should give consideration to access, meaning that sessions should be situated in various urban and rural locations. Financial and physical accommodation should be provided when required to ensure the inclusion of marginalized voices, including transportation, translation, child-care, and scheduling of sessions. Finally, special care should be taken to 
ensure that the invitation for consultation adequately reaches the public. Not taking these issues of accessibility and equitable participation into account could lead to the exclusion of some voices or a biased outcome. (Ballamingie, 2009)

The Indigenous educational reform consultation process featured just eight inperson consultation sessions in urban centres across Canada. Considering the remoteness of some of the 600 First Nations that would be impacted by on-reserve educational reform, this severely restrained the participation of Indigenous peoples in the reform process. Indeed, just 440 people participated in the eight urban consultation sessions across Canada, with 200 people utilizing the option to video/audio conference with AANDC after in-person consultations came to an end. (Wilkinson \& Leclair, 2013) Given that there are approximately 113,000 on-reserve students, these numbers do not reflect the adequate inclusion of Indigenous families and community stakeholders in the consultation process.

Most consultation participants indicated that they did not feel adequate time was provided for effective and authentic engagement with the reform proposal, and that they required more information. The discussion document was the only reference available to participants to inform the in-person consultations, as no further in-person sessions were conducted once the actual draft legislation was released and no terms of reference were shared. Although several methods of submitting feedback to reform were provided, the telecommunications infrastructure in rural Canada is incomplete and not accessible to all people and communities.

Clearly, the consultation process for Indigenous educational reform did not meet basic principles of democratic engagement. Ultimately, even if the final draft legislation 
may have addressed some of the concerns some First Nations carried in regard to funding, language and culture, and joint oversight of implementation and enforcement of legislation, the lack of a reform process that adequately included Indigenous peoples in the creation of solutions resulted in the abject failure of the government-led reform process.

\subsection{Linking Practice to Theory - Consultation}

Why would the government, after the state's long history of imposing educational systems on Indigenous peoples, and in light of its rhetorical support of First Nations control, conduct the reform of on-reserve education in this way? This thesis theorizes that the settler-colonial state maintains paternalistic control over Indigenous peoples through education as a means of suppressing Indigenous sovereignty. According to Patrick Wolfe, the settler-colonial state's logic pertaining to Indigenous peoples is inherently eliminatory due to state goals to subsume all territory for the expansion of national capitalist objectives. (Wolfe, 2006) In other words, the state suppresses Indigenous sovereignty through paternalistic control of Indigenous education to further the oppression of Indigenous rights and culture. The assimilation of Indigenous peoples through state-controlled education erases Indigenous inherent and treaty rights to enable state access to Indigenous territories for capitalist expansion. This long-term strategy is indicative of the dispossession of Indigenous peoples through education for the extension of capitalist relations into Indigenous social relations.

\subsection{Delineating Discursive Findings}

Now, recall the research questions related to the discursive construction of Indigenous education as beneficial for national economic interest: 
1. How does discursive rhetoric shaped by the government construct the education of Indigenous peoples as good economic policy? How does this discursive framing contribute to the commodification of Indigenous peoples and the invisiblization of historical, settler-colonial power relations?

2. How were discursive constructions of Indigenous peoples circulated by the government during the period of consultations regarding on-reserve education reform in Canada? Which discursive frames dominated, and which were silenced, and to what effect?

The government's overarching messages related to Indigenous education reform directly link the education of Indigenous peoples to the national economic interest. Discourse related to education as emancipatory or as necessary for community development is absent, invisiblizing the connection between First Nations control over education and Indigenous sovereignty. The well-being of First Nations communities is not mentioned, but instead Indigenous students are framed as necessary to the advancement of Canadian economic society. According to a recent analysis of the government's attempt to reform the structure of the funding regime for post-secondary Indigenous education, this framing is common: "The language used, particularly the focus on freedom, the placement of Indian cultures within the umbrella of Canadian culture and sovereignty, and the focus on economic self-realization are consistent in the Free to Learn strategy." (Godlewska, Schaefli, \& Chaput, 2013, p. 275)

The government's framing of successful Indigenous students as those that graduate and enter the labour market, filling an anticipated void in the labour force, ensures the domination of economic imperatives in discourse and the silencing of Indigenous social, cultural, spiritual, economic and political well-being. (Godlewska, Schaefli, \& Chaput, 2013) First Nations' controlled education as a means to strengthen 
the cultural identities of on-reserve students and therefore their connection to their inherent and Treaty rights is absent from the government's discursive messaging.

The framing of Indigenous education is underpinned by the settler-colonial logic of commodification/subjectification, which aims for the integration of Indigenous peoples to Canadian free-market society. In the long term, the assimilation of Indigenous peoples into mainstream society has the effect of dispossessing them of their unique cultural identities and their inherent Indigenous rights through processes of commodifying their labour and eventually, their land.

\subsection{Limitations and Future Lines of Inquiry}

This thesis presented a wealth of information toward a political economy of Indigenousstate relations in the area of on-reserve education. The topic is complex and due to time and space constraints, this research was limited in what could be explored within these pages. Had the scope of this thesis been more constrained, the content could likely have focused on one or more of the significant issues touched upon, rather than giving a broad overview of many areas (each worthy of more in-depth research). Moreover, the research could be further improved by the integration of the work of other scholars throughout, linking the evidence herein for comparison with other studies. However, it was not the intention of this work to be comprehensive in nature, nor to be exhaustively situated within scholarship; instead, the objective of this thesis was to provide evidence toward a political economy of Indigenous-state relations in the policy area of Indigenous education.

Certainly, this research could be greatly enhanced with a more in-depth examination of the power differentials between the various parties to the relationship, as 
well as a broader analysis of the variant perspectives on Indigenous sovereignty, autonomy and self-determination. A potential topic of future study is an examination of the factors that affect Indigenous perspectives related to finding educational solutions for recognition within Canada's institutional network, versus denouncing current systems in pursuit of more radical, sovereign solutions.

This research could be strengthened by a more robust analysis of the way discursive messages shaped public and Indigenous perceptions related to educational reform and concepts of consultation, First Nations control, and Indigenous education as emancipatory or as economic benefit. Included in such an analysis should be the discursive messages utilized by First Nations in their public communications regarding Indigenous education. Further, these concepts and more may have come out had in-depth interviews or focus groups been harnessed to collect primary data, the absence of which constrained the extent of these research findings.

In the future, it would be worth exploring the difference between relativism and relationality, and further practicing decolonial methods. Although this research covered a broad base of history upon which to enable a political economy, it mainly focused on policy development and appropriate methods of consultation. Therefore, the findings could be improved by integrating the wealth of research conducted on the issue of consultation by other scholars across various disciplines.

In the future, there are several lines of inquiry leading off from this baseline research. There is opportunity to explore the perspectives of Indigenous parents regarding the quality of education in the provincial and First Nation government operated school systems, and to seek parental input on reform solutions. The Urban 
Aboriginal Knowledge Network funds projects related to urban Indigenous populations and funding may be granted for a comparative analysis of urban versus rural Indigenous community perspectives related to education as well.

Finally, a limitation of this research as well as an opportunity for future inquiry is how theory related to Indigenous issues can better inform policy development, and how the lessons learned from the current failure to reach a consensus on reform can be used to inform future public consultation with Indigenous peoples.

\subsection{Dissemination of Findings}

There are a number of opportunities for the dissemination of the work herein. The formal dissemination of this research in its current form will take place through the thesis defense process and the publication and cataloguing of this work by Carleton University, thereby making it accessible via library search functions. Chapter 3, Theorizing Indigenous-State Relations in Contemporary Canada, will be edited for application to a journal of political economy (e.g., Studies in Political Economy). Chapter 4, Historical Development of Indigenous Education Policy in Canada, will be offered as a resource to inform the creation of Indigenous-focused curriculum modules for New Brunswick public schools. This will be accomplished through my professional partnerships with Three Nations Education Group Inc. (TNEGI) and the New Brunswick Department of Education and Early Childhood Development. TNEGI has launched a Treaty education steering committee to inform the ministry's creation of curricular modules on Indigenous issues for integration into the provincial school curriculum, kindergarten to grade 9. Both partners have relayed their interest in this critical research as a resource for curriculum development, especially at the higher grade levels. The New Brunswick grade 10 Native 
Studies elective course is also being revised in 2015-16 and could feature content inspired by this research.

Chapter 5, Analyzing State-Sponsored Reform of Indigenous Education, will be enhanced through the integration of other scholars' work regarding trends in Indigenousstate consultation and submitted to a policy journal for consideration. Chapter 6 , Reforming Education or Reframing Indigeneity?, will be strengthened through the inclusion of a more in-depth discourse analysis as mentioned above and submitted to an appropriate academic journal.

There are several other lay and policy-oriented possibilities for the dissemination

of this work as well. A synopsis of findings will be submitted to the Canadian Centre for Policy Alternatives for consideration for its periodical The Monitor, as well as to the AFN in response to its request for proposals to improve public awareness of Indigenous education reform. Additionally, the findings herein will be shared with the Indigenous Peoples Solidarity Movement of Ottawa (IPSMO) and the Ottawa Chapter of the Council of Canadians for use in social justice campaigning and building solidarity amongst Indigenous and non-Indigenous activists.

\subsection{Personal Reflections}

Engaging with the research process through this thesis was an immensely beneficial personal experience. I thoroughly enjoyed every minute of research and writing, although I sincerely regretted the time constraints I placed myself under. Additional time would have enabled me to reflect on my writing and rewrite where necessary to make stronger links across chapters. 
I am incredibly grateful for the support of my thesis supervisor Dr. Patricia Ballamingie, and for the patience and advice of my second reader, Dr. Frances Abele. Without either of them I would not have achieved this work, and worse, I would have lost out on this rewarding opportunity for personal development. I am also appreciative of the defense process, not only for the occasion to converse with other scholars regarding the value of this work, but also for the opportunity to make the acquaintance of my external reader, Simon Brascoupé, an ally whom I greatly look forward to working with in the future. 


\section{Appendix A: Assembly of First Nations open letter to the Minister of Aboriginal Affairs and Northern Development Canada}

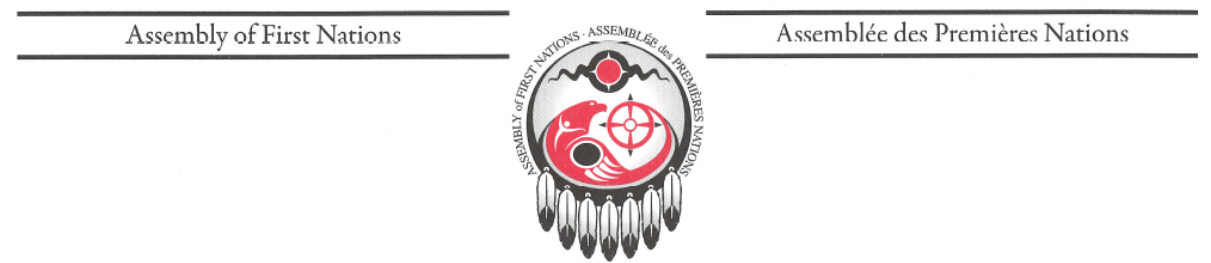

OPEN LETTER to MINISTER OF ABORIGINAL AFFAIRS AND NORTHERN DEVELOPMENT CANADA

November 25, 2013

"There is no place in Canada for the attitudes that inspired the Indian Residential Schools system to ever prevail again. In moving toward healing, reconciliation and resolution of the sad legacy of Indian residential schools... (this) agreement gives us a new beginning and an opportunity to move forward together in partnership." Statement of Apology, Prime Minister Stephen Harper, June 11, 2008

The education of our children is a fundamental and sacred responsibility, and both a right and a duty of our Nations. The residential schools era is a deep scar on the national soul of this country. Every day, our families bear the trauma of this past. Honouring this reality, respecting our rights as Nations and as peoples demands clear actions to achieve reconciliation. First Nations are resolute and determined to resume our responsibility fully to First Nation education. While our ways, our rights and our responsibilities were pushed aside by the federal government in the residential schools era, we have been fighting back ever since to take back this responsibility. Today, we are acting to achieve this better day for our children now. We have welcomed the support, encouragement and agreement of hundreds of thousands of Canadians and Parliamentarians, including the Government's, to take action on First Nations education, in full partnership with First Nations.

On October $22^{\text {nd }}, 2013$ - you sent a proposal to all First Nations: "Working Together for First Nation Students: a Proposal for a Bill on First Nation Education”. On October $23^{\text {rd }}$, the Assembly of First Nations issued a statement reiterating the clear priorities of First Nations based on decades of resolutions, hard work and the initiative of First Nation educators, leaders and families. These include the central principle of First Nation control and the absolute need for a funding guarantee for First Nation children to learn in a safe, secure environment nurtured within their languages and cultures. On November $4^{\text {th }}$, I issued a Special Bulletin to all First Nations affirming our principles and our path forward grounded in our rights and our responsibilities and affirming that as Nations we will stand firm but we will not stand still. We encouraged dialogue and analysis to advance our position because we believe our children cannot, should not and must not wait for a better future. 
Since this time, from coast to coast to coast, our Nations have engaged resolutely in this dialogue and this effort, including at recent Assemblies in British Columbia, Alberta, parts of Ontario, Quebec and the east, and this week at our National Youth Summit where hundreds of young people brought their voices forward determined to achieve a better future. While this discussion continues, the outcome and the message is very clear.

The current Federal Proposal for a Bill for First Nation Education is not acceptable to First Nations. We must work together on a mutual plan that fully respects and reflects partnership, that is consistent with Treaty relationships, and the United Nations Declaration on the Rights of Indigenous Peoples and re-affirmed in countless studies and recommendations.

While our Nations are diverse, thanks to the efforts of our Elders and leaders that have gone before and the countless educators within our Nations that continue to drive this effort forward as first articulated in our policy statement in 1972 - Indian control of Indian education - there is a remarkable degree of consensus, shared values and common ground that must be fully addressed to move forward together. These elements now form clear conditions for success on this critical matter for First Nations and for Canada.

1. First Nation control and respecting inherent and Treaty rights: First Nation control of the education of our children must be the overriding, paramount principle of all our work. It is at the core of reconciliation and, furthermore, is key to achieving improved outcomes and success for our students. First Nations must retain all options to advance their education through Treaty implementation, self-government, partnerships or other agreements, and all such agreements must be fully respected, enabled and supported by the federal government within a framework that honours and respects our rights, affirms federal fiduciary obligations, supports and enables First Nation control and ensures accountability to our families first and foremost. In doing so, First Nations will uphold our duty to ensure access to quality education that achieves strengthened outcomes and results.

2. Funding: As set out and mandated by all First Nations in resolution in 2010 - there must be a full statutory guarantee for funding for education for our children. This is a fundamental matter and requirement of reconciliation. For over a decade, First Nations have engaged in the pre-budget consultation process and every year we have taken forward this need for fundamental transformation - for stable, sustainable and needsbased funding. The Auditor General of Canada clearly stated that current funding practices are completely inappropriate and are failing our children and Canada. We are today tabling a clear and detailed statement of funding requirements to Minister Flaherty. A clear statutory commitment must be advanced and must be reflected in the upcoming Federal Budget 2014.

55 Metcalfe Strect, Suitc 1600, Ottawa, Ontario K1P 6L.5 Telephone: (613) 241-6789 Fax: (613) 241-5808 http://www.afn.ca 55, rue Metcalfe, Suite 1600, Ottawa (Ontario) KIP 6L5 Teléphone: (613) 241-6789 Teléćcopieur: (613) 241-5808 htetp://www.afn.ca Head Office/Siège Social Thenc: (613) 932-0410 Fax: (613) 932-0415 Suite no 5-167, chemin Akwesasne International, Akwesasne (Ontario) K6H 5R7 Teléphone: (613) 932-0410 Télécopieur : (613) 932-0415 
3. Languages and Culture: The interim report of the Truth and Reconciliation Commission notes that as survivors move forward in their healing, they bring clarity and focus to what must happen now. First Nations children must now be nurtured in an environment that affirms their dignity, rights and their identity, including their languages and cultures. First Nations education systems must be enabled, supported and funded in a way that ensures they can design programming that achieves this imperative. Moreover, as a country, and as part of reconciliation, Canada must recognize the importance of First Nations languages and cultures as foundational to this land.

4. Oversight: Achieving the elements described here means that there must not be and cannot be unilateral federal oversight and authority vested in the Canadian bureaucracy. First Nations children deserve fully accountable and successful systems that achieve clear outcomes. The oversight required and remedies to achieve this must be jointly determined and fully respect First Nation rights and responsibilities.

5. Ongoing process of meaningful engagement: To address these conditions, we must ensure meaningful engagement including through commitment to co-development and shared oversight including evaluation.

These are the conditions required now - a mutual plan to advance First Nation education respecting our rights and advancing our responsibilities as well as those of the federal government to this generation of First Nation children. First Nation leadership will be gathering in Ottawa December $10-12^{\text {th }}, 2013$. We seek clear commitment to these conditions and we will be relentless in our advocacy and actions expressing our full support for our children to achieve this change now. We must remove every reason and every excuse to not act - but rather create the proper and rightful environment to act now together for our children today and tomorrow.

We were partners in the past and we can be partners again but First Nations will never compromise on fundamental principles, our rights, our responsibilities and the well-being of our children. In the spirit of the statement of Apology, I, together with First Nations leaders invite you to stand with us - in affirming for all Canadians a solemn commitment to reconciliation and to a path forward that never again will our children be victimized in the name of education, never again will our dignity, languages and cultures be denied and desecrated. Instead, we will rise anew in this new day that was the promise of the Apology, in partnership and pledge our dedication, together, to ensure these conditions are addressed, that we chart a path forward of partnership and respect and that we immediately seize this moment and this opportunity to achieve the change needed for our children - change that is essential for reconciliation and change that is essential for Canada.

Respectfully,

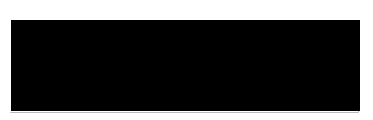

Shawn A-in-chut Atleo

National Chief

55 Metcalfe Street, Suite 1600, Ottawa, Ontario K1P 6L5 Telephone: (613) 241-6789 Fax: (613) 241-5808 htep://www.afn.ca

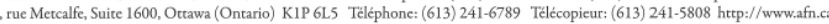
Head Office/Sicge Social

Unit 5-167, Akwesasne International Rd., Akwesasne, Ontario K6H 5R7 Telephone: (613) 932-0410 Fax: (613) 932-0415 Suite no 5-167, chemin Akwesasne International, Akwesasne (Ontario) K6H 5R7 Teléphone: (613) 932-0410 Telecopieur : (613) 932-0415 


\section{Bibliography}

AANDC. (2011, December 1). Frequently Asked Questions - Funding Approaches. Retrieved from Aboriginal Affairs and Northern Development Canada: http://www.aadnc-aandc.gc.ca/eng/1322748384053/1322748516807

. (2012, December 11). Government of Canada Launches Consultations for Development of First Nations Education Act. Government of Canada, New Releases.

. (2012a, June). Summative Evaluation of the Elementary/Secondary Education Program on Reserve. Retrieved from Aboriginal Affairs and Northern Development Canada: http://www.aadncaandc.gc.ca/eng/1365183942467/1365184080356

. (2013). Alberta Consultation Session on a Legislative Approach to First

Nations Elementary and Secondary Education: Box Information for Minister. Ottawa: Aboriginal Affairs and Northern Development Canada.

. (2013a). Approval of Additional Costs for the Kenora Face-to-Face

Consultation Session Related to a First Nation Education Act: Decision by

Minister. Ottawa: Aboriginal Affairs and Northern Development Canada.

. (2013b). British Columbia Consultation Session on a Legislative Approach to

First Nations Elementary and Secondary Education: Box Information for

Minister. Ottawa: Aboriginal Affairs and Northern Development Canada.

. (2013c). Canadian School Boards Association Reponse to First Nation

Education Act Discussion Guide: Information for Deputy Minister. Ottawa:

Aboriginal Affairs and Northern Development Canada.

. (2013d). Kenora Consultation Session on a Legislative Approach to First

Nations Elementary and Secondary Education: Box Information for Minister.

Kenora: Aboriginal Affairs and Northern Development Canada.

. (2013e). Manitoba Consultation Session on a Legislative Approach to First

Nations Elementary and Secondary Education. Ottawa: Aboriginal Affairs and Northern Development Canada.

. (2013f). Ontario Consultation Session on a Legislative Approach to First

Nations Elementary and Secondary Education: Box Information for Minister.

Ottawa: Aboriginal Affairs and Northern Development Canada.

. (2013g). Quebec Consultation Session on a Legislative Approach to First

Nations Elementary and Secondary Education: Box Information for Minister.

Ottawa: Aboriginal Affairs and Northern Development Canada. 
. (2013h). Questions and Answers (For Internal Use Only). Ottawa: Aboriginal Affairs and Northern Development Canada.

. (2013i). Response to the British Columbia First Nations Education Steering Committee/First Nations Schools Associations: Box Information for Minister.

Ottawa: Aboriginal Affairs and Northern Development Canada.

. (2013j, December 17). Transfer Payments. Retrieved from Aboriginal Affairs and Northern Development Canada: http://www.aadncaandc.gc.ca/eng/1100100010035/1100100010036 . (2014). Canada and First Nations reach agreement on First Nations education. Ottawa: Aboriginal Affairs and Northern Development Canada. . (2014a, December 19). Elementary and Secondary Education Program National Program Guidelines 2015-2016. Retrieved from Aboriginal Affairs and Northern Development Canada: http://www.aadncaandc.gc.ca/eng/1418999442065/1418999496718 . (2014b). First Nations Control of First Nations Education Act - Introduction in the House of Commons. Ottawa: Aboriginal Affairs and Northern Development Canada.

. (2014c). Funding First Nations Education: The Way Forward (PPT Draft, for internal discussion purposes). Ottawa: Government of Canada.

. (2015, July 27). Education. Retrieved from Aboriginal Affairs and Northern Development Canada: http://www.aadncaandc.gc.ca/eng/1100100033601/1100100033605

. (2015a, May 22). Federal Funding Levels for First Nations K-12 Education. Retrieved from Aboriginal Affairs and Northern Development Canada: https://www.aadnc-aandc.gc.ca/eng/1349140116208/1349140158945

AANDC Atlantic Regional Office. (2013). Atlantic Consultation Thematic Summary. Halifax: Aboriginal Affairs and Northern Development Canada. . (2014). Summary of Atlantic Stakeholder Reactions to the FNCFNEA and Bill $C$-33. Amherst: AANDC Atlantic Regional Office.

Abele, F. (2004). Urgent Need, Serious Opportunity: Towards a New Social Model for Canada's Aboriginal Peoples. Canadian Policy Research Networks, i-47.

Act, C. (1982). Schedule B to the Canada Act 1982. Constitution Act, 1982, United Kingdom.

Assembly of First Nations. (2014, February 7). Assembly of First Nations National Chief agrees on a new approach to achieve First Nations control of First Nations education. Retrieved from Assembly of First Nations: 
http://www.afn.ca/index.php/en/news-media/latest-news/assembly-of-firstnations-national-chief-agrees-on-a-new-approach-to-a . (2014a). First Nations Control of First Nations Education: A framework to achieve success in First Nation education. Ottawa: Assembly of First Nations. . (2014b, 01 01). Treaty Implementation and Enforcement. Retrieved 04 23, 2015, from http://www.afn.ca/index.php/en/policy-areas/Treaty-Implementationand-Enforcement

Atleo, C. J. (2009). From Indigenous Nationhood to Neoliberal Aboriginal Economic Development: Charting the Evolution of Indigenous-Settler Relations in Canada. Victoria: Canadian Social Economy Hub.

Atleo, S. A.-i.-c. (2013, November 25). Open Letter to Minister of Aboriginal Affairs and Northern Development Canada. Ottawa, Ontario, Canada: Assembly of First Nations.

Auditor General of Canada. (2011). 2011 Status Report of the Auditor General of Canada to the House of Commons: Chapter 4, Programs for First Nations on Reserves. Ottawa: Office of the Auditor General of Canada.

Ballamingie, P. (2009). Democratizing Public Consultation Processes: Some Critical Insights. Journal of Public Deliberation, 1-14.

Bastien, L. (2013). Documents. Retrieved from First Nations Education Council: http://www.cepnfnec.com/PDF/etudes_documents/Article_Lise_Bastien_April_2013.pdf

Battiste, M., \& McLean, S. (2005). State of First Nations Learning. Ottawa: Canadian Council on Learning.

Bradshaw, M., \& Stratford, E. (2010). Qualitative Research Design and Rigour. In I. Hay, Qualitative Research Methods in Human Geography (pp. 69-80). Don Mills: Oxford University Press.

Canadian School Boards Association. (2013). Response to AANDC-Initiated Consultations on Proposed First Nations Education Legislation. Montreal: Canadian School Boards Association.

Council of Atlantic Ministers of Education and Training. (1998). Foundation for the Atlantic Canada Social Studies Curriculum. Halifax: Council of Atlantic Ministers of Education and Training.

Department of Justice, Canada. (2013). A Consolidation of the Constitution Acts 1867 to 1982. Ottawa: Government of Canada. 
Dowling, R. (2010). Power, Subjectivity, and Ethics in Qualitative Research. In I. Hay, Qualitative Research Methods in Human Geography (pp. 26-39). Toronto: Oxford University Press.

Elsipogtog First Nation School. (2013). Recommendations for Improving the First Nation Education Act: Input from Elsipogtog School Administration and Staff. Elsipogtog: Elsipogtog First Nation .

Fiscal Realities. (2010). The True Cost of First Nations Government. Kamloops: Fiscal Realities.

FNESC and FNSA. (2014). Annual Report of the First Nations Education Steering Committee and First Nations Schools Association for 2013-2014. West Vancouver: First Nations Education Steering Committee.

Freire, P. (1970). Pedagogy of the Oppressed. New York: The Continuum International Publishing Group Inc.

Frey, L., Botan, C., \& Kreps, G. (1999). Investigating Communication: An introduction to research methods. (2nd ed.). Boston: Allyn \& Bacon.

Gamble, D. J. (1978). The Berger Inquiry: An Impact Assessment Process. Science, 946952.

Gergen, K. J. (2015, August 12). Relational theory and the discourses of power. Retrieved August 12, 2015, from Academia: https://www.academia.edu/2630295/Relational_theory_and_the_discourses_of_p ower

Godlewska, A. M., Schaefli, L. M., \& Chaput, P. J. (2013). First Nations assimilation through neoliberal educational reform. The Canadian Geographer, 271-279.

Government of Canada. (1969). Statement of the Government of Canada on Indian Policy, 1969. Ottawa: Government of Canada. . (1985). Indian Act. Ottawa : Government of Canada. . (1996). RCAP, Report of the Royal Commission on Aboriginal Peoples. Ottawa: Author. . (2009). Federal Framework for Aboriginal Economic Development. Ottawa: Author.

. (2010, November 12). Canada's Statement of Support on the United Nations Declaration on the Rights of Indigenous Peoples. Retrieved from Aboriginal Affairs and Northern Development Canada: http://www.aadncaandc.gc.ca/eng/1309374239861/1309374546142 . (2010a, 09 15). Peace and Friendship Treaties. Retrieved 04 23, 2015, from https://www.aadnc-aandc.gc.ca/eng/1100100028589/1100100028591 
. (2011). Aboriginal Consultation and Accommodation - Updated Guidelines for Federal Officials to Fulfill the Duty to Consult. Ottawa: Government of Canada. . (2013, June 23). Chronology of First Nations Education. Retrieved from Aboriginal Affairs and Northern Development Canada: https://www.aadncaandc.gc.ca/eng/1358799301258/1358799341720

. (2014, 04 10). Bill C-33: First Nations Control of First Nations Education Act. Ottawa. Retrieved from https://www.aadncaandc.gc.ca/eng/1358798070439/1358798420982 . (2015, July 27). Education Partnerships Program. Retrieved from Aboriginal Affairs and Northern Development Canada: https://www.aadncaandc.gc.ca/eng/1100100033760/1100100033761

. (2015a, July 27). First Nation Student Success Program. Retrieved from Aboriginal Affairs and Northern Development Canada: https://www.aadncaandc.gc.ca/eng/1100100033703/1100100033704

Harvey, D. (2003). The New Imperialism. Oxford: Oxford University Press. . (2004). The 'New' Imperialism: Accumulation by Dispossession. Socialist Register, 63-87. . (2005). A Brief History of Neoliberalism. New York: Oxford University Press.

Howitt, R., \& Stevens, S. (2010). Cross-Cultural Research: Ethics, Methods, and Relationships. In I. Hay, Qualitative Research Methods in Human Geography (pp. 40-68). Toronto: Oxford University Press.

Indian and Northern Affairs Canada. (2005). Evaluation of the Band-operated and Federal Schools (BOFS). Ottawa: Government of Canada.

Kraus, K. (2014, May 5). National Chief of the Assembly of First Nations resigns over First Natons education act. rabble.ca.

Larner, W. (2000). Neo-liberalism: Policy, Ideology, Governmentality. Studies in Political Economy, 5-25.

LeBlanc, H. D. (2014, August 13). Letter to Hon. Bernard Valcourt, P.C., M.P. Beasejour, New Brunswick, Canada: Hon. Dominic LeBlanc.

Leeuw, S. d. (2009). 'If anything is to be done with the Indian, we must catch him very young': colonial constructions of Aboriginal children and the geographies of Indian residential schooling in British Columbia, Canada. Children's Geographies, 123-140.

Legacy of Hope Foundation. (2013, 02 20). 100 Years of Loss: The Residential School System in Canada. Retrieved 04 18, 2015, from Legacy of Hope Foundation: http://www.legacyofhope.ca/downloads/100-years-print.pdf 
Lukacs, G. (1923). History and Class Consciousness: Studies in Marxist Dialectics. MIT Press.

Manuel, A., \& Derrickson, G. M. (2015). Unsettling Canada: A National Wake-up Call. Toronto: Between the Lines.

Marx, K. (1887). Part VIII: The Secret of Primitive Accumulation. In K. Marx, Capital Volume I. Moscow: Progress Publishers. Retrieved from https://www.marxists.org/archive/marx/works/1867-c1/ch26.htm

Mendelson, M. (2008). Improving Education on Reserves: A First Nations Education Authority Act. Ottawa: Caledon Institute of Social Policy.

Miawpukek Mi'kamawey Mawi'omi. (2013, July 17). Letter to Minister Valcourt Re: A Blueprint for Legislation. Conne River, Newfoundland, Canada: Miawpukek Mi'kamawey Mawi'omi, the Government of the Conne River Mi'kmaw.

National Indian Brotherhood. (1972). Indian Control of Indian Education. Ottawa: Assembly of First Nations. . (1980). Brief of the National Indian Brotherhood of Canada. Ottawa: National Indian Brotherhood.

Nelson Education. (2013). Nelson Education Announces Circle of Life, Learning From an Elder. Retrieved from Nelson Education: http://www.nelson.com/literacy/1/documents/LiteracyFirstNationsLittleBookBroc hure2013.pdf

New Brunswick Aboriginal Affairs Secretariat. (2014). Annual Report 2013-14. Fredericton: Government of New Brunswick.

Office of the Auditor General of Canada. (2011). 2011 Status Report of the Auditor General of Canada to the House of Commons . Ottawa: Office of the Auditor General of Canada.

Palmater, P. (2014, May 3). Aboriginal peoples must stay united against the First Nations Education Act. Rabble.ca.

Paquette, J., \& Fallon, G. (2008). First-Nations Education and the Law: Issues and Challenges. Education and Law Journal, 347-378.

Polanyi, K. (2001). The Great Transformation, the political and economic origins of our time. US: Beacon Press.

Province of Canada. (1857). An Act to Encourage the Gradual Civilization of Indian Tribes in this Province. Toronto: Province of Canada.

R. J. Kowalchuk Consulting. (2013). Comparison of the DIAND Funding Formula for Education with the Saskatchewan Provincial Funding Formula. Sasakatchewan: R. J. Kowalchuk Consulting. 
Raptis, H., \& Bowker, S. (2010). Maintaining the illusion of democracy: Policy-making and Aboriginal education in Canada, 1946-1948. Canadian Journal of Educational Administration and Policy, 1-21.

Rheault, D. (2011, 12 01). Solving the "Indian Problem": Assimilation Laws, Practices, and Indian Residential Schools. Retrieved 04 22, 2015, from Ontario Metis Family Records Centre: http://www.omfrc.org/newsletter/specialedition8.pdf

Schumpeter, J. A. (1943). Capitalism, Socialism and Democracy. UK: University of Illinois at Urbana-Champaign's Academy for Entrepreneurial Leadership Historical Research Reference in Entrepreneurship.

Smith, A. (2010). Indigeneity, Settler Colonialism, White Supremacy. Global Dialogue, $1-13$.

Standing Senate Committee on Aboriginal Peoples. (2011). Reforming First Nation Education: From Crisis to Hope. Ottawa: Senate of Canada.

Stavenhagen, R. (2004). Report of the Special Rapporteur on the situation of human rights and fundamental freedoms of indigenous peoples, Rodolfo Stavenhagen. Report on the Expert Seminar on Indigenous Peoples and Education (p. 13). New York: United Nations Economic and Social Council.

Stephen Gagnon, D. G. (2013, February 26). Letter to Chiefs re: Regional Consultatons on First Nations Education Legislation. Ottawa, Ontario, Canada: Aboriginal Affairs and Northern Development Canada.

Stewart, S. C. (2006). First Nations Education: Financial Accountability and Educational Attainment. Canadian Journal of Education, 998-1018.

The National Panel on First Nation Elementary and Secondary Education for Students on Reserve. (2012). Nurturing the Learning Spirt of First Nations Students. Ottawa: The National Panel on First Nation Elementary and Secondary Education for Students on Reserve.

TNEGI. (2014). Submission to the Atlantic Engagement Strategy. Elsipogtog First Nation: Three Nations Education Group Inc.

Tzimas, E. R. (2005). Haida Nation and Taku River: A Comment on Aboriginal Consultation and Reconciliation. Supreme Court Law Review, 461-484.

United Nations. (1948). The Universal Declaration of Human Rights. New York: United Nations. . (2008). United Nations Declaration on the Rights of Indigenous Peoples. New York: United Nations.

United Nations Educational, Scientific and Cultural Organization. (1960). Convention against Discrimination in Education. New York: United Nations. 
University of British Columbia - First Nations Studies Program. (2009, 01 01). The Residential School System. Retrieved 04 23, 2015, from $\mathrm{http}$ ://indigenousfoundations.arts.ubc.ca/home/government-policy/the-residentialschool-system.html

Valcourt, H. B. (2013, December 13). Open Letter to the National Chief of the Assembly of First Nations - December 13, 2013. Ottawa, Ontario, Canada: Aboriginal Affairs and Northern Development Canada.

Waitt, G. (2010). Doing Foucauldian Discourse Analysis - Revealing Social Realities. In I. Hay, Qualitative Research Methods in Human Geography (pp. 217-240). Don Mills: Oxford University Press.

Walton, F., Favaro, B., Goddard, T., Frenette, D., Cooper, L., Peters, N., \& Burgess, J. (2009). Promoting Educational Success for Mi'kmaq Learners on Prince Edward Island. Charlottetown: Centre for Education Research at the University of Prince Edward Island.

Wilkinson, J., \& Leclair, D. (2013, September 9). Aboriginal Affairs and Northern Development Canada Media Lines. Ottawa, Ontario, Canada: Government of Canada.

Wilson, S. (2008). Research Is Ceremony: Indigenous Research Methods. Black Point: Fernwood Publishing.

Wolfe, P. (2006). Settler colonialism and the elimination of the native. Journal of Genocide Research, 387-409.

Wood, E. M. (2006). Logics of Power: A Conversation with David Harvey. Historical Materialism, 9-34. 